University of San Diego

Digital USD

2020-05-20

\title{
Leadership Adapted: Towards an Understanding of How Western- Developed Leadership Theories are Translated and Practiced in the Modern Arab Middle East
}

Derek R. Olson

University of San Diego

Follow this and additional works at: https://digital.sandiego.edu/dissertations

Part of the Business Administration, Management, and Operations Commons, Leadership Studies Commons, Near and Middle Eastern Studies Commons, and the Other International and Area Studies Commons

\section{Digital USD Citation}

Olson, Derek R., "Leadership Adapted: Towards an Understanding of How Western-Developed Leadership Theories are Translated and Practiced in the Modern Arab Middle East" (2020). Dissertations. 182. https://digital.sandiego.edu/dissertations/182

This Dissertation: Open Access is brought to you for free and open access by the Theses and Dissertations at Digital USD. It has been accepted for inclusion in Dissertations by an authorized administrator of Digital USD. For more information, please contact digital@sandiego.edu. 
University of San Diego

Digital USD

2020-05-20

Leadership Adapted: Towards an Understanding of How WesternDeveloped Leadership Theories are Translated and Practiced in the Modern Arab Middle East

Derek R. Olson

Follow this and additional works at: https://digital.sandiego.edu/dissertations

Part of the Business Administration, Management, and Operations Commons, Leadership Studies Commons, Near and Middle Eastern Studies Commons, and the Other International and Area Studies Commons 
Leadership Adapted: Towards an Understanding of How Western-Developed Leadership Theories are Translated and Practiced in the Modern Arab Middle East

by

Derek R. Olson

A dissertation submitted in partial fulfillment of the requirement for the degree of Doctor of Philosophy

August 2020

Dissertation Committee

Afsaneh Nahavandi, Ph.D., Chair

Hans Schmitz, Ph.D., Member

Juan Roche, Ph.D., Member

University of San Diego 
(C) Copyright by Derek R. Olson

All Rights Reserved 2020 


\section{University of San Diego \\ School of Leadership and Education Sciences}

CANDIDATE'S NAME: Derek Olson

TITLE OF DISSERTATION: LEADERSHIP ADAPTED: TOWARDS AN

UNDERSTANDING OF HOW WESTERN-DEVELOPED LEADERSHIP THEORIES

ARE TRANSLATED AND PRACTICED IN THE ARAB MIDDLE EAST

APPROVAL:

, Chair

\begin{tabular}{ll}
\hline Afsaneh Nahavandi, PhD & , Member \\
\hline Hans Peter Schmitz, PhD & , Member
\end{tabular}

DATE: May 20, 2020 


\begin{abstract}
The purpose of this study is to understand how western-developed leadership theories are translated and practiced in the Modern Arab Middle East (MAME). Over the past century the notion of leadership has progressed through phases of understanding, definition, and practice. This evolution continues today and is no longer contained to the academic and practice-oriented institutions of North America and Europe. Through western-styled educational institutions and professional industries, western-developed leadership theories have stretched around the globe, including the MAME. While this is known, what is much less understood is how these theories are adopted and adapted. This study's objective is to understand what theories of leadership are taught at Master of Business Administration (MBA) programs in the Modern Arab Middle East and how are they applied in local contexts.
\end{abstract}

The research design was qualitative, interpretivist, and exploratory in nature. Data was collected from the MBA programs, their faculty alumni, and by the observations of the researcher. Publicly available documents were gathered by from online sources and during visits to the programs. Interviewed with respondents were conducted both in-person and through phone and digital conversations. Documents and transcripts were catalogued and thematically analyzed with the resulting themes constituting the findings of the study.

The first set of findings centers around the question of how leadership is situated as well as what leadership theories are taught and how. It was found that leadership is professed to be highly valued, is broadly defined, and that is taught through traditional educational methods. The second set of findings pertain to what practitioners do with 
this education. It was found that leadership was spoken of in nine ways: local, regional, and internationally; a changing environment; entrepreneurship; family business; management preferred over leadership, and professional or personal development. Additionally, respondents reported that they experience the concept of leadership to be enigmatic, for a few, and future oriented.

This study is hoped to be one of a series to come that considers how westernleadership theory is used in the MAME with an aim that theory may be useful and congruent within local and regional contexts.

Keywords: leadership, western leadership, Middle East, Egypt, Lebanon, United Arab Emirates, cross cultural, MBA, management, family business, entrepreneurship, professional development, personal development, context, environment 


\section{ACKNOWLEDGMENTS}

Thank you to the faculty and staff of both the University of San Diego as well as the School of Leadership and Education Sciences, and specifically to Dr. Afsaneh Nahavandi, Dr. Hans Peter Schmitz, Dr. Juan Roche, Dr. Robert Donmoyer, Dr. Fred Galloway, Dr. Zacary Green, Sister Terri Monroe, Professor René Molenkamp, Dr. Mariko Peshon, Dr. Lea Hubbard, Dr. Linda Dews, Dr. Laura Deitrick, Dr. Cheryl Getz, Dr. Marcus Lam, and Emma Mackey. Thank you to my peers Ebtesam, Carmeline, Daniel, Joe, Ish, Phillip, Sanket, Taylor, Khaled, Justin, and Ankit. Thank you to all the past and current educational institutions, including Greenfield Unified School District, King City High School, the University of California San Diego, Semester At Sea, the American University in Cairo, the Middlebury Institute of International Studies at Monterey, the University of San Diego's School of Business, the American University of Beirut, and the American University of Sharjah.

Thank you to my beautiful and beloved wife Alair. Thank you to the life-long support of my parents Phoebe, Tim, and Leon. Thank you to my siblings Loni, Leland, Paula, and Megan. Thank you to the best friends with whom I've shared life: Brandon, Jeff, Skyler, Jacques, Travis, and Steven. Thank you to the spiritual companions of David, Eric, as well as the whole Theodyssey community and Flood Church. Thank you to the encouragers, including Jim Galvin, Dr. Jeff Bourgeois the Jernigan family, the Shaheen family, Suzanne Krause, Mr. Masters, Mr. Cavanagh, Mr. Graham.

Thank you Father. 


\section{TABLE OF CONTENTS}

ACKNOWLEDGMENTS _ _

TABLE OF CONTENTS _..._. vii

LIST OF FIGURES $\ldots \ldots \ldots \ldots$

LIST OF TABLES _ _ _

CHAPTER 1: Introduction and Background 1

The Modern Arab Middle East

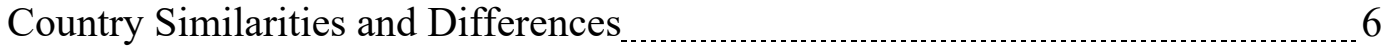

Universities and MBA Programs

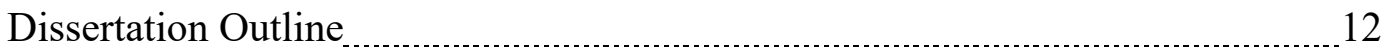

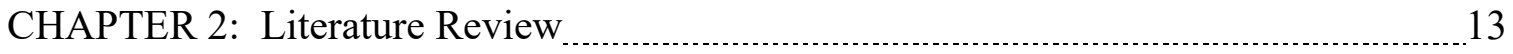

Western Leadership Theories 13

Great Man and Trait Theories $\quad 14$

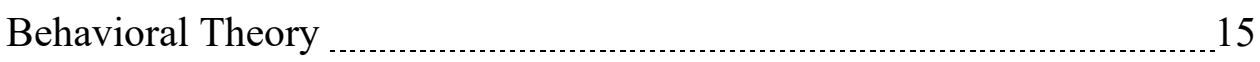

Ohio State Leadership Studies _......................................... 15

University of Michigan Leadership Studies

Scandinavian Leadership Studies _............................................... 16

Role Theory 17

Contingency/Situational Theory $\quad 19$

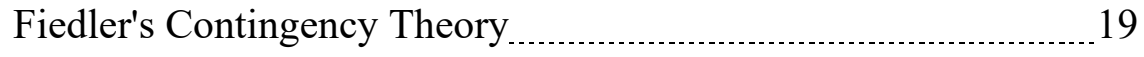

Hersey-Blanchard Situational Leadership Theory _........................ 21

Goleman's Situational Leadership _ _ $\quad 22$

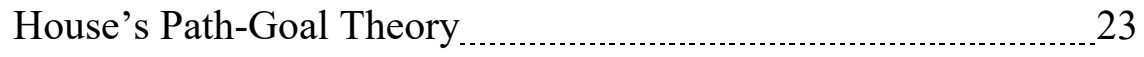


Vroom-Yetton-Jago’s Decision-Making Model of Leadership .... 24

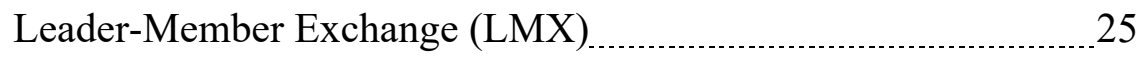

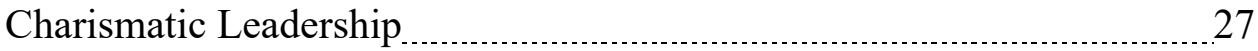

Transactional \& Transformational Leadership $\ldots . \ldots 31$

Transactional Leadership

Transformational Leadership

Kouzes and Posner's The Leadership Challenge _.................. 33

Values-Based Leadership Theory

Servant Leadership

Authentic Leadership

Positive Leadership Theory

New Directions in Theory 38

Cross-Cultural Values and Leadership Models _ 38

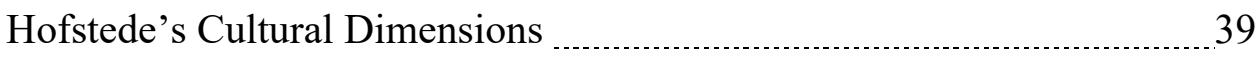

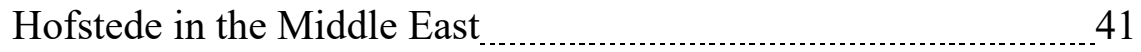

Critique and Contributions

The GLOBE Project

GLOBE and the Middle East 45

GLOBE Critique 49

Leadership in the MAME

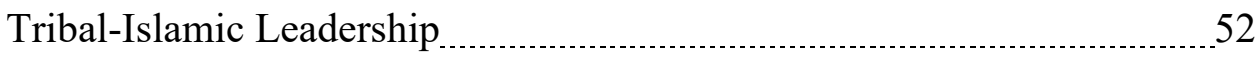

Tribal Foundations

Desert 
Trading and Wealth 54

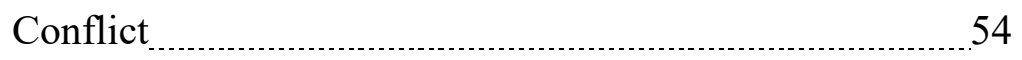

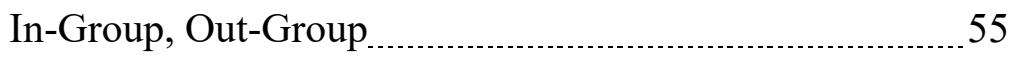

Authoritarian and Consultation $\ldots . \ldots \ldots$

Muhammad as the Archetypal Leader $\ldots \ldots$

Broad Characteristics

Specific Characteristics $\quad 58$

Critique 60

Islamic Work Ethic

From the Prophet

Dimensions

Critique 63

Western Management and Leadership Theory in the MAME 65

Western Theory "Translated"

Management

Leadership

The Competing Commitments within Bioecology _...................................... 68

Bioecology 68

Competing Commitments

The Inherent Competing Commitments in Bioecology Theory .................. 76

Conclusion

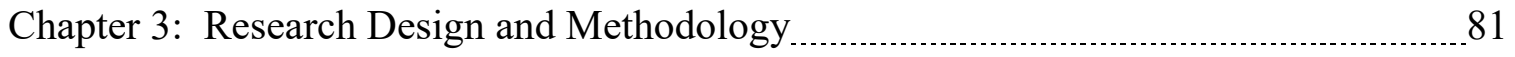

Research Design 
Site Selection

Data Collection

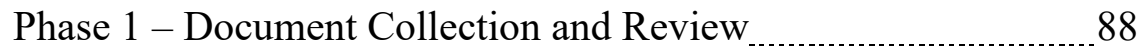

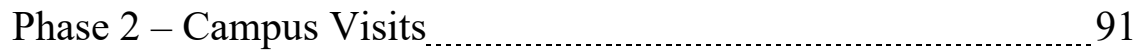

Phase 3 - Alumni Interviews 99

Data Analysis

Chapter 4: Findings

Research Question Set 1

Positioning of Leadership Education

What Leadership is Taught

How Leadership is Taught 122

Research Question Set 2

Local, Regional, and International Perspective and Aim of Impact _....... 124

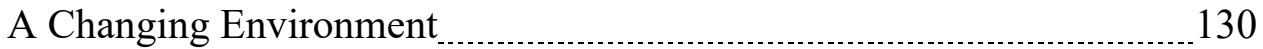

Entrepreneurship and Innovation

Family Business

Management $>$ Leadership 142

Professional and Personal Development 146

Leadership Is

Leadership is Enigmatic $\ldots$

Leadership is for the Few

Leadership is in the Future 
Chapter 5: Discussion

Summary

Discussion

Findings vis-à-vis What We Already Know.

Great Man, Great Traits

Transactional

The GLOBE Study

Out of the Desert

An Individual within Context

Within Self

Between Self and Microsystem

Between Self, Microsystems, and Larger Systems

Professional and Personal Development

Management Preferred

Leadership Emerging?

Entrepreneurship and Innovation

Time

Surprises

In-Group, Out Group

Little Culture

Absence of Faith

Conclusion 
A. Hofstede's Cultural Dimensions

B. Hofstede's Cultural Dimensions for the Middle East

C. GLOBE Project - Global Cultural Competencies

D. GLOBE Project - Culture Clusters

E. Coding Example

F. Email to Faculty, Initial

G. Introduction from Dr. Nahavandi

H. Study Proposal Abstract

I. Email to Faculty, Second

J. Interview Guide

K. Local, Regional, and International Perspective and Aim

L. A Changing Environment

M. Entrepreneurship and Innovation

N. Family Business

O. Management

P. Professional and Personal Development 265

Q. Leadership Is 273 


\section{LIST OF FIGURES}

Figure 1: Research Question Orientation

Figure 2: GLOBE Study, Cultural Practices and Values in the Middle East Group.........46

Figure 3: GLOBE Study, Leadership Scores for Outstanding Leadership in the Middle

East

Figure 4: Development of MAME Values of Leadership

Figure 5: Bronfenbrenner's Biecology Systems

Figure 6: Bronfenbrenner's Bioecology Time 73

Figure 7: Research Question 1 Components. 109

Figure 8: Research Question 2 Themes 124 


\section{LIST OF TABLES}

Table 1: Goleman's Situational Leadership Styles.

Table 2: GLOBE CLTs

Table 3: Interpretivist Characteristics

Table 4: Distribution of Documents

Table 5: Distribution of Faculty Participation

Table 6: Distribution of Alumni Participation

Table 7: AUS Online Leadership Content

Table 8: AUC MBA Course Descriptions Including Leadership Component

Table 9: Leadership Situated, Faculty

Table 10: Leadership Course Descriptions

Table 11: What is Taught, Faculty

Table K1: Local, Regional, and International Perspective and Aim, Documents

Table K2: Local, Regional, and International Perspective and Aim, Respondents 230

Table L1: A Changing Environment, Documents 234

Table L2: A Changing Environment, Respondents 237

Table M1: Entrepreneurship and Innovation, Documents 242

Table M2: Entrepreneurship and Innovation, Respondents

Table N1: Family Business, Documents

Table N2: Family Business, Respondents 253

Table O1: Management, Documents 258

Table O2: Management, Respondents 262

Table P1: Professional and Personal Development, Documents 265 
Table P2: Professional and Personal Development, Respondents

Table Q1: Leadership is Enigmatic

Table Q2: Leadership is for the Few. 275

Table Q3: Leadership is in the Future 277 


\section{CHAPTER 1}

\section{INTRODUCTION AND BACKGROUND}

The majority of research and theory development about leadership has taken place in the West, and more specifically in the United States. These ideas then diffuse across the world and are localized through teaching and practice. The transfer and exchange of academic knowledge and best practices has been particularly unidirectional (Von Oorschot, 2014). For decades, western-developed leadership theories have spread in the modern Arab Middle East (MAME). A primary way that leadership theories are exported to the MAME is through the expansion of Western-styled and oriented higher education. However, there is little research on how Western leadership theories and concepts are applied to the diverse cultures of the Middle East. The goal of this research project is to explore the extent and application of Western leadership theories in the MAME where increasingly Western, and particularly American-centric universities, are offering courses and degrees.

The relevance of studying the diffusion of western-developed leadership in the MAME is three-fold. First, it is known that western-developed leadership theory is being exported to the MAME but it is unclear how it is incorporated into different local contexts. This study seeks to bring some insight to this. Second, it is unknown how western-styled and oriented schools, particularly MBA programs, teach western leadership. This study will investigate three programs in how they teach westerndeveloped leadership. Finally, with the understanding of the previous two relevancies, this study will encourage further research with the aim of producing practices that are better suited for the MAME context. 
This study will provide timely and relevant knowledge about the applicability and appropriateness of Western-based leadership theory to the modern Arab Middle East. By focusing on Egypt, Lebanon, and the UAE, the research will consider three Arab countries that are unique in their history and culture. Egypt is an ancient culture with deep-rooted values; Lebanon is one of the most diverse countries in the region; the UAE is a young country that is one of fastest developing countries in the world with a fast shifting culture. The results of this study can provide the groundwork for a more careful and considered knowledge exchange and application.

The purpose of this research therefore is to address the following questions:

What theories of leadership are taught at MBA programs in the Modern Arab Middle East and how are they adapted into local contexts by alumni?

- Research Question Set 1 (RSQ1): How is leadership education situated within these MBA programs? What leadership theories and models are taught? What methods are used to teach leadership education?

- $\quad$ Research Question Set 2 (RSQ2): How are western-developed leadership models adapted and applied into local environments? How has history and culture affected this adaptation? 


\section{Figure 1}

Research Question Orientation
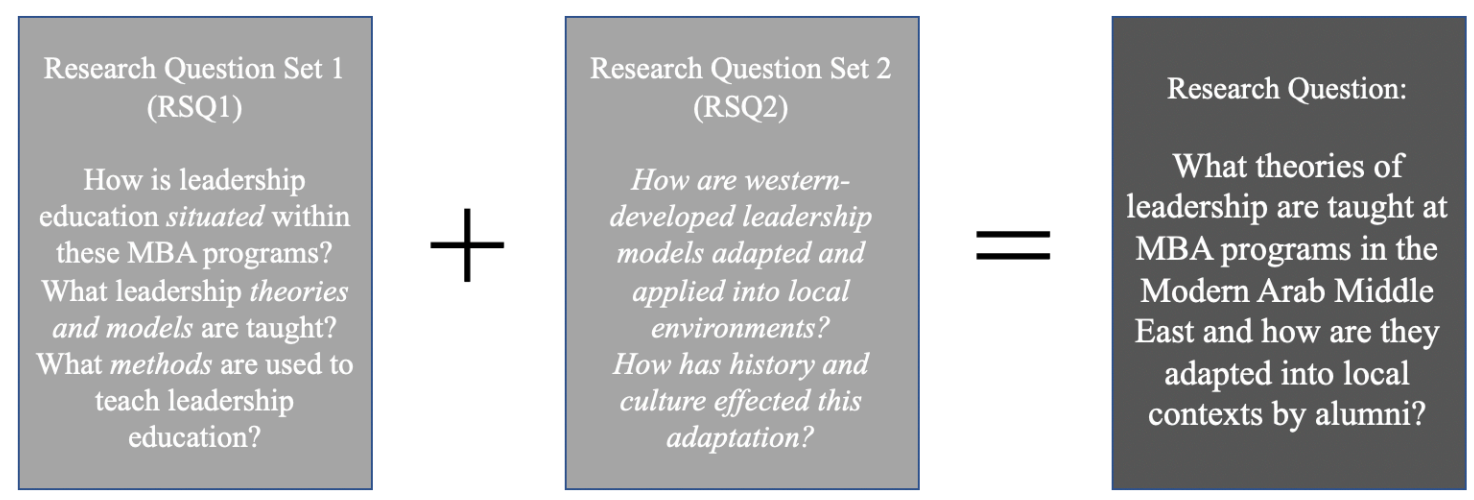

In seeking to understand how western-developed leadership theories are converted into MAME expressions through MBA programs it is important to describe the context from the broadest setting, the MAME, down to the most specific sites: the schools and MBA programs themselves. The MAME helps to define the region in terms that is geographic (Middle East), ethnic (Arab), and situated in the present area (modern). After describing what constitutes the MAME then each of the three countries, Egypt, Lebanon, and the UAE, are understood through a variety of lenses that include religion, history worth colonialism, politics and military, population size and demographics, recent economic trends, and the orientation each has both regionally and toward the west. From the country level we then dial down into one university in each country and dial again further to briefly describe the MBA program at each school. This funnel from regional context, to country context, to school and program context is necessary as each level is expected to affect the local expression of western-developed leadership theories. 


\section{The Modern Arab Middle East}

In this study we are concerned with the modern expression of western-leadership theory in the Middle East. The identifying characteristic of this time component is that it is post-colonial (Bernard, 1994). The region has experienced two unique periods of outside political and economic control. The first was under the Ottoman/Turkish Empire beginning in the mid $15^{\text {th }}$ century and lasted through the end of World War I (Mansfield, 2013; Cleveland \& Bunton, 2016). The second period began after World War I when European powers carved up the region and dominated it into the 1950s and 1960s (Bernard, 1994; Cleveland \& Bunton, 2016). The experience of nearly five centuries of outside domination profoundly affects the region today (Kandiyoti, 2002; Watenpaugh, 2014). Through-out this paper we will see the broad consequences of the colonial eras and, specifically, the effects on leadership theory.

A second important point of this study is that it is focused on the Arab experience of western-developed leadership theories. Broadly, an Arab is a member of a Semitic people, originally form the Arabian Peninsula and neighboring territories. This includes people in the region but also the many hundreds of thousands that are part of the diaspora. For the purposes of this paper we will take relatively a narrow perspective and include the peoples of the Arabian Peninsula and those directly connected and ethnically, and thus geographically, to the peninsula. This constricted consideration provides greater cohesiveness about what we do and do not know about the modern Arab Middle East and leadership theory.

A third and final facet to delineate is what is the "Middle East?" If modern has to do with time and Arab is about ethnicity, then Middle East is about geography. It is 
important to note that the term "Middle East" itself is western-oriented. From the English and French, the primary European colonialist of the region, there was the "east" (now known as Eastern Europe, the "far east" (now countries including India and China), and between the two there was the Middle East (Louis \& Louis, 1984). While the phrase is western-oriented in origin, the region itself commonly refers to itself as الثرق الأوسط (ash-sharq al-awsat) which translates directly to "Middle East" (Fisher, 2013).

From these geographic, ethnic, and time boundaries we can explicitly state which nation-states fall in the "modern Arab Middle East." The countries included in the modern Arab Middle East are: Egypt Jordan, Lebanon, Syria, Iraq, Kuwait, Saudi Arabia, Qatar, the United Arab Emirates, Oman, and Yemen. Countries that must be excluded are: Turkey, Iran, Israel, and the North African countries west of Egypt. Turkey is excluded because both Arabs and those from Turkey consider Turks ethnically and linguistically distinct (Weiker, 1992). Similarly, Iran is ethnically and linguistically Persian and distinctive from both Arabs and Turks (Katouzian, 2010). Thirdly, along with differences in language and religion the country of Israel is a relatively unique and recent readdiction to the region and is thus excluded (Gordis \& Sanders, 2016). Lastly, while the Middle East and North Africa, commonly referred to as MENA, are combined this is primarily because North Africa cannot adequately be grouped with the rest of Africa and is thus often, inappropriately, combined with the Middle East (Issawi, 2013). With these boundaries we are left with 11 countries that make up the MAME. Within this narrowed understanding of the MAME there are both similarities and differences as expressed by three countries: The Republic of Egypt, the Lebanese Republic, and the United Arab Emirates (UAE). 


\section{Country Similarities and Differences}

One of the most important aspects of the MAME is role that religion and faith play in every area and in at all levels of society. When looking specifically at Egypt, Lebanon, and the UAE, it is important to note both the similarities and differences among them. One of the commonalities is that each has a majority Muslim population: Egypt 95\%, Lebanon 55\%, and UAE 76\% (Pew-Templeton, 2010; World Population Review; Zubaida, 1993). In Egypt and the UAE, the great majority of Muslims identify as Sunni Muslim while the split in Lebanon is nearly equal at 45\% Sunni and 55\% Shia (Faour, 2007). In Al-Azhar Mosque and Madrasa Egypt has one of the oldest and most important centers of Sunni thought and scholarship in MAME (Zeghal, 2007). The commonality of Sunni Islam in Egypt and the UAE has in recent years brought the countries together as allies (Omran, 2018). Alternatively, the religious divisions in Lebanon, Sunni-Muslim, Shia-Muslim, and Christian, helped fuel a 15-year civil war that still simmers today (Hägerdal, 2019). The second largest faith in each country is Christian: Egypt 5\%, Lebanon 33-40\%, UAE 9\% (Pew-Templeton, 2010; World Population Review).

Two other features of similarity and dissimilarity among the three countries are the length of settled cities and their experiences with colonialism. Up until recently the history of the UAE has been of Bedouin tribes roaming the desert (Harpwood, 2015). It was not until the mid $19^{\text {th }}$ century that settlements became permanent with the foundation of Dubai in 1833 and only in 1971 was the capital, Abu Dhabi, created (Zahlan, 2016). Cairo on the other hand was founded nearly 4,000 years and Beirut is one of the longest continually inhabited settlements with its foundations being more than 5,000 years old (Iliffe, 2017; Makdisi, 2016). In recent centuries all three countries have experienced 
both direct and indirect colonial influence. Lebanon, and to a lesser extent in Egypt, were colonized by the Ottoman Empire; the regions covered by the modern UAE were also part of the Ottoman Empire (Kilinçoğlu, 2015). In the late $18^{\text {th }}$ and early $19^{\text {th }}$ centuries the French and then later the British exercised control in Egypt (Colla, 2003; Powel, 2003). Then, after the fall of the Ottomans at the end of WWI the French and British split up the Middle East under the Sykes-Picot Agreement that seeded Lebanon to France and Egypt to Britain (Rogan, 2015). The history of each country's major cities and their colonial experiences still directly affect the countries and their citizens today.

Two legacies of the imperial past are the modern expression of politics and the military. The Egyptian and Lebanese political systems take a distinctly westernEuropean form in both being unicameral parliamentary democratic republics with three branches of government: executive, legislative, and judicial (Korotayev \& Zinkina, 2011; Salamey, 2013). The UAE framework is a federation of seven absolute monarchies that are united under a federal, presidential, and constitutional monarchy with the sovereign of Abu Dhabi being the president and head of state, with the monarch of Dubai as the Prime Minister and head of government (Goodwin, 2006). Like most countries, each of these three have politics and the military highly integrated with the president also being the supreme commander/commander-in-chief of the armed forces (Hinnebusch, 2018). Egypt, perhaps more than any other country, has a long history of military rulers also being political rulers under the role of pharaoh. In the Egyptian, Lebanese, and the Emirati context it is important to understand their politics in relation to the military and vice-versa. 
The size and makeup of each of the three country's populations differs greatly. Egypt has a large population with over 100 million people with $99 \%$ of those being Egyptians and less than 1\% being international residents (CIA World Factbook Egypt). At the other end of the spectrum is the UAE that has under 10 million residents of which only $12 \%$ are UAE citizens (CIA World Factbook UAE). Much of the UAE growth strategy relies on importing service-sector jobs from the west and labor from Africa and south Asia which has created the vast majority of residents being non-citizens (El Mallakh, 2014). The population of Lebanon is also small but has seen more than $33 \%$ growth in the last 6 years due to a surge of refugees who have fled the turmoil of neighboring Syria (Turner, 2015; Yahya, Kassir, \& El-Hariri, 2018). While Lebanese are generally defined as ethnically Arab the country has a blended panethnicity that includes many small, yet distinct groups (Saouli, 2019). A final important aspect of the Lebanese population is that it has a diaspora that is larger than current residents of Lebanon (Haddad, 2018cite). It is estimated that there are 8-14 million Lebanese living outside Lebanon (Kechichian, 2015).

The current economic condition of the three countries could not be more different. The UAE is seen as a "fast developing society" as it has seen more than 3 decades of significant economic growth from GDP being less than $\$ 85$ billion in 1987 to more than \$383 billion in 2017 (CIA World Factbook UAE; Valenta, Knowlton, Jakobsen, Mouawiya, \& Strabac, 2019). As the economy has grown so too has the metropolises of Dubai and Abu Dhabi and international transportation networks through shipping trade and massive expansion of air travel on Emirate Airlines and Etihad Airlines (Dhabi, 2016). Egypt's economy also has experienced significant growth though not nearly as 
much as the UAE. The GDP of Egypt in the late 1980s was nearly $\$ 50$ billion and over \$330 billion in 2015 (CIA World Factbook Egypt). For the past two years the economy has been struggling through a currency adjustment that has had significant negative shortterm effects but is expected to lead to better economic health in the future (Sivabalan, 2017). The economy of Lebanon has also grown but only slightly year-over-year with GDP in 1985 being $\$ 28$ billion and \$88 billion in 2017 (CIA World Factbook Lebanon). The 1.5 million recent refugees have put a significant strain on housing, infrastructure, government services, and the economy as a whole (Eldawy, 2019).

Another important consideration are these countries' regional focus and their attitudes toward the west. Egypt's historic influence in the Middle East, north Africa, and the whole of the eastern Mediterranean continues today (Daly, 1998). Its history, large population, strategic location at the confluence of Africa and Asia, and now as the caretaker of the Suez Canal makes it an important regional player (Shaw, 2003). Lebanon shares the eastern Mediterranean regional focus but is less of a player in the Middle East as it struggles with internal divisions and refugee effects from the Syrian Civil War (Cleveland, 2018). Lebanon has a complicated relationship with the west. On the one hand, the relationship is positive with several million of the diaspora who live in western Europe and the United States; but, on the other hand, it is strained by west's support for Israel and lack of support for Lebanon in the wake of the Syrian Civil War (Hancock, 1998). While Egypt and Lebanon have a significant Mediterranean focus, the UAE has a distinctly Persian Gulf Focus (Al-Kandari \& Gaither, 2011). Located along the waterway between the Sunni Arab peninsula and Shia Iran the UAE and its allies have sought to come together and seek to be a counter balance to increasing Iranian 
aggression (Katzman, 2010). This, combined with a desire and concerted drive to be a hub of technology, trade, and transportation, has made the UAE important in the minds of the west (Zahlan, 2016). With the context set for Egypt, Lebanon, and the UAE it is now time to turn to the context to each of the three universities.

\section{Universities and MBA Programs}

The privately founded American University of Cairo (AUC) traces is founding back 100 years when in 1919 a preparatory school and university were opened by American missionaries (AUC History, 2019). For much of its history AUC was located on Midan Tahrir (Tahrir Square) in downtown Cairo and sat inside the business and political epicenter center of Egypt (Tahrir Square's place in Egypt's history, 2011). This location welcomed a wide variety of students from the elite of Arab Middle East, middle class Egyptians, and international students from the west. Then, following the regional trend of building glitzy new economic and political centers outside the historic centers, AUC opened its fresh campus in New Cairo in the Fall of 2018 and now has 5,600 undergraduate and nearly 1,000 graduate students (Kingsley, 2015; AUC, New Cairo Campus, 2019). Across all disciplines there is an emphasis on developing students who will work and lead in cross-cultural environments. The emphasis is reflected in English as the language of instruction, and alumni leaving the school to work both in the region and abroad (AUC, History, 2019). A long-standing cornerstone of the university is its MBA program that is modeled after western universities (AUC, School of Business, About, 2019). In fact, the AUC School of Business holds accreditations from western organizations including and actively recruits from American and European undergraduate programs (AUC School of Business, Accreditation,). To graduate students take a 
minimum of 39 units and choose from one of five concentrations. Today the highly ranked MBA program hosts seven different post-graduate programs, five centers focusing on special topics on business in the region, numerous regional partnerships, and continuing executive education (AUC School of Business, About).

The American University of Beirut (AUB) is one of the oldest centers of higher education in the Middle East (AUB, History). Founded more than 150 years ago on the "philosophy, standards, and practices on the American liberal arts model" it has endured periods of growth, war, and rebirth (AUB, History). Situated in the heart of Beirut and overlooking the Mediterranean, AUB today has just under 8,000 full-time students across 140 undergrad and graduate programs (AUB, Facts and Figures). AUB holds US accreditation and has nearly 90 different countries represented that make up over $20 \%$ of the student population (AUB, Facts and Figures). Their MBA program, founded in the 1940s, is a 36-unit program where students choose from one of seven specialization. The program, constantly rated as one of the top $10 \mathrm{MBA}$ programs in the region, seeks to build both the general knowledge and specific skills of experienced practitioners through an immersive experience (AUB, MBA).

The American University of Sharjah (AUS) is a relatively new university with its inception in the late 1990s (American University of Sharjah, History, 2019). Founded during the early assent of the neighboring Emirate of Dubai the school was envisioned as being a home to both social study and sciences with a general focus well beyond the UAE (American University of Sharjah, History, 2019). The private school has a current enrollment includes roughly 4,700 undergraduates and 405 graduate students coming from 90 different countries (American University of Sharjah, Fast Facts, 2019). One of 
their flagship programs is the MBA program within the School of Business

Administration (American University of Sharjah, History, 2019). Graduating students complete a minimum of 33 units in 1 of 3 concentrations. In 2012 Forbes Middle East ranked the program as best offered by a private institution in the Arabian Gulf Region and is near the top of the same list today (Naidoo, 2012).

\section{Dissertation Outline}

Chapter One introduced background information and set the stage to state the gap in knowledge that this dissertation addresses. Chapter Two is an extended literature review covering the topics of western-developed leadership theories, the understanding of leadership from a Middle East perspective, cross-cultural models that address leadership, and the bioecological understanding of how an individual is affected by and navigates their environment. Chapter Three describes the qualitative methods employed. Chapter Four details results of addressing the research questions in stating what and how leadership is taught and how alumni of these MBA programs integrate these teachings into local practice. This dissertation concludes with Chapter Five where results are examined, contributions stated, limitations noted, and future directions of study identified. 


\section{CHAPTER 2}

\section{LITERATURE REVIEW}

This review covers three areas of literature relevant to this study. First, the current and dominant leadership theories used education and in practice will be presented. Second, two cross-cultural, value-based models that attempt to address the contextual effectiveness of leaders will be reviewed including details of the cross-cultural values reported in the Middle East: Hofstede's Cultural Dimensions and the GLOBE Study. The view of leadership from a historic MAME perspective is detailed. In this progression of these three sets of literature from broad theory to regional specificity help us to know what is known and what gaps there are thus setting the stage for this study. Finally, the concepts of bioecology and competing commitments are introduced as a possible view of understanding the findings.

\section{Western Leadership Theories}

It is well established and accepted that the vast majority of modern leadership theories have their inception and validation in Western Europe and North America (Blunt \& Jones, 1996; Metchalfe \& Mimouni, 2011). The foundations of modern academic leadership theory began in the mid $19^{\text {th }}$ century with the concept of Great Man Theory by Thomas Carlyle and the rebuttal by Herbert Spencer (Carlyle, 1840; Spencer, 1873). All significant families of theory have been conceptualized and developed in the western hemisphere: from Great Man Theory came Trait Theory (first half of the $20^{\text {th }}$ century), from which developed Behavioral Theories (1950s-1970s), then Contingency Theory (1967-1990) that led to Transactional and Transformational ideas of leadership (1980spresent), and finally today's emerging theories around Systems Thinking, Positive, Plural 
and Critical models of leadership (Maslanka, 2004; Stone \& Patterson, 2005). Further, these models and philosophies have been exported to every corner of the globe (Dorfman et al., 1997; Blunt \& Jones, 1996) often without careful consideration of the cultural context. This includes the modern Arab Middle East. From Cairo to Dubai and from Beirut to Riyadh, Western leadership theory has been taught in universities and adopted by organizations in every sector (Hutchings \& Weir, 2006; Mercer, 2006; Romani, 2009).

\section{Great Man and Trait Theories}

Historian Thomas Carlyle is credited with one of the first leadership theories, which presupposed that leaders are born with certain characteristics that make them great leaders (Organ, 1996). Though not scientifically grounded, Carlyle used his understanding of history to point out that the most well-known leaders had a set of inherent characteristics that made them the leaders we know them as today (Halaychik, 2016). Further, Carlyle argued that these divinely inspired leaders would rise when the need for them came about (Spector, 2015). Another early thinker and contemporary of Carlyle was Herbert Spencer, who saw the Great Man Theory as unsophisticated and immature (Great Man Theory, Villanova, 2019). He focused on how the person came to be who and where they are, and argued that it was the environment that made the leader (Kellerman, 1986). Thus, began the debate of "Are leaders born or made?"

Trait Theory grew out of Carlyle and Spencer's writings and suggested leaders were born, had certain traits that make them leaders and, likewise, those without these traits were destined to be followers (Nahvandi, 2014). With this assumption researchers set out to identify exactly which traits made a leader a leader. Some of the commonly identified characteristic included, but are not limited to, charisma, drive, decisiveness, 
trustworthiness, creativity, intellectual intelligence, and emotional intelligence (Goff, 2003). The overarching criticism of the theory is the breadth in number of traits identified is broad and that within this long list there is much inconsistency and controversy as to which specific traits are critical to and which are supportive of effective leaders (Nahavandi, 2014; Zaccaro, 2007).

\section{Behavioral Theory}

The development of leadership theory continued in the west with a new era that focused on leadership behaviors. Those who promote Behavior Theory argue that it is the leader's deeds and actions that are the best factors in their success or failure. Of the many streams of Behavioral Theory, there are five worth detailing here.

Ohio State Leadership Studies. In the 1940s, the Ohio State Leadership Studies inaugurated Behavior Theory by moving away from a focus on traits and into identifying visible behaviors (Shartle, 1979). This series of studies distilled leadership behavior into two independent dimensions of the relationship between leader and follower (Stogdill, 1950). First, Initiating Structure Behaviors are the clarity of communication about expectations delegated to specific roles and tasks (Schriesheim \& Bird, 1979). Second, Consideration Behavior are those behaviors of the leader that attempt to create an encouraging, understanding, kind, and friendly environment (Schriesheim \& Kerr, 1974). In both of these dimensions a leader can be rated as high or low, thus creating a simple chart. The conclusion of the Ohio State Leadership Studies saw effective leaders as those who matched their leadership behaviors with what their followers wanted (Smith, Helm, Stark, \& Stone, n.d.). A common critique of the Ohio State Leadership Studies is that it is bi-polar in application and the reality is that the world of work is never that clear and 
is, in fact, somewhere in between the two poles and often shifts as do roles and tasks and circumstances.

University of Michigan Leadership Studies. A decade later another mid-west university took up a series of studies looking at what behaviors create effective leaders and job satisfaction from followers (Derue, Nahrgang, Wellman, \& Humphrey, 2011). Unlike those at Ohio State, the University of Michigan Leadership Studies found there were two orientations of which leaders are more of one than the other. On one end of the spectrum is employee orientation that focuses on the follower as having personal, individual needs (Boje, 2000). The other end of the spectrum focuses on the technical features of the job and sees the follower as a tool to get the work done (Boje, 2000). The series of studies point to a preference for employee orientation rather than a production orientation (Smith, Helm, Stark, \& Stone, n.d.). Further, the study identified three primary behaviors of effective leaders: task-oriented to get a task done, relationshiporiented where relationships are nurtured, and participative leadership where in-group members are involved in planning (Katz, Maccoby, Morse, 1950). The foundational critique of the University of Michigan Leadership Studies is that context was not considered. Similarly, the temper of followers was not directly addressed.

Scandinavian Leadership Studies. Behavioral theory continued to be developed in the 1990s when Göran Ekvall and Jouko Arvonen re-examined the dual-factors of leadership introduced by the Ohio State Leadership Studies and found a third factor (1991). The third factor of effective leaders is that they pursue development-oriented behavior (Blom, 2016). This behavior includes valuing experimentation, searching for novel ideas, and it also generates and implements change (Lumen, History of Leadership 
Theories, n.d.). Ekvall and Arvonen surmised that this third theory was not identified in the 1940s because the state of the world did not elicit the need; World War II was ending and the world was looking for stability, not change (1991). But now, at the end of the century, much change was taking place after the fall of the Soviet Union and rise of internet technologies, which led leaders and followers alike to need different behaviors in order to respond (Grenness, 2006; Grenness, 2011). A critique of the Scandinavian Leadership Studies focuses on its broad application and argues that it is only applicable to a few countries totaling a very small part of the world. Further, in recent years questions concerning the viability of the model have come about. These critiques are related to the subservient role the Scandinavian model often takes in the acculturation process of leadership and theories meeting those of management.

Role Theory. The last sub-set of behavior theories covered here is Role Theory, which has a long history and continues to be researched and written on today (Fellows, 2012; Winkler, 2010). This family of concepts sees behavior as directed by the role an individual has or is perceived to have (Fellows, 2013). The role, and thus behaviors, that middle-level managers have when interacting with their followers will be quite different than their role when interacting with their director or senior leadership. Further, these roles can change and thus behaviors change. An individual's roles, and thus behaviors, will be different when they go from home where they may be a spouse and/or parent, to their commute as a passanger or driver, to work where they will move in and out of multiple roles in the same day, to the role of a friend at happy hour, back to home where they started. Specific to effective leadership, "Role theory of leadership understands leadership within a group as a result of a process of differentiation by which group 
members achieve group aims faster and whereby, they meet their individual needs" (Winkler, 2010, p. 75). The core critique to Role Theory is that other factors pertaining to each individual are not addressed. Some of these include gender, national origin, and personality dispositions.

Behavioral theory took the necessary next step from Great Man and trait leadership theory by considering the interactions between leaders and followers. The Ohio State Leadership Studies differentiated leadership styles that focused either on tasks or on relationships. The University of Michigan Leadership Studies argued that followers had both personal needs and technical needs that a leader must attend to in order to find success. The Scandinavian Leadership Studies added a third factor to the Ohio State Leadership Studies that maintained leaders should behave toward their followers in ways that are development focused. Finally, role theory surmises that a leader will behave differently depending on who they are interacting with. These early contributions to leadership theory come with their fair share of criticism including their simplicity and lack of nuances including the consideration of culture. Of the developed behavior theories, the Scandinavian Leadership Studies is the only one to address values placed on leadership. As noted earlier, this consideration has become a critique of its applicability outside of the three countries. A possible reason for the lack of attention to culture in behavior theory is that that the understanding of cultures impact on leadership was not studied nor quantified until later in the century. Another is that leadership theories moved on from being solely behavior focused onto considering the context of leadership. 


\section{Contingency/Situational Theory}

The contingency, or situational, set of leadership theories are those that consider both the leader and the context of leadership. The effectiveness of a leader is determined not just by innate characteristics, developed traits, or certain behaviors but by the leader, or leadership style, matching the environment and situation in which they work.

Fiedler's Contingency Theory. In the late 1950s, Fred Fiedler developed the Contingency Theory where the leadership style does not change to match the environment, but the aim matching the leader with the most well-matched situation (Fiedler, 1967; Fiedler, 1978; Peters, Hartke, \& Pohlmann, 1985). The Least Preferred Coworker Scale (LPC) was created to understand who would work best where. Leaders with a high LPC score are more people-oriented, have mature interpersonal skills, and use others to get work done (Strobe \& Garcia, 1981). Those with a low LPC score are more task-oriented and get the work done by using positional power (Strube \& Garcia, 1981). Once leaders know their style, they can be matched with the situation in which they can be most effective. The situation or context is based on overall situational control which includes leader-member relation (how a leader interacts with followers and the overall group cohesion), task structure (the nature of the task and degree of clarity and structure it provides moderated by the leader's experience with that task) and positional power (how much formal power a leader has over followers (Strube \& Garcia, 1981; Triandis, 1993). These factors combine to present the leader with a degree of favorableness. When all three are high, the situation control is high; when they are low, the situational control is low (Fiedler, 1978; Strube \& Garcia, 1981). Task-oriented leaders are most effective when they perceive that they have high control. Relationship- 
oriented leaders are most effective when they have moderate control (Fiedler, 1978; Strube \& Garcia, 1981). In low control situations, the task-oriented leaders are more effective than their relationship-oriented counterparts (Fiedler, 1978; Strube \& Garcia, 1981).

The preeminent cross-cultural application of Fiedler's Contingency Theory was by Triandis (1993, 1995). Triandis (1993) as well as Singelis, Triandis, Bhawuk, \& Gelfand (1995) see cultural values as the definitive arbitrator of effective leadership. With Fielder's model as the basis three culturally contingent values were considered: individual vis-à-vis collective responsibility, how and when power and authority may be used, and the amount of control a society feels they need over their environment (Triandis, 1993). Ayman, Chemers, and Fiedler (1995) note Triandis (1993) in their article detailing contingency theory and multiple the levels of analysis including individual, didactic, and group characteristics and values.

The critiques of Fiedler's Contingency Theory are levied at both the model and the LPC scale. The broad critique of the model is that it is inflexible in that in the belief that because leadership style is fixed that the best way to change a situation is to change the model (Cruz, Nunes, \& Pinheiro, 2011). The inflexibly of leadership has been directly challenged in more recently developed families of leadership theory. When it comes to the LPC scale there are at least two issues. The first is that the scale has a $50 \%$ reliability variance and thus it may not be a reliable measure (Mitchell, Biglan, Oncken, $\&$ Fiedler, 1970). Also, for those who score toward the middle of the scale it may be unclear what style of leader you are (Cruz, Nunes, \& Pinheiro, 2011). 
Hersey-Blanchard Situational Leadership Theory. The Hersey-Blanchard Situational Leadership Theory, developed in the late 1960s, states that a leader should match their style to each follower depending on the follower's maturity in the task being pursued (Graeff, 1997). The best style depends on how mature (high to low) the follower is at the task and the degree (high to low) of relationship between the leader and follower (Vecchio, 1987). From these two continuums the model details four specific styles a leader can adopt: telling, selling, participating, or delegating (Fernandez \& Vecchio, 1997). A leader will "tell" low readiness followers if they are high on task but low on relationship. The leader will "sell" moderate readiness followers if they are high on both task and relationship. Or, the leader will invite participation if the task is low but relationship is high. Finally, the leader will delegate to high readiness followers when they are low both on task and relationship. This leadership model continues to enjoy popularity primarily because of ongoing marketing and trainings by The Ken Blanchard Companies.

There are multiple and long ranging critiques of the Hersey-Blanchard model. First and foremost is the lack of academic, peer-reviewed researcher and literature (Meirovich \& Gu, 2015; Vecchio, 1987) The theory is known primarily because of it being widely marketed and disseminated for financial gain. Another critique is that the unit of analysis is the individual and the group is left out of the consideration (Graeff, 1997). Additionally, there are no accurate standards of maturity and thus the leader may misjudge the readiness of an individual (Graeff, 1987, 1997; Yeakey, 2002). Lastly, the cross-cultural applicability is in deep doubt as cultures differ in their preference for the 
different leadership styles of participation, telling, or deligation (Vandayani, Kartini, \& Hilmiana, 2015).

Goleman's Situational Leadership. Closely associated with Situational Leadership Theory is Daniel Goleman's six types of leaders. In Leadership that Gets Results, Goleman details the six types of leaders:

\section{Table 1}

Goleman's Situational Leadership Styles

\begin{tabular}{|c|c|}
\hline $\begin{array}{l}\text { Pacesetting } \\
\text { Leader }\end{array}$ & $\begin{array}{l}\text { The leader sets aggressive goals and standards and drives employees to } \\
\text { reach them. This works with highly motivated and competent } \\
\text { employees, but can lead to burnout due to the high energy demands and } \\
\text { stress levels. }\end{array}$ \\
\hline $\begin{array}{l}\text { Authoritative } \\
\text { Leader }\end{array}$ & $\begin{array}{l}\text { The leader authoritatively provides a direction and goals for the team, } \\
\text { expecting the team to follow his lead. The details are often left up to } \\
\text { the team members. This works well when clear direction is needed, but } \\
\text { can be problematic if the team members are highly experienced and } \\
\text { knowledgeable and might resent being dictated to. }\end{array}$ \\
\hline $\begin{array}{l}\text { Affiliative } \\
\text { Leader }\end{array}$ & $\begin{array}{l}\text { A positive reinforcement and morale-boosting style. The leader praises } \\
\text { and encourages the employees, refraining from criticism or reprimand. } \\
\text { The goal is to foster team bonding and connectedness, along with a } \\
\text { sense of belonging. This approach works best in times of stress and } \\
\text { trauma or when trust needs to be rebuilt. It is not likely to be sufficient } \\
\text { as a long-term or exclusive strategy. }\end{array}$ \\
\hline
\end{tabular}




\begin{tabular}{|l|l|}
\hline Coaching & $\begin{array}{l}\text { The leader focuses on helping individual employees build their skills } \\
\text { and develop their talents. This approach works best when employees } \\
\text { are receptive to guidance and willing to hear about their weaknesses } \\
\text { and where they need to improve. }\end{array}$ \\
\hline Democratic & $\begin{array}{l}\text { The leader intentionally involves followers in the decision-making } \\
\text { process by seeking their opinion and allowing them a voice in the final } \\
\text { Lecision. This works well when the leader is in need of guidance and/or } \\
\text { the employees are highly qualified to contribute and there are not } \\
\text { strenuous time constraints that require quick decisions. }\end{array}$ \\
\hline Coercive & $\begin{array}{l}\text { The leader acts as the ultimate authority and demands immediate } \\
\text { compliance with directions, even applying pressure as needed. This can } \\
\text { be appropriate in times of crisis or disaster, but is not advisable in } \\
\text { healthy situations. }\end{array}$ \\
\hline
\end{tabular}

(Reproduced from Situational Theories, Lumen Learning)

Just like Hersey-Blanchard's model, this theory declares that each style works most effectively depending on the situation (Goleman, 2000). The styles can be both developed and should be used interchangeably as the task and situations change (Goleman, 2000).

House's Path-Goal Theory. In the early 1970s, updated in the 1990s, and inspired by the works of Georgopoulos \& Tannenbaum (1957), Vroom (1964), and Evans (1970), Robert House developed the Path-Goal Theory of leaders. In this theory a leader is to clear a path for followers to work by considering employee characteristics, task and environmental characteristics, and the path to the goal (House, 1971, 1975). Employee 
characteristics include experience, abilities and skills, and the amount of control they have toward the known goals (House, 1971). Tasks and environmental characteristics produce certain obstacles such as the composition of the group, how authority is organized, and the design of the task (House, 1996). Then, considering these two sets of characteristics, the leader selects a leadership style and focuses on motivating the group (Evens, 1996). Possible leadership use behavior rather than style styles are directive, supportive, participative, or achievement-oriented (House, 1996). Motivation includes defining goals, clarifying the path, removing obstacles, and providing support (House, 1996). A critique of this theory is the innate complexity and that thus it may be out of reach as helpful for practitioners (Northouse, 2016). Similar to Hersey and Blanchard, there has been a dearth of empirical research addressing the effectiveness of the theory (Northhouse, 2016).

Vroom-Yetton-Jago's Decision-Making Model of Leadership. The DecisionMaking Model of Leadership was conceived by Vroom and Yetton in the 1970s and later updated in the 1980s by Jago (Lunen Burg, 2010). The process includes first considering three important factors, then answering either seven or eight questions, and through using a decision tree the appropriate one style of leadership is decided upon out of five options (Field \& Andrews, 1998). The three factors to first study are, how important the quality of decision is, how involved or collaborative the team wants to be, and how much time there is to make a decision (Slack \& Cooke, 1984). The questions to answer are done in order and direct the leader into one of five styles of leadership. Autocratic I leaders make the decisions independently of the group, take little time to make decisions, but communicate the decision clearly to the group (Reber, Auer-Rizzi, \& Maly, 2004). 
Leaders demonstrating Autocratic II style also make the decision but take some time to gather information from the group (Reber, Auer-Rizzi, \& Maly, 2004). The Consultative I leaders still make the decision but actively pursue input and thoughts from individuals from within group (Reber, Auer-Rizzi, \& Maly, 2004). Consultative II leaders take another step in bringing the group together to get the options not just of individuals but also as a whole (Reber, Auer-Rizzi, \& Maly, 2004). Lastly, a leader can take up the Group/Collaborative II where they support the group and leave the decision to the group itself (Reber, Auer-Rizzi, \& Maly, 2004).

Three common critiques are aimed at this model. First, there are questions concerning what size of group this can be used with as the larger the group the more difficult it may be to have agreement on answers to the questions. Also, the model does not include personal factors of the leaders, followers, nor stakeholders. Lastly, the rigidity of the model may not flexible enough to fit most situations.

Leader-Member Exchange (LMX). Perhaps the most well-known situationally contingent leadership theory is LMX. In the 1970s, George Graen and Mary Uhl-Bien developed LMX, also known as the Vertical Dyad Linkage Theory, which describes how leaders and followers should relate and interact (Schriesheim, Castro, \& Cogliser, 1999). The relationship can either be disruptive or constructive not only to a particular leader and follower but also the team as a whole (Volmer, Spurk, \& Niessen, 2012). The LMX process involves three stages: Role Taking, Role Making, and Routinization. Role Taking involves the leader learning the skills and capabilities of the new follower while both the leader and follower learn how to respect the other (Erdogan \& Bauer, 2014). In Role Making there is an informal negotiation where the role is refined and trust is built 
between both parties (Rockstuhl, Dulebohn, Ang, \& Shore, 2012). Finally, Routinization is the ongoing pattern of exchange between follower and leader (Erdogan \& Bauer, 2014). Important in LMX is that not everyone in the group has the same closeness of relationship with the leader; there are those who are in-group and those who are outgroup (Martin et al., 2016). The in-group is the small, trusted inner circle who have higher levels of influence, decision-making, and shared resources (Martin et al., 2016). These individuals tend to work harder and are expected to be loyal to the leader (Volmer, Spurk, \& Niessen, 2012). The out-group has much lower levels of influence, decisionmaking, and access to resources. The leader must balance their relationships with those who are a part of the in-group and those of the out-group, to maintain cohesiveness of the group (Martin et al., 2016).

The cross-cultural implications of the LMX has been given significant attention in the past few decades. One study looked to understand paternalistic leadership in through a LMX and found that in both in India and the United States paternalistic leadership was positively related to LMX and organizational commitment (Pellegrini, Scandura, \& Jayaraman, 2010). Another recent study found that the LMX elements of organizational citizenship behavior, justice perceptions, job satisfaction, turnover, and leader trust are is more strongly related to western, horizontal-individualist contexts that in verticalcollectivist contexts (Rockstuhl, Dulebohn, Ang, \& Shore, 2012). The same study also found that national culture does not affect relationships of task performance, transformational leadership, organizational commitment in the LMX model (Rockstuhl, Dulebohn, Ang, \& Shore, 2012). 
One critique of LMX theory cites the likelihood of alienating some in-group members and probability of doing the same to out-group members (Power, 2013). Another critique notes that LMX does not give guidance on how high-quality relationships can be developed (Management Study Guide, 2012; Dienesch \& Linden, 1986). A broad critique is that organizational and other contexts are not considered (Hogg et al., 2012). Finally, Dienesch and Linden argues that LMX is not actually dyadic but is multidimensional and thus it should be measured as so (1986).

Coming on the heels of behavior leadership theory, contingency, or situational, leadership took the next step in saying, yes, there are things, including behaviors that leaders can take up but they should be done in context. This is the central contribution to this family of leadership theories: the context and environment matters and thus modulates what a leader does. While there are disagreements between researchers of this era and critiques about, this collection of theories

\section{Charismatic Leadership}

Where situational leadership taught that leaders must adapt to the situation in order to enable or motivate their followers to be successful, charismatic leadership teaches that successful leaders inspire their followers and from that stimulation they will pursue success (Conger \& Kanungo, 1998). This theory specifies three requirements for charismatic leadership to be successful: the characteristics of the leader, the characteristics of followers, and the characteristics of the environment (Nahavandi, 2014).

The charismatic leader must exude and actively use several characteristics to elevated degrees. This leader must have high energy and enthusiasm not only for the 
work being done but for other people and for life in general (Conger \& Kanungo, 1998). Similarly, there is great energy about how the individual sees themselves and their selfconfidence (Conger, 1989). This self-assurance extends to active persona building, role modeling, and brand management (Nahavandi, 2014). They have strong beliefs about ideas and the future as expressed in the vision for the ideal future (Howell \& Frost, 1989). Not only do they have these strong convictions but they express them confidently and continuously through clear and common communication devices (Conger \& Kanungo, 1998).

The characteristics of the charismatic leader must be matched with certain characteristics of the followers. The four categories of characteristics begin with followers having a high-performance orientation where their own expectation is that they and the group are expected to accomplish impressive feats (Shamir, House, \& Arthur, 1993). They have an extraordinary confidence in their leader and, simultaneously, identify with them on a personal level (Howell \& Shamir, 2005). This connection precipitates an emotional bond that then creates respect, affection, and esteem in the leader which in turn culminates in devotion and loyalty, and sometimes, absolute obedience to the leader (Nahavandi, 2014).

The third critical component of charismatic leadership is the context of the environment. A balanced, unchanging, monotonous situation is not what charismatic leaders and followers need nor want. Charismatic leadership thrives in contexts where this is an ongoing crisis or series of calamities that create the desire for revolutionary change (Conger \& Kanungo, 1998). Followers must be intimately involved in working toward change by being given and the opportunity to take up specific roles in dealing 
with the crisis (Nahavandi, 2014). Lastly, leaders and followers alike find and take opportunities to talk about the ideological aims and often do so with employing dramatic symbols (Howell \& Shamir, 2005; Nahavandi, 2014). Taken together, the characteristics of the leader, the followers, and the context create a powerful opportunity to move forward.

Modern or contemporary examples abound and indeed contribute to the continued popularity of the theory. In the United States many point to the most recent two presidents and, possibly, the next. President Obama brought "hope" and "change" to his two campaigns while President Trump promised to "make American great again," emphasis on 'again.' Meanwhile Senator Bernie Sanders and his army of "Bernie Bros" are in round two of not only seeking to change the Democratic Party but also seeking to move dramatically away from traditional American capitalism. Indeed, one former candidate who has stayed out of the 2020 fray also sought to bring change by being the first female American President: Secretary Hillary Clinton. Another realm where charismatic leadership is endemic are in tech and, specifically, entrepreneurial tech fields. Examples abound from the late Steve Jobs of Apple, Elon Musk of Tesla and SpaceX, Jeff Bezos of Amazon and Blue Origin, to Travis Kalanick of Uber. All of these charismatic leaders have had their fair share of controversy but continue to enjoy extraordinary popularity within the groups of followers have bought in and endeavor to change the status quo.

Culture as a moderator of charismatic leadership is an ongoing conversation. Nahavandi (2014) notes the cultures with traditions of saviors and prophets, such as Judaism, Christianity, and Islam, will broadly adopt the charismatic leader while those 
with faith traditions that shun the rescuing leader, such as far eastern traditions and preChristian African faiths, are less likely to embrace charismatic leadership. Further, some of the most recent and ongoing study of culture and leadership is through the GLOBE Study. The GLOBE Study specifically looks at the role of charisma in different cultures across the world. The researchers found that some aspects of charismatic leadership are universally endorsed, some are unanimously negative, and some are culturally dependent (Den Hartog et al., 1999; Nahvanadi, 2014).

Critiques of charismatic leadership fall into both the methodological and practical realms. Criticisms of the methodology include lacking a clear definition of 'charisma,' "fails to sufficiently specify the casual model capturing how each dimension has a distinct influence on mediating processes and outcomes," a 'conceptualization and operationalization confounds charismatic leadership with its effects," and "the most frequently used measurement tools are invalid in that they fail to reproduce the dimensional structure specified by theory and fail to achieve empirical distinctiveness from other aspects of leadership" (Van Knippenberg \& Sitkin, 2013, Abstract). On the practical side, there is a worry about what happens when the charismatic leader fails, falls, dies, or otherwise leaves the group. This reliance on the leader is argued to be, in the end, unhealthy because of the inability for the followers to easily shift a new leader. Further, it has been broadly noted that charismatic leadership has a dark side in that not all leaders are ethical and many have used their charisma for reprehensible aims. Indeed, much of the controversy surrounding the above noted tech titans is that they took their charismatic leadership too far and became damaging and destructive to their followers and organizations. 


\section{Transactional \& Transformational Leadership}

Leadership research and theory spent much of the last two decades of the $20^{\text {th }}$ century understanding and defining the difference between transactional and transformational leadership. Transactional leadership developed first and focused on motivating followers based on appealing to their self-interest but failed to develop an understanding of how organizations and groups pursue change. Charismatic leadership began to address these contexts of change and development but it did not satisfy some. Thus, transformational leadership was developed as an outgrowth of charismatic leadership and as a corollary to transactional leadership. Transformational leadership seeks the same change that charismatic leadership does but is more expansive in including "charisma and inspiration, intellectual stimulation, and individual consideration (Nahavandi, 2014, p. 189).

Transactional Leadership. With its first mention by the sociologist Max Weber in the 1940s, the notion of Transactional Leadership stayed dormant until the 1970s and came into popular understanding in the 1980s when Bernard Bass made the concept well known (Nikezic, Puric, \& Puric, 2012). Sometimes called managerial leadership, the transaction between leader and follower is based on rewards and punishments to motivate the follower (Weber, 1947). With this understanding, leaders value order and structure and spend their energy on organizing and ensuring performance (Avolio, Bass, \& Jung, 1999). The assumptions of transactional theory are that reward and punishment are the only things that motivate followers, that followers are not self-motivated and must be tightly controlled, and that followers have no other choice than to obey the leader (Management Study Guide, Transactional Leadership Theory, 2020). This style focuses 
on three concepts: organizing, controlling, and short-term planning (Paschall \& Large, n.d.). Specific transactional leadership theories, including Path-Goal, have been discussed above.

Transformational Leadership. At the same time that transactional leadership was being codified another type of leadership was being defined. Transformational leadership, also known today as charismatic leadership, was first noted by James Downton in the early 1970s, then popularized and expanded by James Burns later in the decade and then again by Bernard Bass in the 1980s (Stewart, 2006). This set of leadership theories focuses on the leader encouraging and motivating their followers in order for the group to move forward (Ross \& Kendall, n.d.). The biographer Burns defines transformational leadership as a process where "leaders and their followers raise one another to higher levels of morality and motivation" (1978, p. 6). A decade later Bass (1985) began to quantify transformational leadership with the Multifactor Leadership Questionnaire (MLQ Form 5X).

The three fundamentals of transformative leadership are charisma paired with inspiration, cerebral stimulation, and distinctive consideration. Charisma and inspiration are the same pieces found in charismatic leadership where there is an emotional bond between leader and follower, that creates loyalty that motivates followers toward the vision (Nahavandi, 2014). The second element is that followers are challenged so that intellectual stimulation occurs but simultaneously supported by the leader through the bond they share (Nahavandi, 2014). Lastly, through personal relationship the leader considers each of their followers as individuals and acts accordingly (Nahavandi, 2014). 
From these 3 parts transformational leadership identifies 4 roles a leader could take up. Inspirational motivation says that leaders are to be motivating and inspiring to all of their followers (Bass, 1997, 1999). Leaders are also to be intellectually stimulating where followers are encouraged to be creative and innovative (Bass, 1997, 1999). Leaders are also to be an idealized influencer where they embody values, are someone who followers can look up to, and who walk the talk (Bass, 1997, 1999). Lastly, leaders are to give individualized consideration to their followers where they people driven and have genuine concern for the needs of the followers (Bass, 1997, 1999). The critiques of transformational leadership are the same as noted by Van Knippenberg and Sitkin (2013) above.

Kouzes and Posner's The Leadership Challenge. Transformational leadership continues to be popular as evidenced by Kouzes and Posner's recent publication of the $7^{\text {th }}$ edition of The Leadership Challenge that was first published in 1987. In the text they detail five attributes that they believe makes a leader successful. A leader is to Model the Way by clarifying and affirming shared values, finding and encouraging individuals to use their voice, and setting the example by supporting actions with stated values Leaders are to also Inspire a Shared Vision by "imagining exciting and ennobling possibilities" and to connect with others by pointing to a desired and shared future. Challenging the Process values innovation and continuous improvement with a focus on present, small wins and learning from experience Leaders are to Enable Others to Act by encouraging collaboration through trust building and building relationships that precipitate others' growth and courage. Lastly, the best leaders Encourage the Heart by recognizing contributions, showing appreciation, celebrating values and wins, which creates growth 
in individuals and the group alike. To support the development of leaders, Kouzes and Posner developed the Leadership Practices Inventory (LPI) for teams and individuals to use to understand where they can grow (Kouzes \& Posner, 2012, 2017). Kouzes and Posner's theory of leadership is often placed simultaneously in the transformational category as well the following values-based theory of leadership.

The critiques against transformational leadership are very similar to those of charismatics leadership. In fact, the arguments made by Van Knippenberg and Sitkin (2013) discussed above were levied at both charismatic and transformational leadership. Again, the lack of clarity in agreed definition of the components of being 'inspirational,' 'intellectually,' and 'individualized.' And yet again, the tendency for charismatic to be or become unethical is true for transformational leaders (Avolio and Howell, 1992; Yukl, 1998). And additional and but hardly unique critique of transformational leadership is that it is simply too complex to be trained in and thus useful for leaders in the real world. Lastly, there is concern that transformational leadership is simply a regression to trait and behavior leadership (Brayman, 1992).

\section{Values-Based Leadership Theory}

Values leadership theory grew out of the expanding understanding and experience of failed leadership at multiple levels in many areas of industry and government alike. This leadership family shoots for the stars in wanting to be thee wholistic understanding of the leadership. Three subsets of this group of theories are servant leadership, authentic leadership, and positive leadership.

Servant Leadership. As transformational leadership got its start in the 1970s, so did servant leadership when Robert Greenleaf first lectured, wrote on, and coined the 
term (Greenleaf, 1977, 2002). The theory developed over the next several decades before maturing and becoming widely known at the end of the $20^{\text {th }}$ century. According to the Greenleaf Center for Servant Leadership it is "a philosophy and set of practices that enriches the lives of individuals, builds better organizations and ultimately creates a more just and caring world" (Greenleaf Center for Servant Leadership, 2020). Whereas transformational leadership focused on the effects of leaders and followers on the organization, servant leadership seeks first and foremost to develop the follower with the thought that they would then do better work for the organization (Stone, Russell, Patterson, 2003). Servant leadership presupposes that both individuals and organizations can be servant focused; a servant leader leads by serving followers within an organization while servant organizations serve and lead other organizations (Stone, Russell, Patterson, 2003). Characteristics of servant leadership include both functional and accompanying attributes. Functional attributes are detailed as vision, honesty/integrity, trust, service, modeling, pioneering, appreciation of others, and empowerment (Russell \& Stone, 2004). The accompanying attributes are communication, credibility, competence, stewardship, visibility, influence, persuasion, listening, encouragement, teaching, and delegation (Stone, Russell, Patterson, 2004).

The first critique of servant leadership is that it is not for every person and not for every organization. Many traditional business managers and environments work nearly in the antithesis of servant leadership. Further, this style of leadership may lead to less motivated followers. Servant leadership, being based on trusting relationships between individuals and teams, takes time to develop and may not work in groups with a shortterm orientation. Thirdly, the theory tends to ignore the power dynamics that comes with 
leadership and intersecting power relations between genders, sexuality, age, class, race, and so on (Liu, 2019). Lastly, there are definitional problems in that over 40 different traits have been associated with the concept (Nahavandi, 2014).

Authentic Leadership. With the publication of Authentic Leadership in the early 2000s by Bill George, a new subcategory of values-based leadership was popularized that had been gaining traction in the previous decade (Avolio \& Walumbwa, 2014). George (2004) argues that the best leaders are those who are most authentic and who shun inauthenticity. These leaders, being true to themselves, are then able to connect more closely with their followers and be the leader the group and individuals need (Cooper, Scandura, \& Schriesheim, 2005). It is generally agreed that there are four components of authentic leadership. Authentic leaders are self-aware and continuously pursue deeper understandings of the self (Avolio \& Walumbwa, 2014). Their moral perspective is internalized in that they self-regulate based on their own moral values and express these in both decision-making and behavior (Ladkin \& Taylor, 2010). These leaders also have a balanced processing ability where the initial stances is objectivity during which others are asked to give input, question, or challenge (Avolio \& Walumbwa, 2014; Ladkin \& Taylor, 2010). Lastly, authentic leaders seek relational transparency where there is honest sharing of one's thoughts, feelings, values with others (Avolio \& Walumbwa, 2014; Ladkin \& Taylor, 2010). Some authors have argued that authentic leadership is, or should be, influenced by positive psychology and would thus embrace a more positive focus while others have argued against this by claiming that not all people at all times are positive and thus to be so would, in fact, be inauthentic (Avolio \& Gardner, 2005). 
With all of its promises there are bound to be ample critiques of authentic leadership. First is that there is a perceived impossibility of an authentic leader having 'arrived' as there is always deeper a leader can go in their self-understanding (Ford \& Harding, 2011). Others, including Garnder (2011) note that sociohistorical circumstances affect each leader and that thus power and privilege is unequally distributed. Finally, and similar to the critiques above, authentic leadership can be corrupted and used to control and manipulate followers and thus the damage the organization (Alvesson \& Sveningsson, 2013; Costas and Fleming 2009)

Positive Leadership Theory. Positive leadership theory came as out of the growth of positive psychology and positive organizational behavior. This cluster seeks to turn traditional views and language that are considered 'negative' into the positive. Crises and challenges become opportunities and openings. Some common characteristics identified by Cameron (2008) include: being and expressing optimism, encouraging positive deviance, focusing on strengths, creating a positive culture, building and maintaining healthy and positive relationships, making communication positive, and squashing negativity quickly (Nahavandi, 2014).

The heaviest critiques of positive leadership come from Collinson who dubbed it 'prozac leadership' (2012). In several articles over the past decade Collinson has convincingly argued that we as a society have become "addicted to an excessive and artificial positivity" (2012). He also points out that such a simple tactic may not address the complexities that leaders in the real-world face. Similarly, Nahavandi questions if it is applicable to every leader in all situations (2014). Lastly, there is a concern that this 
style of leadership actually diminishes the abilities followers to think critically and disagree with leadership and their decisions (Banks, 2008).

\section{New Directions in Theory}

Since the turn of the millennium a broad scope of new theories of leadership have branched out. These include, but are not limited to, the contextual school of leadership, ethics and moral development, biology and neuroscience, critical leadership, strategic leadership, plural leadership, positive leadership, and system leadership theory. None of these theories are mature enough nor relevant to this study to be given space here.

\section{Cross-Cultural Values and Leadership Models}

As noted in the previous sections, although some of the leadership theories have been tested in other cultures, sustained and deliberate research of these theories in crosscultural settings is still severely limited. Researchers have tested theories to other cultures with varying degrees of success. In doing so, they have taken an etic approach and applied them to other cultures. Culture is not considered a contextual variable in any of them and thus the moderating factor of culture is rarely considered. There is, thankfully, a growing body of knowledge on cross-cultural values and, more importantly, the direct impacts culture has on the application of leadership.

While leadership theory has not considered culture fully, there is considerable research about the impact of culture on management in general. The phenomenon of globalization has affected every corner of the planet and no-where more-so than the MAME. With the expansion of transportation and information networks the MAME has become a vast proverbial salad bowl where people of every background interact together in the realms of politics, business, military, and education (Friendman, 2000). Because of 
this, cross-culture models are helpful in both defining culture but also in then being able to compare and contrast between cultures. While many of these models were created in North America and Western Europe, they were in fact built in cross-cultural environments where the involved scholars came from various and differing cultural contexts (Trompenaars \& Hampden-Turner, 2011). Academics and practitioners often are both outside of their "home" culture and are working alongside others who did not share the same cultural values and were thus created in multi-cultural settings (House et al., 2004). More importantly, these models were created for the international environment. The initial and maintained purpose of these theories was and is for them to be applicable in virtually any corner of the globe (Hofstede, Hofstede, \& Minkov, 2010; House et al., 2004). These theories aim to be insightful in cross-cultural circumstances from Patagonia to Indo-China, from Sub-Saharan Africa to North America, from the South Pacific to Eastern Europe, and, of course, everywhere in-between. Two of the most widely studied, cited, and used models will be discussed in the MAME context: Hofstede's Cultural Dimensions and the GLOBE Project.

\section{Hofstede's Cultural Dimensions}

Geert Hofstede's model of national cultural dimensions has been the most widely used and referenced cross-cultural construct over the past five decades (Jones, 2007). While working for IBM in the late 1960s and early 1970s Hofstede observed and heard of the difficulties of the organization which had offices and production facilities in dozens of countries across the globe. From a position in human resources Hofstede was able to gather from thousands of IBM employees from 40 different countries and subsequently used factor analysis to find six common themes across cultures (Nakata, 2009). He came 
to see these themes, now called dimensions of values, as situated within culture, as defined as "the collective programming of the mind" (Hofstede, 2003). While Hofstede's work built off of previous cross-cultural thought and models it was his work that established the convention and application of cultural values as his work continues to be cited both in the academy and in practice-oriented contexts (Marcus \& Gould, 2000; Nakata, 2009).

Hofstede's cultural dimensions have matured into six distinct dimensions:

- The Power Distance Index that deals with how much a society accepts and expects power to be allocated equally or unequally.

- The Individualism Versus Collectivism where a culture is either more looselyknit (individualism) or more tightly-knit (collectivism).

- Masculinity Versus Femininity, also called the tough and tender measure, says that some cultures are more or less competitive and achievement oriented and that others are more or less cooperation and consensus-oriented.

- The Uncertainty Avoidance Index details how much a culture feels comfortable with uncertainty or ambiguity.

- The Long Term Orientation Versus Short Term Normative Orientation is focused on a culture maintains linkages with its past in order to deal with the present.

- The Indulgence Versus Restraint continuum where they are either more willing to pursue gratification or more likely to be restrained form doing so.

For more detail on each cultural dimension see Appendix A. 
Hofstede in the Middle East. Hofstede's research includes seven countries that have typically placed together as the Middle East: Egypt, Iraq, Kuwait, Lebanon, Libya, Saudi Arabia, United Arab Emirates. Generally, the group's scores hold to smaller ranges that other regions:

- high on Power Distance (range of 70-95),

- lower on the Individualism scale (range of 25-40),

- moderately higher on the Masculinity scale (range of 45-70),

- high scores for Uncertainty Avoidance (range of 68-85),

- very low on the Long-Term Orientation score (range of 7-36),

- and very low to moderate on the indulgence scale (range of 4 to 52) (HofstedeInsights, Country Comparison, 2018).

Collectively, this group is "characterized by long power distance/high hierarchy, collectiveness, masculinity, relationship orientation, high avoidance of uncertainty, humane orientation, tribal and family receptiveness, gender discrimination, past orientation and long power distance" (Najm, 2015, p. 424). For a detailed breakdown of each MAME's Hofstede's scores see Appendix B.

Critique and Contributions. While Hofstede's model has been used for many decades, has been applied broadly across every industry, and refined over time there are still significant critiques. The first concerns by the fact that all the data was collected from one company, IBM. Every organization has its own beliefs, values, shared myths, ways of doing things which very well moderate the assessment of other, external, and more broad values such as the ones Hofstede was interested in (Jones, 2007). A second critique to be levied is related to the first issue. Specifically, the data was collected almost 
exclusively from individuals with formal education, and a professional job who constituted the upper socio-economic classes of society (Obeidat, Shannak, Masa'deh, \& Al-Jarrah, 2012). This was especially true in developing countries that, at the time, included every country in the Middle East group. Those who worked for IBM has professional/technical positions that came from a combination of education, experience, and, often family connections that were not available to all in developing societies. Thus, the data collected was not done in a wide-ranging manor to be able to characterize an entire country.

A third and fourth critique relate to Hofstede's unit of analysis and its changing use of application over time. Hofstede intended the unit of analysis to be solely at the nation-state level but as it grew in popularity many academics and practitioners mistakenly applied the insights to the individual level (Bond, 2002). As this misapplication became endemic Hofstede first attempted to clarify that it was to be only applied to countries and then he himself haltingly and with little success attempted translate what the values could mean for individuals (Bond, 2002; Maznevski, Gomez, DiStefano, Noorderhaven, \& Wu, 2002). A fourth and final critique is the question of "is the nation-state unit of analyses appropriate?" (Jones, 2007). It is both true that value systems are not bounded by boarders and that within boarders culture is divided again and again (DiMaggio, 1997; McSweeney, 2000; McSweeney, 2002).

The contributions of Hofstede's Cultural Dimensions is the foundation for the modern and growing understanding of the varying values of cultures. Hofstede did not aim to have his dimensions applied to leadership but that is exactly what has happened over the past 30 years. Many researchers and practitioners have used Hofstede's 
researcher as a guide in application. Even with these critiques accounted for and knowing that his work was not intended to be used for leaders, Hofstede's effort catapulted a fledgling field of research into the spotlight and led to today's largest and most well-developed cross-cultural study: the GLOBE Project.

\section{The GLOBE Project}

The Global Leadership and Organizational Behavior Effectiveness Research Project (GLOBE Project) is arguably the most comprehensive and well-developed theory tied to leadership across national cultures (Dorfman, Javidan, Hanges, Dastmalchian, \& House, 2012; Cambridge Institute, 2017; Chhokar, Brodbeck, \& House, 2013). An extensive study of 62 countries in which 27 hypotheses were investigated through both quantitative and qualitative methods of more than 17,000 managers in more than 950 different organizations (House, Hanges, Javidan, Dorfman, \& Gupta, 2004). The data was first sorted into 112 leadership attributes, then distilled into 21 different leadership dimensions and then again into condensed again into 9 global cultural competencies (Dorfman, Javidan, Hanges, Dastmalchian, \& House, 2012). For a list and description of the cultural competencies see Appendix C.

The authors of the GLOBE Project took these competencies and clustered all 62 participating countries into 10 culture clusters (House, Hanges, Javidan, Dorfman, \& Gupta, 2004; Kabasakal \& Bodur, 2002). To see the clusters and which countries are included in each, see Appendix D. One of the innovations that the GLOBE Project offers is a direct link from the cultural values and cultural clusters to what it means for leadership in the understanding of six cultural endorsed theories of leadership (House, 
Dorfman, Javidan, Hanges, De Lugue, 2013). The culturally endorsed theories of leadership are described in the following table.

\section{Table 2}

\section{GLOBE CLTS}

Charismatic/Value-Based Leadership: Reflects the ability to inspire, motivate, and
expect high performance outcomes from others based on firmly held core values. It
includes the following six primary leadership dimensions: (a) visionary, (b)
inspirational, (c) self-sacrifice, (d) integrity, (e) decisive and (f) performance oriented.

Team-Oriented Leadership: Emphasizes effective team building and implementation of a common purpose or goal among team members. It includes the following five primary leadership dimensions: (a) collaborative team orientation, (b) team integrator, (c) diplomatic, (d) malevolent (reverse scored), and (e) administratively competent. Participative Leadership: Reflects the degree to which managers involve others in making and implementing decisions. It includes two primary leadership dimensions labeled (a) nonparticipative and (b) autocratic (both reverse scored). Humane-Oriented Leadership: Reflects supportive and considerate leadership and includes compassion and generosity. This leadership dimension includes two primary leadership dimensions labeled (a) modesty and (b) humane orientation.

Autonomous Leadership: Refers to independent and individualistic leadership attributes. It is measured by a single primary leadership dimension labeled autonomous leadership, consisting of individualistic, independence, autonomous, and unique attributes. 
Self-Protective Leadership: Focuses on ensuring the safety and security of the individual and group through status enhancement and face saving. It includes five primary leadership dimensions labeled (a) self-centered, (b) status conscious, (c) conflict inducer, (d) face saver, and (e) procedural. (GLOBE Overview, 2020)

To date no other theory or model has come close to the GLOBE Project as it pertains to the direct association of cultures, countries, and clusters with specific leadership characteristics/traits (Cambridge Institute, 2017).

GLOBE and the Middle East. The Middle East cluster in GLOBE includes Egypt, Kuwait, Morocco, Qatar, and Turkey (Kabasakal \& Bodur, 2002; Kabasakal, Dastmalchian, Karacay, \& Bayraktar, 2012). This cluster shares some common history in the form of the influence of Islam and a history of political and economic dominance of external powers (Dorfman, Javidan, Hanges, Dastmalchian, \& House, 2012; Kabasakal \& Bodur, 2002; Kabasakal, Dastmalchian, Karacay, \& Bayraktar, 2012). From this history, it is not surprising to find that four countries targeted in this study scored similarly on the cultural values/practices and on what constitutes effective leadership. Generally, in the Middle East cluster:

- Performance is highly valued but far less practiced,

- Assertiveness is both valued and practiced at appropriately the same level,

- Future Orientation is valued but much less practiced,

- Humane Orientation is also valued but less practiced,

- Institutional Collectivism is approximately-valued and practiced equally,

- In-Group Collectivism is valued and practiced nearly-equal (with a large range of practice), 
- Gender Egalitarianisms value and practice is slightly separate,

- Power Distance is skewed with practice being significantly higher than value,

- and Uncertainty Avoidance being nearly-exact in equality between value and practice, (GLOBE, Middle East, 2018).

\section{Figure 2}

GLOBE Study, Cultural Practices and Values in the Middle East Group

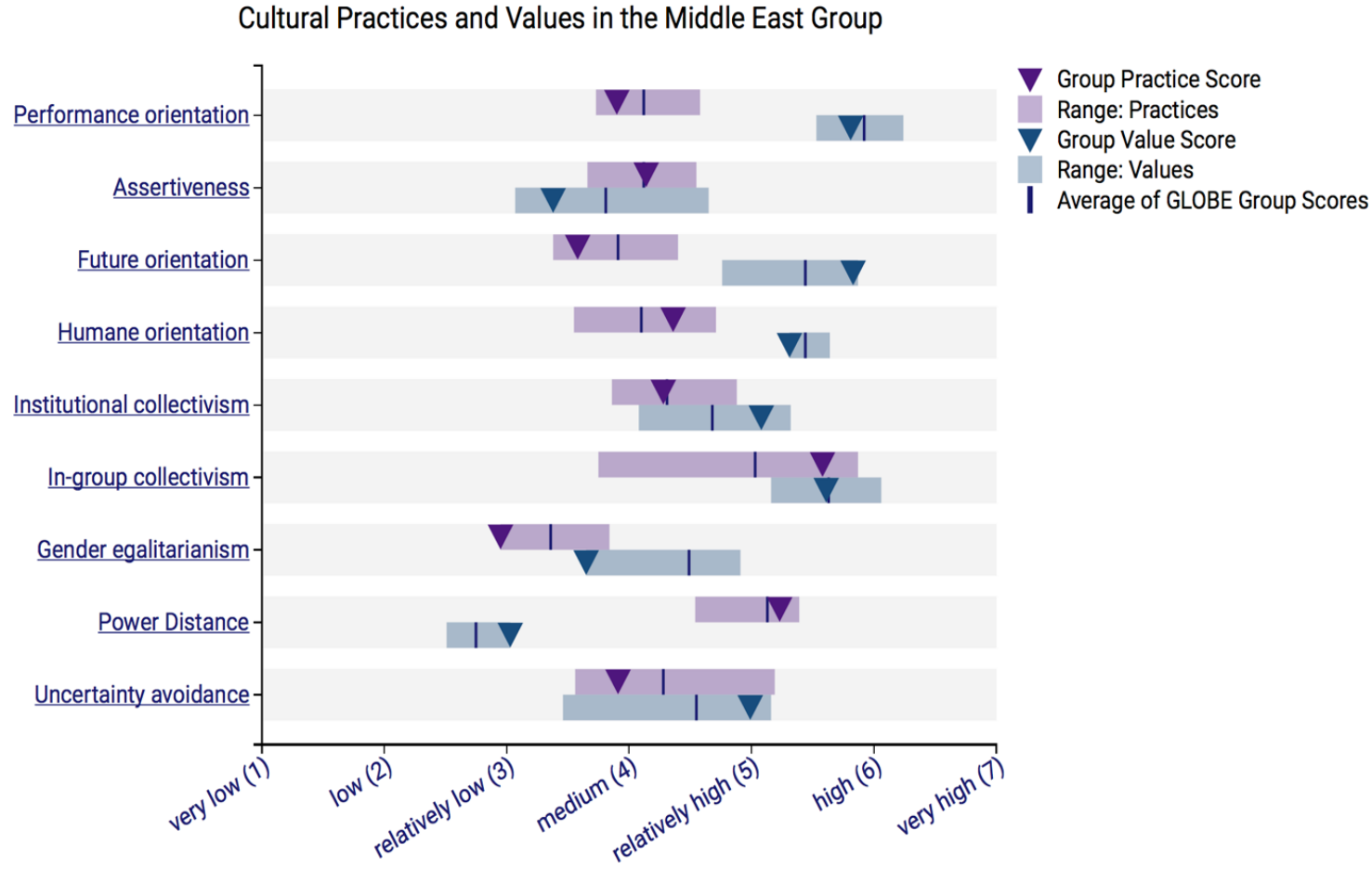

(Reproduced from GLOBE, Middle East, 2018)

When it comes to the CLTs dimensions of the Middle East cluster Charismatic and Team Oriented leadership are nearly tied for the strongest contribution to effective leadership in the contributes-slightly to contributes-somewhat range (Den Hartog et al., 1999). Just below this, around contributes slightly, is Participative leadership with Humane Oriented just below that (Kabasakal, Dastmalchian, Karacay, \& Bayraktar, 2012). The bottom two leadership scores are Autonomous and Self-Protective leadership 
that showed up in the slightly-inhibits to has-no-impact range (Kabasakal, Dastmalchian, Karacay, \& Bayraktar, 2012).

\section{Figure 3}

GLOBE Study, Leadership Scores for Outstanding Leadership in the Middle East

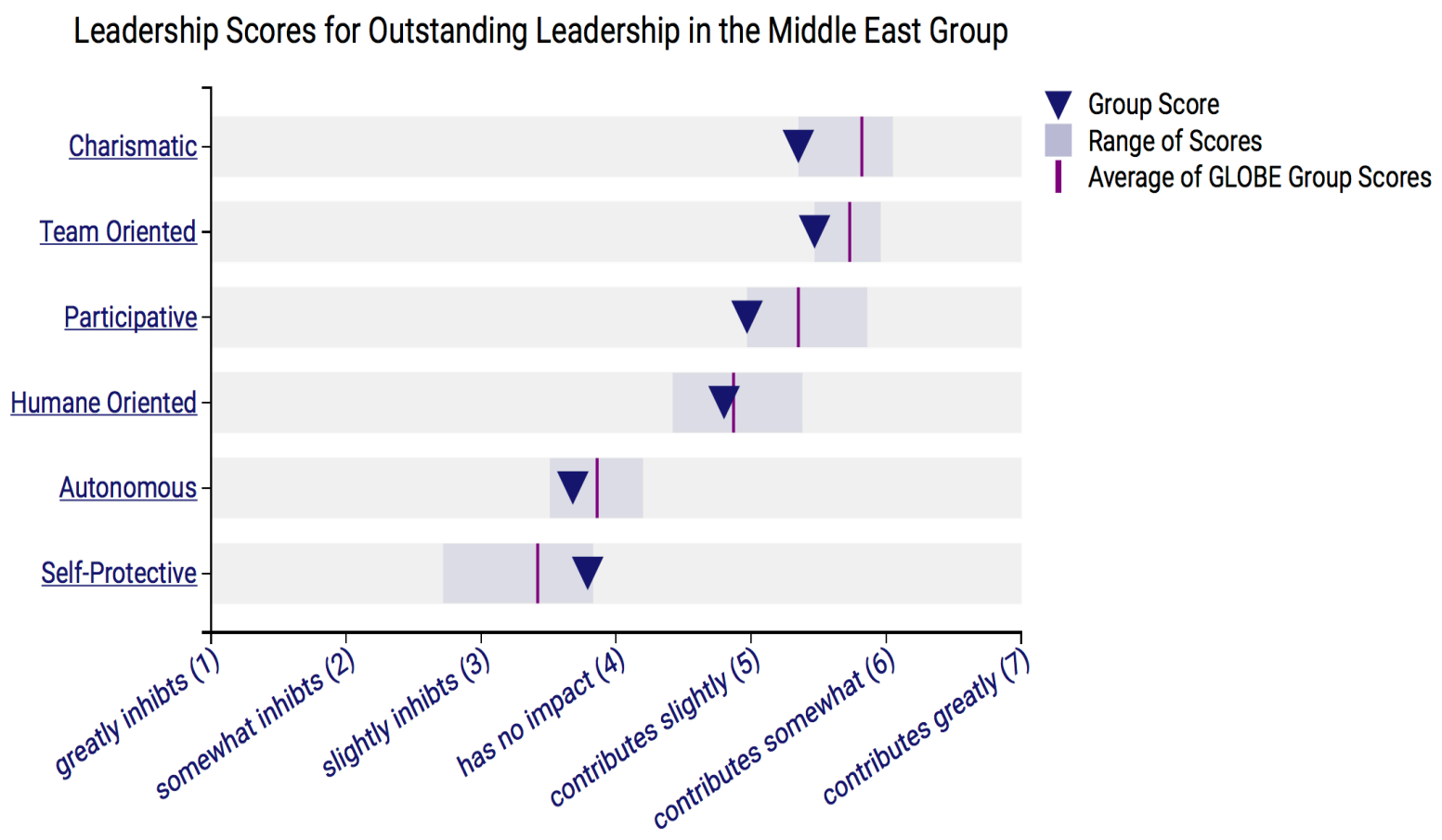

(Reproduced from GLOBE, Middle East, 2018)

The GLOBE Middle East cluster is comprised of the countries of Qatar, Egypt, Morocco, Turkey, and Kuwait. The societies belonging to this cluster reflect high scores of the societal cultural practices on the dimensions of In-Group Collectivism and Power Distance, or the degree to which the community accepts and endorses authority, power differentials, status privileges, and social inequality. The Middle East societies are highly group and family-oriented indicating that individuals who belong to these societies take pride and loyalties in their families and organizations. Power is not expected to be distributed equally and is seen as providing social order and stability. The Performance 
Orientation Scores are lower than average. This cluster is also low on dimension of Future Orientation and particularly low on Gender Egalitarianism. They are higher than the average on Humane Orientation and lower than average on Uncertainty Avoidance. Other culture dimensions including Assertiveness and Institutional Collectivism are rated in the mid-range. Overall, these societies are not particularly performance oriented, but are family oriented with unequal distribution of power. Gender inequality is the norm.

The Middle East cluster's societal values (what society believes should be) on the other hand, are considerably different than its cultural practices. Specifically, all societies in the Middle East cluster desire to be much more Future and Performance-Oriented, but interestingly, also desire to have more Uncertainty Avoidance (i.e., relying on social norms, rules and procedures to alleviate unpredictability). While they also desire to have lower levels of Power Distance, this cluster's values score is the highest of all clusters. They seek roughly the same levels, or slightly more Gender Egalitarianism, but this cluster scores the lowest in this dimension. These countries wish to be slightly less assertive but wish to maintain the same high level of In-Group Collectivism. There is also a desire to increase Institutional Collectivism indicating a willingness to increase the collective distribution of resources and rewards. Overall, the essential features of the Middle East cluster encompass societal practices that embody a strong attachment to the family and other closely-knit groups (e.g., neighborhood, village, and school friends). They are characterized by an unequal distribution of power and significant gender differences with male domination characterizing both societal practices and values.

Although leadership dimensions viewed as contributing to outstanding leadership include Charismatic and Team-Oriented Leadership, these dimensions have the lowest 
scores and ranks relative to those for all other clusters. The Charismatic attributes that are somewhat endorsed include a realistic vision, high performance orientation, integrity, and decisiveness. These societies also value team-oriented leaders whose characteristics include developing outstanding teams and using their administrative and interpersonal skills to create cohesive working groups. While Participative Leadership is somewhat valued, it is the lowest of all clusters. Humane-Oriented Leadership is viewed positively but only about equally to other cluster scores. While the Autonomous score is lower than average, the Self-Protective dimension has the second highest score and rank of all clusters. These leadership scores show that overall, the Middle East leadership profile is unique among the 10 clusters. Supplemental research has provided an explanation as additional leadership dimensions such as familial, humble, and faithful represent the pervasive influence of the Islamic religion in understanding the Arab world (GLOBE, Middle East, 2020)

GLOBE Critique. Despite the GLOBE Project having enjoyed more than two decades of prominence at the top of cross-cultural leadership theory there are significant challenges with it. This reality is true for the whole of the paradigm and this is even more true when it comes to Middle East cultural cluster (Taras, Steel, \& Kirkman, 2010; Terlutter, Diehl, \& Mueller, 2006). At first glance the combination of the five countries Egypt, Kuwait, Morocco, Qatar, and Turkey might seem appropriate but when beginning to think about "do these make sense together?" several important questions arise. A first critique is that there are relatively few countries listed in this cluster. There are at least 13 other countries in the MENA region, many of which are quite accessible to investigating scholars, for which data has not been collected. This first critique is 
compounded by a second: these countries are cover a very wide geographic area. The east-west distance between the capitals Kuwait and Morocco is more than 3,500 miles, and north-south from Istanbul to the bottom of Egypt is more than 1,000 miles. Additionally, as noted above, there are many other countries that were "skipped over" that could, or even should, be included in the study. The other cultural clusters that also have a 3-6 countries listed generally, with only one exception, are located quite close to each other. These two considerations, the number of countries included and the distances between them, bring into question whether they should be placed in the same cluster at all (Javidan, House, Dorfman, Hanges, \& De Lugue, 2006).

Another line of critique are the shared "histories" and shared "todays" of these five countries. As mentioned earlier in this paper, the Arab Middle East is both a sub region of the often-cited MENA region and is also can be clearly divided into three regions given the combination of common record and today's economic realities. he five countries in the Middle East cluster do share a similar religion, Islam, and histories of being controlled politically, and oft economically by outside powers (Rogan, 2017). But within these commonalities many dissimilarities appear. First, when looking at historic dominance from the colonial period on: Morocco was primarily influenced by Spain; Egypt was dominated first by the French, then the British, and then the United States; Qatar and Kuwait were part of the Ottoman Empire and then colonized by the British; and Turkey was the colonial power in much of the Middle East during the Ottoman empire, but was, for decades, was dominated by Western Europe (Cleveland \& Bunton, 2016; Mansfield, 2013; Rogan, 2017). The influences on these countries over the past 200 years has both come from other external powers and also shifted over time. Further, 
these five countries do not share much when it comes to the present. Primarily, the economic realities of Qatar and Kuwait with their massive oil wealth is in stark contrast to the resource-poor, tourism-dependence of Egypt and Morocco, with Turkey placing somewhere in between the two extremes (Cooper, 2012; Shwadran, 1985). Today's economic realities are widely varied, especially when considering other more homogenic clusters such as poorer Latin America and rich Nordic Europe. Both the lack of shared experiences of these countries and the desperate economic and political realities of today bring a significant question of whether these countries should be placed in the same cluster at all. A possible remedy to these critiques will be the 2020 expansion of the number of MAME countries included in the GLOBE Project. It is anticipated that data will be collected for Yemen, Saudi Arabia, Jordan, Lebanon, Syria, Iraq, and the United Arab Emirates (GLOBE 2020, 2018).

These cross-cultural models of culture and leadership have had a significant impact on both our understanding of the MAME culture but also how leaders can be effective in the region (Hofstede, Hofstede, \& Minkov, 2010; House, Hanges, Javidan, Dorfman, \& Gupta, 2004; Kabasakal, Dastmalchian, Karacay, \& Bayraktar, 2012). The Arab models provide some insight into unique characteristics of culture in the MAME while the international models provide an opportunity to compare and contrast both within and between regions. Hofstede's Cultural Dimensions provide the foundation for the current, ongoing GLOBE Project that seeks not only to understand aspects of cultures but also how leaders may work within various contexts. Each of these models has its own weaknesses but collectively they have been beneficial not only in academia but also in every other sector. 


\section{Leadership in the MAME}

Leadership as it is understood today in the MAME is derived from centuries and indeed millennia of ways of life, towering figures, and modern interpretations. The roots of the current culture, and thus understanding of and experience of leadership, are found in the tribal traditions of the nomadic tribes and settled populations of the Arabian Peninsula and the areas immediately north and north west. Perhaps the seminal event of the region happened when The Prophet Muhammad stepped onto the scene and galvanized the innumerable clans and tribes under the banner of Islam. In fact, the word Islam is derived from the Arabic noun that translates to accept, surrender, and/or submit (Mir, 2010). From Muhammad's revelations (the Quran) and through his sayings (Hadith and Sunna) much of what is today the MAME was unified, or at least pacified, and eventually led to a Middle East renaissance (Rogan, 2017; Bloom \& Blair, 2002; Esposito, 2005).

Muhammad is looked to as the seminal, perfect leader for Muslims (Greaves, 2012). Fast forward to today where there is much consideration about the Islamic Work Ethic (IWE) in relation to leadership in the MAME. Through the tribal foundations, Muhammad's example, and the IWE there is a clear ideal of Middle East leadership.

\section{Tribal-Islamic Leadership}

Tribal Foundations. The MAME that we know today is based on what came before and what came before modern bustling cities from Cairo to Baghdad, Damascus to Riyadh was a culture organized in families, clans and tribes. Lacking natural resources, this desert region relied on trading to garner wealth. Limited resources and the desire to control trade routes brought about conflict and created clear lines of who is in-group and 
who is out-group. These factors clearly defined tribal groups supported the development of leadership structures that were both authoritarian to those not part of the group, and simultaneously consultative to those who were within the group.

\section{Figure 4}

\section{Development of MAME Values of Leadership}

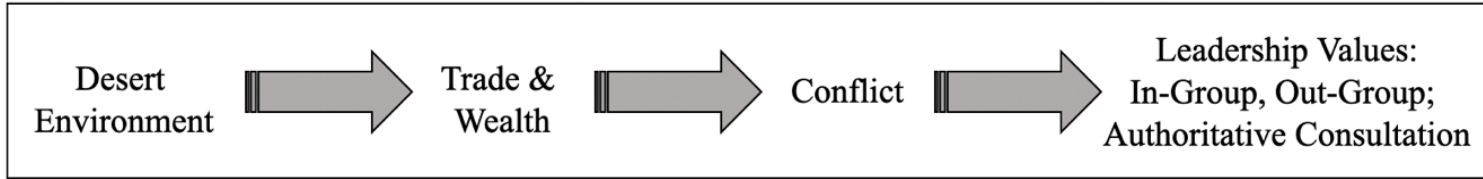

Desert. In stark desert of the regions has impacted the Arabian Peninsula and influenced its the people (Salzman, 2008; Rogan, 2017). The overriding consideration are finite resources and the great difficulty in creating and sustaining any activity and mode of production. The foundation of the limited assets is the lack of water which then restricts agriculture when then bounds how much life may be sustained (Bechtold, 2014; Salzman, 2008). Desert oases and springs were the only places were humans and animals alike could find potable water. Intimately tied to the people of pre-Islamic times were two key assets: camel and sheep. The well-suited desert camel were not only the primary mode of transportation but also provided nutrition from their milk (Brath, 2009; Crouwel, 1987). The total number of camels in the region was strictly limited by the location and quantity of water and feed around oases and springs (Lancaster \& Lancaster, 1988). Similarly, sheep were used for both food and clothing and were restricted to certain regions and to limited numbers (Miller \& Hayes, 2006). The western regions boarding the Mediterranean were where sheep could find enough rain-grown grass to sustain herds (Miller \& Hayes, 2006). 
Trading and Wealth. Another important facet of physical and economic survival was the ability to trade and the trade routes that developed (Freedman, 2008; Hodges, 1982; Issawi, 2013). Internally, trade was based around the basic needs of food, clothing, and shelter and typically occurred intermittently between the few established communities that settled at sources of water (Gibson, 2004). Another type of trade was critical to these towns, the regions bordering the Middle East, and also to the broader world. International trade between the continents of Africa, Asia, and Europe occurred in the nexus of the Middle East. Two of the well-established trade routes which developed over centuries were the Silk Road and the Sea Route (Gibson, 2004; Issawi, 2013). The famous Silk Road ran through northern parts of what is now the MAME and was the land route running from China in the east to what is now western Europe (Cleveland \& Bunton, 2016). The Sea Route is lesser known but equally important alternative for trade running east-west and also up from the east coast of Africa (Gibson, 2004). As we will see, influence and control over these both internal and external trade routes significantly influenced the ancient Middle East and MAME (Hodges, 1982; Issawi, 2013).

Conflict. Struggle between groups was inevitable in an environment of limited resources where survival and wealth are based on control of domestic resources and trade routes (Ali, 1990; Rogan, 2017). The way to simply survive or attempt to thrive was to control resources through vulturine enlargement where the way to obtain more of anything was by taking from others (Salzman, 2008). The preferred techniques for this type of expansion were not conquering and destruction, but instead raiding and, occasionally, expulsion (Greaves, 2012). 
Raiding is the modus operandi of predatory expansion with the capture of livestock the first priority. ... But resistance is met by force, and injuries or deaths lead to blood feuds. Tribes can respond to blood feuds with large parties bent on vengeance. Conflict can thus escalate to all-out battle. Losers can escape by retreat, taking their household and livestock with them. This leaves the territory open for occupation by the winners. (Salzman, 2008, p. 26)

These incursions that can intensify to territory changing hands then directly affects control over the trade routes (Rogan, 2017). This pattern of resource and territory control continued for centuries on end and, in many ways, continues to play out in the MAME (Rogan, 2017; Salzman, 2008; Shwadran, 1985).

In-Group, Out-Group. One significant consequence of the desert context and the conflict that grew from it is the distinction between those who are in-group and those who are excluded from the group (Greaves, 2012; Ali 1990). This nested sets of familial collections that could be very small (the nuclear family) or very big (tribal networks) (Mansfield, 2013). When confrontations happened "families faced families, lineage faced lineage, clan faced clan, tribe faced tribe" (Salzman, 2008, p. 23). A balance between these warring groups let any antagonist know that they were not facing an individual or a small group but in fact a potentially large group and large conflict (Salzman, 2008; Mansfield, 213). Knowing how you, an individual or group itself, were connected or related to another group became incredibly important and continues to this day. For example, there is a clear distinction between Saudis who are and those who are not part of the royal family with every great distinctions within the 15,000 Saudi royals (Lacey, 2009). This in-group and out-group value orientation continues to be a tightly 
held throughout the MAME. The importance of family relations endure today in public life, business, and government.

Authoritarian and Consultation. What grew out of the in-group/out-group paradigm of conflict that was produced from the desert environment were leadership practices that were simultaneously authoritarian and consultative (Ali, 2005; Mir, 2010). Consultative practices are a necessary leadership characteristic but are reserved for dealing with those who are in-group (Ali, 2005). Tribal tradition necessitates discussion in all aspects of life and thus any and all leaders must seek the input from members of their group on all matters that concern collective welfare (Ibn Kahldun, 2015). While ingroup members are met with consultation, out-groups often experience tribal leaders as authoritarian (Ali, 2005; Ibn Kahldun, 2015). The appeal of authoritarian leadership qualities when working non-familial groups comes directly from the competition over resources and it meant to be put on a "strong" face to rivals (Greaves, 2012). Today in Arab led organizations, whether it's public or private, adopt an authoritarian structure where there is large power distance and where power is highly centralized (Ali, 2005).

Muhammad as the Archetypal Leader. Just as the two other major monotheistic relations have seminal leadership figures, Moses and Abraham for Jews and Jesus for Christians, Islam has the Prophet Muhammad as its archetypal leader (Adair, 2010; Greaves, 2012). Indeed, the Hadith is a collection of the sayings and teachings of Muhammad that is only second in authority to the Quran in giving religious prescription and moral guidance to Muslims (Bloom \& Blair, 2002). The idealization of Muhammad behaviors and moral character has, from the very beginning of Islam, been both a source of inspiration and contradiction (Campbell, 2008). The inspiration has given many pillars 
that include courage, humility, goodness, kindness, humanness, compassion, wisdom, integrity, and confidence in truth (Adair, 2010). These traits of Muhammad fall both under Trait Theory of the early $20^{\text {th }}$ century and also under the Charismatic and Servant leadership traditions popular since the end of the $20^{\text {th }}$ century (Ali, 2009; Mohtsham, 2007). Unfortunately, before Muhammad died, he left not instructions as to who would succeed him nor direction on how to choose succeeding leaders of the new religion (Esposito, 2005; Bloom \& Blair, 2002). This lack of direction led the new religion to be both focused on Muhammad as the epitome of leadership for Muslims, but also profoundly and disastrously discontent with the leaders who immediately followed him (Beekun \& Badawi, 1999; Campbell, 2008).

Broad Characteristics. As the essence of all perceived forms of true leadership Muhammad's personal characteristics are held up as the aim for every Muslim, especially religious, political, and business leaders (Adair, 2010; Yawar Baig, 2012). The leadership attributes and character of Muhammad are seen as follower-focused and can be grouped into 4 broad sets of qualities with an additional 10 more specific characteristics:

1. The first characteristics is that of honesty in which there is a consistency between word and deed (Beekun \& Badawi, 1999). A common story of young Muhammad is that many in his Quraish tribe used the name for him "صادق" which translates as "truthful" (Khan, 1982). In Islam, honesty makes better leaders in this life, but they are also held accountable for it in the next (Beekun \& Badawi, 1999). 
2. A second characteristic is that of competence which, in Islam, is experienced as not leading from a position of weakness but instead one of strength (Esposito, 2005). At times, competence is also seen as the ability to consult with others as it is not expected that one person at all times knows and knows how to do everything/anything (Ather \& Sobhani, 2007). Throughout the Quran, Muhammad seeks advice from others in matters they are more competent in (Esposito, 2005; Adair, 2010).

3. Thirdly, Muhammad is perceived as one who is forward-looking and has or is able to receive a vision (Safi, 1995). Indeed, from the very beginning, in the Cave of Hira, Muhammad received his first vision of many from Allah (Ali, Liu, \& Humedian, 2004).

4. Lastly, Muhammad is known for being highly inspirational (Beekun \& Badawi, 1999). Muhammad himself stated that "indeed, I was only sent to complete the most character traits" (Mundhirī, 2000).

Specific Characteristics. In addition to the preceding four general traits, there are ten specific traits attributed to Muhammad. First, leaders are to be strong in character by keeping good company and not allowing themselves and others fall into temptation (Beekun \& Badawi, 1999). Further, in the Quran there are two specific characteristics given of leaders, the first being patience (صبر): “And We appointed from among them leaders giving guidance under Our command so long as they preserved with patience" (Haleem, 2008, Surah As-Sajdah, 32:24). The other characteristic of leadership that the Quran trumpets is that of humility: Muslim leaders are "those who walk on earth with humility (Haleem, 2008, Surah As-Sajdah, 25:63). Muhammad stated that kindness as 
expressed in forgiveness are to be hallmarks of leaders: "avert the infliction of prescribed petalites on Muslims as much as you can, and if there is any way, let a man go, for it is better for a leader to make a mistake in forgiving than to make a mistake in punishing" (Al-Tirmidhi, 2007, 3570).

Self-understanding and consultation seeking are a fifth and sixth leadership qualities are often grouped together though they can be seen as unique as one is a result of the other. Leaders are not only be willing to seek consultation but active in doing so (Al-Burey, 1985). This consultative practice is meant to both create better decisions for the group but is also to help produce deepening understanding of a leader's self which then helps create a more effective leader (Beekun \& Badawi, 1999). Leaders are to be simple and modest and reflect the image of Muhammad who ate basic food, wore simple unadorned clothing, and lived in a retiring house (Faqih, 1988). Leaders are also supposed to, at times, be good followers as expressed by many of Muhammad's actions in stepping into follower or servant roles when the context required it (Safi, 1995). Whether a Muslim leader is dealing with other Muslims or non-Muslims he is to act impartially and with equity in all situations (Beekun \& Badawi, 1999). Lastly, leaders in Islam are ultimately responsible for the wellbeing of those they under their care (Esposito, 2005; Adair, 2010). Interestingly, there are regional similarities between these values and those identified by Nahavandi and Krishnan when identifying Indo-European principles (2017).

Critique. While Islamic leadership is codified in the example of Muhammad there are at least two specific critiques that can made of this understanding of leadership for Muslims. The first is that while Muhammad is extoled at a charismatic/servant 
leader in many ways is, still, simply Trait Theory repackaged. Trait Theory, just like Charismatic and Servant Theory, broadly seeks leaders as having and not having certain physiognomies that lead to be a "good" or "successful" leader (Pervin, 1994). While it is currently popular to see Muhammad a charismatic/servant leader, there has been little-tono development of the understanding of leadership in Islam. The second critique is that because these traits as idealized in the person and essence of Muhammad, they have also created unrealistic expectations of who leaders in the MAME could be and indeed should be. The struggle for leadership immediately after Muhmmad's death foreshadowed greater struggles to come. After the four caliphates who immediately led Islam after Muhammad's death the religion suffered a civil war that divided the faith into two groups that continue to be alienated today: Sunnism and Shi'ism. The expectation of perfection continues today in the MAME in the dissidence between modern leaders and their struggle to be seen in Muhammad-like ways but the realities of realpolitik are quite different.

These idealized views of Muhammad obscure that he often made strategic changes in policy and teaching that would benefit him and those who were part of the ingroup. Examples include the utility and aim of jihad, the meaning of marriage and thus how many wives a man could have, and the direction in which adherents should orient while in prayer. These opportunistic changes fall very much into contingency theory in that as the situation changes so does the leader in tone and voice.

Perhaps if the notion of Islamic leadership could be developed and distanced from the perfection of Muhammad there could be more room for the realities of today's leaders who are Muslims. When Muhammad as the archetype of Islamic leadership is 
amalgamated with traditional tribal and family values the $20^{\text {th }}$ and $21^{\text {st }}$ century result is the Islamic Work Ethic.

\section{Islamic Work Ethic}

On the heels of the first industrial revolution Max Weber, in The Protestant Work Ethic and Spirit of Capitalism, introduced the concept that there is a direct relationship between religion and views of economics, business, and work in all it is forms (Weber, 1992). From this understanding came other religious-labor orientations including the Confusion Work Ethic, Australian Work Ethic, South African Work Ethic, and more recently, the Islamic Work Ethic (IWE) (Lim \& Lay, 2003; Ho, 1984; Slabbert \& Ukpere, 2011; Yusuf, 2000). In Islam, it is believed that all areas of life are encompassed by Allah and that the realm of labor and economic development is no different. Therefore, the IWE is the expression of Islamic values in all areas of work, business, and economics in the MAME (Nasr, 1984; Ali \& Al-Owaihan, 2008; Ali, 2015). While it is not a focus of this literature review, it is important to note that the IWE and the PWE are often contrasted because of the significant differences in cultural values that directly affect the behavioraleconomic perspectives (Ali \& Al-Owaihan, 2008; Chanzanagh \& Akbarnejad, 2011). We may better understand the IWE through both the sayings of the Prophet and also several IWE dimensions that have been developed through Islamic literature (Ali, 2010; Adnan Khurshid, Al-Aali, Ali Soliman, \& Mohamad Amin, 2014; Rizk, 2008).

From the Prophet. As discussed earlier, the Prophet Muhammad looms large over all leadership theory in the MAME and so does he when it comes to the IWE. Ali (2005) catalogued the saying of The Prophet into 11 groups that directly speak to the IWE: 
- First, in pursuing legitimate business, Muhammad equated work to worship and thus elevated work that served people above work that did not.

- Wealth must be eared and should not be obtained through nefarious practices, aggression, or injustice.

- The quality of work where the faithful are told that "God blesses a person who perfects his craft (does the job right)" (Ali \&Al-Owaihan, 2008, p. 11).

- Workers must be given wages that are reasonable, just, and timely forms of compensation.

- Work is meaningful to the individual: "no one eats better food than that which he eats out of the work of his hand" and "no earnings are better than that of one's own effort'” (Hadith, n. d., 34:15).

- Monopolies and bribery, are forbidden as they are seen as producing suffering and deepening inequality in society.

- Allah is more concerned about one's intentions rather than their deeds (Ali, 2005).

- Transparency where Muhammad is to have said "Those who declare things frankly, will not lead to each other destruction" (Ali, 2014, p. 73).

- Finally, greed and generosity can be viewed at opposite ends of the virtue spectrum. The very beginning of Muhammad's teachings centered around the injustice of greed of the merchants of Mecca (Randeree, 2008). Alternatively, generosity is a principle virtue where generous people are close to Allah, close to heaven, and close to people while also being away from hell (Kılınç, \& Warner, 2015). 
Dimensions. An alternative way to view the IWE is to see it as seven dimensions as delineated by Chanzanagh \& Akbarnejad (2011). The first, which was also noted above, is arguably the most important as it affects the other dimensions is that of intentions in work. It is through intentions that work is either bringing us closer to Allah or further away from. A second dimension is that the IWE is to be in service of the Islamic community, also know the Islamic Ummah, where work is to benefit the whole. Similarly, cooperation and collaboration are exalted and individualism and exclusion of community members frowned upon. Fourthly, only through being close to Allah may Muslims be both just and fair in their gathering of wealth that minimizes significant class differences. Closely related to many other dimensions of the IWE is the issue of trusteeship where Muslims are called to take care not only of their nuclear community but also of broader society. Paradoxically, work is also seen as the legitimate source of ownership where every individual must labor and not live parasitically off others. And finally, stemming from historic roots, there is an emphasis on trade rather than other types of economic activities.

Critique. The critique of the IWE is broken down into three different views. The first is that of the various Islamic schools of thought which have had relevance in government and politics over the last 14 centuries, the only current one is in contrast to the IWE (Ali \& Al-Owaihan, 2008). The Jabria emphasizes predestination and is thus incongruent with IWE that stresses that individuals and groups have volition in what happens today and tomorrow. The second critique is that the definition of the IWE is varied. Like the idea of "leadership," there is no one understanding of what the IWE is, at best, a constellation of characteristics rather than a codified theorem. Because of this 
there is varied acceptance of its existence and relevancy (Najim, 2015). A similar and third critique is the lack of formal research. The IWE is often discussed, but has not tested with a critical eye (Essid, 1995). This is congruent with the larger trend within Islam that dissuades questioning, disagreement, and independence (Essid, 1995). This is especially true for those who are not in the in-group. As the modern expression of Islamic culture in business the IWE is an area ripe for developed and continued critique.

From the MAME's tribal roots we understand how the desert environment encouraged conflict and thus created different leadership behaviors between those who are in-group and those who are out-group. It is also understood that the seminal leader figure for many in the MAME is Muhammad and that specific leadership characteristics are shown through his sayings, teachings, and the stories about him. Lastly, we see the modern expression of tribalism and Muhammad in the IWE that emphasizes certain behaviors as being important for leaders to demonstrate. While this is important to understand, it should be clear that not all leadership influence has been internal to the Middle East. Through centuries of contact and, especially, over the past 100 years, the understanding of leadership emanating from the west has influenced the understanding in the MAME.

\section{Western Management and Leadership Theory in the MAME}

What we understand to be the MAME, and leadership in this context, have been impacted by what has happened internally but also from centuries of outside influencing empires (Lewis, 1994). Following the end of the Ottoman-Turk empire at the end of 
World War I and until the 1950s and 1960s, a group of victorious western European countries established and solidified colonies throughout the region (Cleveland \& Bunton, 2016; Fromkin, 2001; Mansfield, 2013). The independence of many MAME countries coincided with the initial carbon fuel boom and the subsequent economic, infrastructure, and education development in countries of the gulf (Cooper, 2012; Marcel, 2006).

During this time the West's influenced in the region morphed from primarily political to principally economic (Lewis, 1997). Along with the economic relationship came other needs of the region which included business-to-business services, education, and labor (Little, 2008). This meant an incredible amount of information transfer came from the west to the MAME, including that in the realm of management and, a bit, of leadership (Mellahi, Demirbag, \& Riddle, 2011).

\section{Western Theory "Translated"}

One important concept in this information transfer is the degree to which the models, theories, and programs have been integrated or "translated" from their original context in to that of the MAME. The range integration can be placed into three categories: theories that are still westernized, Arab-ized, and Islamicized (Ali, 1990). Those that fall into the westernized classification are those where the endeavor is to adopt theories whole sale without any attempt to amend them for the local context. With this this approach there are seen to be both environmental factors (political, economic, legal, social, and religious) and behavioral (motivation, values, beliefs, decision styles, etc.) methodologies (Ali, 1990; Ali, 1995). Some academics and practitioners have attempted to Arab-ize western theory by adapting it to the MAME in a secularized way that is unique to the region's context (Al-Kusbaisy, 1985; Ali, 1989; El-Fathaly \& Chackerian, 
1983). The third group also attempts to adapt Western knowledge to the MAME but does so in a way that also is congruent with Islam (Abu-Sin, 1981; Hawi, 1982; Khadra, 1984). Islam is used as the foundation and western concepts are brought in full or in part that are harmonious with the religious tenants. While these three modes of dealing with the adoption of western concepts was first understood in the early 1990 s they continue to be the modes used today (Ali, 2005). Of all the western models imported to the MAME the two of concern to us are in the realm of management and of leadership.

\section{Management}

Of the two, the area of management in business in the MAME is the most well developed. Beginning in the mid 1980s Abbas Ali began writing on managerial beliefs and value systems of Arab managers and while he was not the first to write he was the first to write prolifically on the topic of managers in the MAME (Ali, 1985; Ali, 1986). Over the years Ali has published over 200 articles, book chapters, and op-eds along with 8 major works (Indiana University of Pennsylvania, 2018). From his work and alongside his work, the discipline of the study management in the MAME has flourished. It seems that management and Islam are a well suited for each other as both are structured in what is good and right as opposed to what is not (Ali \& Weir, 2005). Topics that are popular within the management-Islamic context are business and, especially, finance and ethics. The characteristics of Muhammad that were discussed earlier have been clearly and directly applied to this management-business environment (Adair, 2010).

While great progress has been made over the past 30 years in the area of management in the MAME there is still much to learn. Due to crisis in the region "the study of Arab managerial thought is still in its infancy" (Ali, 1990, p. 26). This crisis was 
true three decades ago and many argue that the crisis is truer today than it was then (Jebnoun, Kia, \& Kirk, 2013; Kuran, 2003). Another critique of the study of management in the MAME is that it is often equated with the study of leadership (Gill, 2002). While it is true that these realms often interact simultaneously and seemingly the same, it is critical to differentiate between the two. These decades of crises have not only stunted research on management in the MAME but it has also done so when it comes to that of leadership.

\section{Leadership}

It is difficult to do a review of Western leadership theory as applied to the MAME because there is so little literature available and what is available is generally disconnected and dispersed in geography, time, and topic (Blunt \& Jones, 1997; Cullina, 2016; Dickson, Den Hartog, \& Michelson 2003). Constructs that are commonly discussed within the discipline, such as the "great man," trait, and behavioral theories as well as situational, transactional, leader-member exchange, and servant leadership are almost none existent in research that focuses regionally on the MAME (Cullina, 2016; Mentcalfe \& Mimouni, 2011). Further, topics of interest across various leadership constructs are sporadic and under developed. Searches for "women, leadership, Middle East" come up with just a few relevant works by Bano \& Kalmbach (2008), Marmenout (2009), and Metcalf (2008). The recent text Leadership Development in the Middle East, edited by Metcalfe \& Mimouni (2011), seeks to give fill a gap in our understanding of leadership development in the region but succeeds little actually addressing the cultivation of leadership. A bright spot in this are a few recent articles that focus on transformational leadership in the MAME context: Mohtsham (2007) investigated at 
how visionary leadership is expressed in Islam, Khoiri (2016) looked at transformational culture in Islamic schools, and Litz \& Scott (2017) studied transformational leadership in the education system of the United Arab Emirates.

\section{The Competing Commitments within Bioecology}

The notion that leadership and its application is moderated by culture and context is well founded (Nahavandi, 2014). One way to understand the environmental forces exhorted on individuals as they western leadership in their setting is through Bronfenbrenner's model of bioecology. Additionally, it must be recognized that these same individuals have multiple forces tugging at them that may be complimentary or in competition. Kegan and Lahey's theory of competing commitments is helpful in understanding that an individual has contenting obligations that must be resolved. Together, the bioecological model and theory of competing commitments may provide a bridge to understanding how western theories of leadership are applied in local contexts.

\section{Bioecology}

The first theoretical foundation surrounds the concept of the bioecological theory. Bioecology is the branch of biology that studies the relationship between a living organism and the ecology around them. In the 1990s and into the 2000s, the theory was converted to the social sciences and popularized by educational researcher Urie Bronfenbrenner. In the social sciences the organism is the self and the ecology is the environment or context in which the self is positioned. The core concept of Bronfenbrenner's bioecology theory of adult development is one where the individual is both being influenced by and is influencing the environment (Bronfrenbrenner, 1975;

Bronfrenbrener, 2005; Rosa \& Tudge, 2013; Shelton, 2018). Initially Bronfenbrenner 
was interested only in how children develop, but over the course of 30 years the model grew to encompass adult development and now has been adapted for other types of development, including leadership development (Tudge, Mokrova, Hatfield, \& Karnik, 2009). The mature version of the bioecology model studies the relationship between living organisms and their environment in the interactions of process, person, context, and time (PPCT) (Rosa \& Tudge, 2013). While these pieces are ever present and always interacting, it is helpful to break them apart, just for a moment, to understand them on their own before understanding their interactions and the resulting complexity.

The process (in the literature called proximal processes) simply describes the continual, systematic interaction between an individual and their environment (Bronfenbrenner, 1977). Bronfenbrenner saw the relationship between the person and the context as the center of his theory and believed it to be the primary driving force of the individual's development $(1997,1992,2005)$. As an individual grows, their process with their environment grows increasingly complex with interactions being either more frequent, to greater extents, or both (Bronfenbrenner, 1977; Rosa \& Tudge, 2013). Thus, time, as we will discuss later, plays a critical role in this theory and the development of individuals.

The person includes biological aspects of an individual, though Bronfenbrenner paid particular attention to person characteristics an individual brings into social, contextual situations (Rosa \& Tudge, 2013). These person characteristics are divided into three different types. The first characteristic is force, also called disposition, which are the parts of a self that include character, temperament, motivation, resolution and so on. The second characteristic is resource, which may not be immediately known and 
includes both "mental and emotional resources such as past experiences, skills, and intelligence and also to social and material resources (access to good food, housing, caring parents, educational opportunities appropriate to the needs of the particular society, and so on) (Tudge, Mokrova, Hatfield, \& Karnik, 2009, p. 209). Those characteristics that support the proximal process are "ability, knowledge, skill, and experience" while those that hinder "include genetic defects, low birthweight, physical handicaps, severe and persistent illness, or damage to brain function"' (Bronfenbrenner \& Morris, 2006, p. 812). Formerly called personal stimulus, demand is the third characteristic, which is easily seen and includes "those easily noted qualities of the developing person that can invite or discourage reactions from the social environment, influencing the way in which proximal processes are established" (Rosa \& Tudge, 2013, p. 253). Bronfenbrenner thought that people may have nearly equal resource and demand characteristics, but their force characteristic could send the two on very different paths of development (Bronfenbrenner \& Ceci, 1994).

Context is the area of Bronfenbrenner's theory that typically gets the most attention because of its notable absence in other theories of development (Tudge, Mokrova, Hatfield, \& Karnik, 2009). The four levels of types of systems are actually numerous nested systems that all have influence on and, to varying degrees, are influenced by the individual (Bronfenbrenner, 1997). The person, as described above and often called the "self," is surrounded by multiple microsystems, which are the most immediate layer of the nested system. It incorporates an individual's interpersonal relationships and environments by including immediate family, extended family groups, school, peer groups, neighborhoods, extracurricular activities, faith communities, etc. 
The next system is not a new set of systems but instead are interactions between systems. The mesosystem is the space where microsystems have direct contact with each other and thus influence the development of the individual. The effects on an individual can be positive if different microsystems are working together for the individual but could be negative if different elements of the micro-system are working against each other. In Figure 5 the interactions between microsystems in the mesosystem are indicated by the white arrows. The exosystem are systems that do not directly affect the individual but still have an indirect effect. In essence, the exosystem includes decisions made that have a bearing on an individual but in which the individual had no direct participation. The broadest systems are the macrosystems that are the mega, encompassing environments in which the individual lives. Examples of macrosystems are national governments, cultural values, state of the economy, wars, global warming, etc. 


\section{Figure 5}

Bronfenbrenner's Biecology Systems

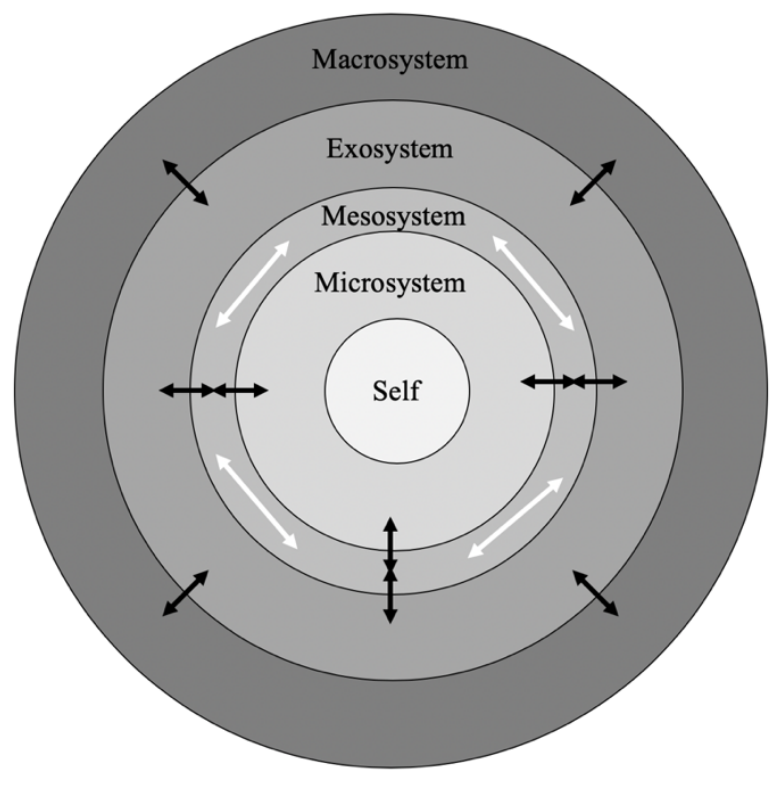

\begin{tabular}{|l|l|}
\hline System & Examples \\
\hline Self & Gender \\
& Age \\
& Health \\
\hline Microsystem & Family \\
& School \\
& Faith Community \\
& Friends \\
\hline Exosystem & Neighborhood \\
\hline & Local Government \\
& Media \\
& Local Industry \\
& School Leadership \\
\hline Macrosystem & National Cultures \\
& Federal Government \\
& National Economy \\
& Regional Happenings \\
& Religious Ideology \\
\hline
\end{tabular}

The fourth and final aspect of Bronfenbrenner's model is that of time, which is also divided into three parts. Microtime is the "continuity vs discontinuity in ongoing episodes of the proximal processes" (Bronfenbrenner, 2006, p. 796). That is, how often the individual is interacting with the various systems. Mesotime is the number of occurrences of microtime over days and weeks (Shelton, 2108). Macrotime, often called chronosystem, is divided into two parts. The first are the sociohistorical conditions and events that occur in a person's life. Examples of this part of the chronosystem for the Middle East may include the discovery of oil in a particular country, conflict and wars with neighbors, revolutions, or, more recently, the Arab Spring. The second part of the chronosystem is focused on when important events actually occur in a person's life. For 
example, whether one gets married or is a parent for the first time will have a significantly different effect if those events happen at age 16,26 , or 36 .

\section{Figure 6}

\section{Bronfenbrenner's Bioecology Time}

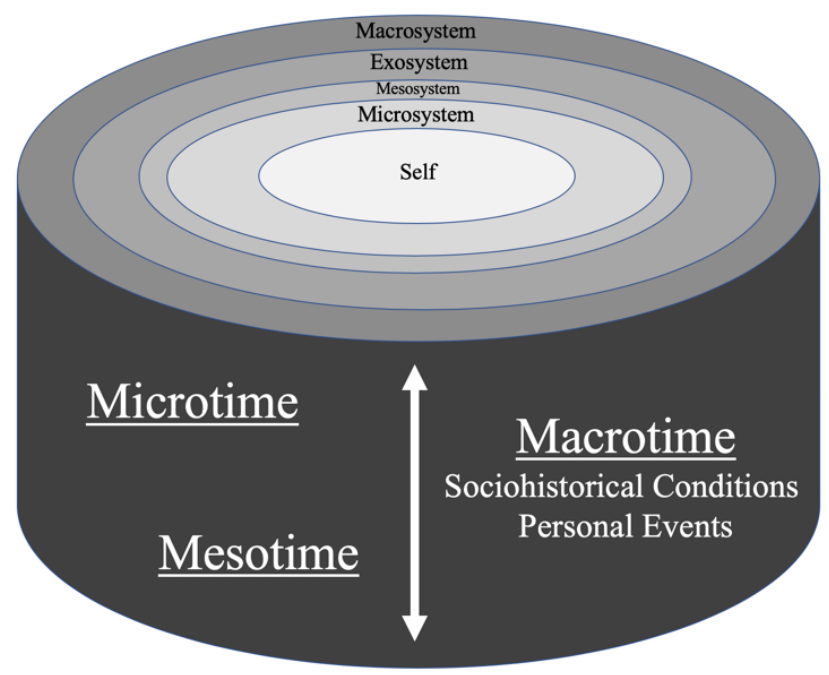

The essence of this nested systems model is the understanding that there are multiple systems directly, indirectly, and jointly affecting an individual, the individual is also affecting these systems, and all of this is happening over time.

The critiques of Bronfenbrenner's bioecological model focus on its complexity and what is placed at the center of the concentric circles. The complexity of the model includes the multiple dimensions of and interactions of levels systems and types of time. This complexity and the subsequent inability for an individual to fully consider all their influencing systems and components of time may lead to an unfounded understanding or conclusions (Tudge, Payir, Merçon-Vargas, Cao, Liang, Li, \& O’Brien, 2016). Further, the complexity makes systematic application and research difficult which could ultimately lead to complete inaction or abandonment of the potential understanding brought by the model (Sontag, 1996). Importantly, the placement of the individual in the 
privileged center of the model might be disagreeable in many cultures. In the West, where individualization is prioritized, it may be appropriate. In other cultural contexts, where the group (family, extended family, clan, tribe, or faith group) is advantaged, the center of developmental focus very well may not be entirely the individual with the microsystem is much tighter.

The bioecology model is easily applied to individuals in any part of the world, including the MAME. At the microsystem level family is expected to play a prominent role in the individual's life. Schooling, friends, and local faith community (mosque or (مَنْجد also have significant influence. At the macrosystem level there are identifiable qualities of national cultures, specific systems of government, different levels of economic health, and differing views of the role of religion and faith. In considering the sociohistorical conditions within the macrotime concept it is easy to understand how these affect individuals. Events such economic boom or downturn, flare-ups of societal discontent, or violent armed conflict are talked about in broad terms but eventually effect each individual. These different levels of systems and the effects of time and timing often create a situation where individuals need to reconcile the ways they are influenced and pulled that are not harmonious.

\section{Competing Commitments}

Competing commitments, sometimes called priority conflicts, was introduced just after the turn of the millennia by organizational psychologists and researchers Robert Kegan and Lisa Lahey (2001). The pair first described in the now ubiquitous 2001 Harvard Business Review article "The Real Reason People Won't Change," and was then expanded into two books: Immunity to Change (2009) and An Everybody Culture 
(2016). Competing commitment comes down to the fact that individuals have multiple obligations that are incompatible and that each commitment has significant resource needs which cannot be fully satisfied across the board (Bochman \& Kroth, 2010). The outcome of these numerous conflicting responsibilities is a strained individual that struggles with the dissidence between stated goals and what is more immediate (Reams, 2016).

Typically, these incompatible duties are negotiated unconsciously as they vie for position and resources (Cervone, 2007; Kegan \& Lahey, 2009). The individual is not typically aware that energies are being redirected into more immediate requirements and which then demotes the stated, affirmed ambitions (Wagner et al., 2012). These selfinflicted obstructions toward overarching desires and aims elicits eventual frustration and fear in the individual as they struggle to maintain the present while not being able to work toward what they really want (Reams, 2016; Wagner et al., 2012). The frustration is that what they want is not a reality in the moment. The fear is that there is no guarantee that the desired future will come about. The lack of resources, frustration, and fear create an immunity to change. Kegan and Lahey describes the immunity to change as akin to our physical immune system that resists and protects us against various illnesses (Kegan \& Lahey, 2001, 2009). While Kegan and Lahey primarily applied this behavioral theory to the difficulty of change, it has in recent years been expanded and applied broadly across the social sciences (Reams, 2016).

The critique of the competing commitments concept is just that: it is a concept. While central to Kegan and Lahey's recent works it is not the aim of their work. Their work is focused on "why people don't change" and creating organizations that welcome 
and directly address these opposing obligations. Thus, the conception of competing commitments is seen as foundational in work and personal life and is thus not questioned nor developed. If something is, as the authors believe competing commitments is, there is no need to question it. Lastly, outside of Kegan and Lahey, there is little empirical research or literature on the concept.

It is not difficult to understand how this can look for an individual in the MAME. There may be competing commitments between the expectations of parents and family and the individual's hopes for themselves. The values espoused by a faith may not be compatible with those taught in an MBA program. There might also be clashes of principles between one's born-in cultures and those expressed by media from other regions of the world. No matter the individual being considered, the experience of competing commitments are frequent and diverse.

\section{The Inherent Competing Commitments in Bioecology Theory}

The inborn competition commitments within the bioecology theory is not hard to understand, as each of us have the common experience of "being pulled in different directions" and having limited resources to put toward those directions. In bioecology theory, these contesting responsibilities frequently take place within or between at least several aspects: within the individual, between the individual and the microsystem, between the individual and the two larger exo and macro systems, within the same level of a system, between levels of systems, and in the variations of time. Here the researcher will relate the tensions and discuss how those were present in the research findings, how or if they relate to the existing literature, and how one might make sense of the whole. 


\section{Conclusion}

Countries in the ME, and particularly those in the MAME, are increasingly becoming key economic and geo-political players in today's interconnected world. While the region is fast becoming westernized, the cultural roots in Islam and tribal traditions remain strong. The ideals of leadership therefore have unique and distinct elements. All the while, the younger MAME generation is being educated in the West and many Western universities and consulting firms are spreading Western leadership theories in the region. There is little evidence regarding whether, and how well, those may fit and be accepted.

The foundations of leadership theory in the MAME are deeply rooted in the tribal traditions of the desert region and in Islam through the characteristic of exemplary leadership as portrayed by Muhammad. These traits and aims are expressed today in the IWE. Unfortunately, there is little agreement on what exactly the IWE is and in this lies possibilities for the future. If consensus could be found in clear principles of the IWE centuries of experienced could be brought into the $21^{\text {st }}$ century in all realms where leadership is experienced in the MAME. More importantly, an area of future study could be the development of an indigenous leadership theory or group of theories. From the origins of tribal and Islamic values a rich, effective, and practical understanding of leadership could be developed.

Western leadership is just that - Western. While attempts have been made to look at leadership within a cultural context through research such as Hofstede's values and GLOBE, the perspective is still Western. Therefore, the integration of western-developed leadership theories into the MAME is generally underdeveloped. Going forward, one 
helpful distinction to be doubled down on is the difference between management and leadership. If the focus on management could be left behind then the understanding of leadership may have more room to expand. Further, much more work is needed on how these western theories apply to the MAME and are they effective: more families of leadership theory need to be investigated in broader regions of the MAME. The rich and increasing understanding of leadership that emanates from the west and the deep history of leadership in the Middle East provides ample opportunity for integration, refinement, and growth on both sides.

It is in the area of cross-cultural, value-based leadership models where there is the most energy and near-horizon opportunities lay. The foundations provided by Hofstede and others have brought the GLOBE Project the opportunity to bring great insight not only to cultural differences but also to leadership effectiveness in various regions of the world. Regrettably, the Middle East group is ill paired and thus leaves much more understanding to be had. The up-coming GLOBE Project 2020 phase that expands the number of Middle East countries brings great hope of a deeper understanding of the values and leadership traits important in the region. Lastly, the indigenous, Arab-Islamic understanding of cross-cultural value-based leadership could be deepened. It is likely that this native awareness of leadership in its own context would enrich the comprehension and experience of leadership both in the west and all areas of the planet. There is a clear need to understand leadership in the MAME from a more emic perspective and consider how and to what extent Western leadership approaches fit and would work in this significant and strategic region of the world. 
Generally, there is little to less-than-little understanding of how successful western-leadership theory is applied to the MAME and thus much more could be added to the literature (Blunt \& Jones, 1997; Cullina, 2016; Dickson, Hartog, \& Michelson 2003). Critical to this conversation is the acknowledgement that leadership theory that is indigenous and developed for the modern area in the Arab Middle East is nearly nonexistent (Ali, 1990; Ali, 1995). As will be explored later, there is a foundation of leadership tradition in the Arab Middle East that gives great reverence to both Great Man and Trait theories based on the archetype embodied in Muhammad (Adair, 2010; Greaves, 2012). Reasons for the lack of development of leadership theory beyond the foundation vary from a millennium of absence of independent academic institutions to the effects from centuries of western imperialism to nearly constant conflict and wars in the modern era (Patai, 2007). The current bright spots that show encouraging signs of potential progress are both in the worlds of academic and of business and other practitioners. The well-established academic institutions in Amman, Beirut, and Cairo as well as the recently-founded "education cities" in Gulf nations including Kuwait, Qatar, and The United Arab Emirates provide prospects for academic investigation (Lewin, 2008; Murphy, 1987). Further, there is a growing awareness in organizations of the region that wholesale adoption and translation of western theories may not be enough and indigenous philosophies may be more appropriate (Blunt \& Jones, 1997). There are significant opportunities for further development of leadership theories that are specific to the MAME.

It is very possible that both the lack of domestically developed leadership models and privation of understanding of how western leadership theories are applied in the 
MAME can better be understood through the view of competing commitments within a bioecology framework. Bioecology sees the individual being affected directly and indirectly by multiple system levels over time. Competing commitments acknowledges that an individual cannot completely fulfill different responsibilities that are in contrast to each other. Finally,

The purpose of this study is to address the question of how Western-developed theories of leadership are adapted, translated, and absorbed into local contexts through MBA programs. The research questions focus on what leadership is taught in MBA programs in the MAME and how they have been adapted into local contexts by alumni of the same programs. The importance of this research is that it offers the foundation for understanding how western-leadership theory is adopted in the MAME and future research. 


\section{CHAPTER 3}

\section{RESEARCH DESIGN AND METHODOLOGY}

This study was specifically designed and carried out with methods congruent with the research questions and the researcher's personality. The research design, the philosophy of the study, was qualitative, interpretivist, and exploratory in nature. Further, how the research was carried out included site selection, identification and collection from a range of data sources, and analysis.

\section{Research Design}

The purpose of this study is to address the question of how Western-developed theories of leadership are adapted, translated, and absorbed into local contexts through MBA programs. Given this purpose, it is most appropriate for the research design to be qualitative, interpretivist, and exploratory. Interpretivist research assumes that reality is dynamic and thus is focused on understanding one's own experience (Minchiello et al, 1990). The methodological approach of qualitative research involves non-numerical data collected through interviews or observations, which are then analyzed for commonalities and resulting themes (Neuman, 2015). The interpretivist methodological framework is focused on the verstehen, or understanding, of socially constructed realities (Sage, Interpretive Research, 2008). With the absence of a well-developed body of research on the topic, this study takes an exploratory stance that aims to be the basis for future study of leadership practices in the Middle East (USC, Types of Research Design).

A qualitative research approach is most fitting because it accommodates an interpretivist understanding of knowledge production focused on the making of meaning, nature, or essence of a thing. Qualitative research methods are often associated with 
"understanding the meaning people have constructed" and is the study of things "in their natural setting, attempting to make sense of, or interpret, phenomena in terms of the meanings people bring to them" (Merriam, 2009, p. 13; Denzin and Lincoln, 2005, p. 3). Interpretivist's central purpose is to understand and not to predict, emancipate, or deconstruct (Glesne, 2016). In this specific study, the meaning we are looking for is how western leadership theories are altered when being applied in local contexts. This direction of inquiry could be investigated by quantitative methods but the researcher choose to do so qualitatively because of their experience and relationship with the region. Beneath interpretivist umbrella an approach to the study design must be designated.

Nested under the interpretivist lens is a family of related, yet distinct, approaches. Of these various methodologies the most fitting for this study is the grounded theory methodological framework. Studies of this genre do not start with theory/hypothesis testing but are meant to build theory (Savin-Bvaden \& Major, 2013). Here the "researcher starts with data and tries to derive a theory about the phenomenon of interests from the observed data" (Lumenleanring.com, Chapter 12). Other specific characteristics of interpretivism important to this study are:

\section{Table 3}

\section{Interpretivist Characteristics}

\begin{tabular}{|l|l|}
\hline Inductive & $\begin{array}{l}\text { Moving from specific observations to broader generalizations } \\
\text { and theories. Often called a "bottom up" approach. In } \\
\text { inductive reasoning, we begin with specific observations and } \\
\text { measures, begin to detect patterns and regularities, formulate } \\
\text { some tentative hypotheses that we can explore, and finally }\end{array}$ \\
\hline
\end{tabular}




\begin{tabular}{|c|c|}
\hline & $\begin{array}{l}\text { end up developing some general conclusions or theories } \\
\text { (Bhattacherjee, 2012; Carroll \& Swatman, 2000). }\end{array}$ \\
\hline $\begin{array}{l}\text { Researcher as a } \\
\text { primary instrument }\end{array}$ & $\begin{array}{l}\text { Researchers are often embedded within the social context that } \\
\text { they are studying and are considered part of the data collection } \\
\text { instrument in that they must use their observational skills, their } \\
\text { trust with the participants, and their ability to extract the correct } \\
\text { information. Further, their personal insights, knowledge, and } \\
\text { experiences of the social context are critical to accurately } \\
\text { interpreting the phenomenon of interest. At the same time, } \\
\text { researchers must be fully aware of their personal biases and } \\
\text { preconceptions, and not let such biases interfere with their } \\
\text { ability to present a fair and accurate portrayal of the } \\
\text { phenomenon (Bhattacherjee, } 2012 \text {; Schwandt, 1994). }\end{array}$ \\
\hline $\begin{array}{l}\text { Naturalistic in } \\
\text { Nature }\end{array}$ & $\begin{array}{l}\text { "Social phenomena must be studied within their natural setting. } \\
\text { Because interpretive research assumes that social phenomena are } \\
\text { situated within, and cannot be isolated from their social context, } \\
\text { interpretations of such phenomena must be grounded within } \\
\text { their socio-historical context. This implies that contextual } \\
\text { variables should be observed and considered in seeking } \\
\text { explanations of a phenomenon of interest, even though context } \\
\text { sensitivity may limit the generalizability of inferences" } \\
\text { (Bhattacherjee, 2012, pp. 105-06). }\end{array}$ \\
\hline
\end{tabular}




\begin{tabular}{|l|l|}
\hline Circular & $\begin{array}{l}\text { Interpretive interpretation is an iterative process of moving back } \\
\text { and forth from pieces of observations (text) to the entirety of the } \\
\text { social phenomenon (context) to reconcile their apparent discord } \\
\text { and to construct a theory that is consistent with the diverse } \\
\text { subjective viewpoints and experiences of the embedded } \\
\text { participants. Such iterations between the understanding/meaning } \\
\text { of a phenomenon and observations must continue until } \\
\text { "theoretical saturation" is reached, whereby any additional } \\
\text { iteration does not yield any more insight into the phenomenon of } \\
\text { interest. (Bhattacherjee, 2012; Glesne, 2016; Schwandt, 1994). }\end{array}$ \\
\hline Temporal & $\begin{array}{l}\text { Interpretive research is often not concerned with searching for } \\
\text { specific answers, but with understanding or "making sense of" a } \\
\text { the study site for an extended period of time in order to capture } \\
\text { the entire evolution of the phenomenon of interest }\end{array}$ \\
\hline
\end{tabular}

The reality of the practical use of western-developed leadership theories in the MAME context is certainly complex and directly affected by the local environment. It will be shown in the following Methods section how these specific characteristics of the interpretivist methodological framework are relevant and incorporated into this study.

While there are strengths to the interpretivist methodological framework, there are also difficulties that must be acknowledged, addressed, and mitigated. First, it is 
time-intensive and there must be a balance struck between having too much data and too little data (Bhattacherjee, 2012). Too much data can overwhelm while too little can result in inconclusive findings. Second, the data collected may not all be equally credible or trustworthy. There may be wide differences in the understanding of a subject or their ability to convey their experience. Thirdly, and closely related to the previous point, the researcher(s) must be well-trained not only in the methods of this research but also must have a deep understanding of the historic and cultural contexts of the subjects being studied (Patton, 2015). A fourth challenge is that because of the comprehensively contextualized environment of the study, conclusions and insights may not be replicable or generalizable (Bhattacherjee, 2012; Patton, 2015).

This study adopts an exploratory design to understand the adoption of westerndeveloped leadership theories in the MAME. The absence of systematic research on the topic, combined with position of the research question, necessitates an exploratory approach (Sheild \& Rangarjan, 2013). The focus of the exploratory design is to create a picture of the chosen situation that generates insights with an eye to possible future study and practice (Creswell, Shope, Plano-Clark, \& Green, 2006). This is consistent with the practice-focused orientation of the research agenda that this study seeks to support. Additionally, definitive conclusions should be avoided with the aim of the study on future areas of research (Sheild \& Rangarjan, 2013). Exploration is facilitated by adopting a multi-site approach across and within the three countries and programs.

Within this study grounded theory design has three design elements. First, this framework is appropriate for investigating cultural-specific, distinctive, or eccentric events (Glesne, 2016). Similarly, this framework is adept at exploring complexities that 
are interrelated or multifaceted social processes (Bhattacherjee, 2012). Secondly, and important to this study, this framework is helpful as there is little prior research conducted on the context-specific translation of western-bred leadership theories (Glesne, 2016). Lastly, this sort of approach acts as a foundation and a starting point for future research agendas (Bhattacherjee, 2012; Glesne, 2016).

\section{Methods}

This study was carried out through site selection, identification of data sources, the collection of data, and analysis of data. The site selection needed to be from several different geographic locations across the MAME but also had to have very similar physical and structural contexts. Diversity of sites was sought to increase the likelihood of getting a diverse set of translation practices of leadership theories. In this exploratory study, it is important to maximize variation in national contexts. The sites selected were MBA programs in Egypt, Lebanon, and the UAE. To address the research questions a range of data was collected primarily from documents, program faculty, and alumni. These data sources were collected in three phases over the course of approximately 9 months. Lastly, the data was analyzed using thematic coding methods.

\section{Site Selection}

Site selection for this research occurred within the MAME region and specifically took place through the lens and experience of MBA programs and their alumni. Within the MAME, Egypt, Lebanon, and the UAE, were identified because of their variety of history, differences in current contexts, and accessibility. Egypt has a rich and wellknown history of strength and regional, both MAME and Africa, influence. While the country has been very much stable over the past 60 years the past 10 have seen several 
revolutions and economic turmoil. Lebanon has had a tumultuous 45 years that continues to this day. Despite this, and partially because of, Lebanon through diaspora has a significant influence in the MAME region, Europe, and in the United States. The UAE also exerts significant regional and international influence through being an economic and transportation hub as well as through growing regionally political and military alliances. The country is prosperous but lies in the middle of multiple, regional powers that are in nearly constant conflict and is thus sit in a precarious location. All three countries have national cultures that are typically welcoming of western visitors and thus more accessible than many other nation states of the region.

The schools chose for this study are: the American University of Beirut (Lebanon), American University in Cairo (Egypt), and the American University of Sharjah (UAE). Their MBA programs were chosen for three reasons. First, MBA programs are quite similar no matter the country or region of the world. Second, they often address leadership topics either directly or indirectly in their curricula. Finally, an advanced degree was chosen with the expectation that students will have had or do have leadership positions in organizations outside of the school setting and therefore would be able to address the research questions. The selection was further narrowed to universities and MBA programs that both have deep histories in their countries and that are based on a western education model. The three schools that were eventually chosen are some of the oldest and best grounded in their country context. The selection of those with western education models is an important difference than those schools with a wholly or blended form of Islamic-madras education. Further, each school has a foundation in liberal arts but grew to include other sciences. Lastly, each school is roughly the same size. The unit 
of analysis for this study is at the individual level. The context of each country and the environment of the MBA programs are intimately integrated into the experiences of these individuals but they, the countries and MBA programs, are not the units being analyzed here. The focus of this research is on individuals and their experiences regarding Western leadership theories applied in local contexts.

\section{Data Collection}

With an eye toward gathering data from a wide range of sources, this study gathered data from three categories of sources. In Phase 1, documents (printed and electronic) were collected that pertain to how leadership theory is positioned by the MBA programs. Then, in Phase 2, the researcher visited each school and program twice with the objectives of meeting with faculty and learning about the programs from those who facilitate courses and from being present in the programs' physical space. Finally, in Phase 3, interviews were conducted with alumni in order to gain insight from the individuals most closely related to the topic. Analysis of the gathered data occurred over a broad period of time and was completed by straightforward coding and deducing themes. The purposes of collecting data from a variety of sources is to obtain both a broad and deep view of how leadership theory is incorporated into local contexts. Further, this variety of sources adds to both the reliability and internal validity of this study.

Phase 1 - Document Collection and Review. The first phase of this study included the collection and review of documents relevant to the positioning of how leadership is valued by the school and programs, and to how leadership was taught. Over a 9-month period, documents were collected both physically and digitally, and these 
documents included broad program and school-wide texts as well as those specific to how leadership is taught. The review and analyzing of these documents occurred in several different rounds. Analyzing the data included simple coding by which words or phrases were identified and collected to be later grouped into themes. An example of a coded document is in Appendix E.

Documents were collected both physically and digitally. Documents were initially collected from publicly accessible documents found on each program's website. In addition, document collection occurred during each visit to each school and program. These materials were collected from public displays as well as materials offered from faculty and staff. As the study progressed, the researcher returned multiple times to the available online materials in search of newer versions. Similarly, as the study went on, specific documents were requested from programs when the researcher found important or helpful documents from one of the other programs. The aim was to have both the most recent documents as well as a balance of similar types of documents from each program.

Two types of documents were collected: The first category includes a wide range of documents that may help situate how leadership education is expressed by the school and MBA program. Documents of this sort include general program information, marketing materials, mission and vision statements, annual reports, school and program fact sheets, dean's messages, program brochures, activity reports, and alumni profiles. The second category includes documents that speak directly to the academic nature of how leadership was taught, such as curricula overviews and requirements, syllabi from courses that incorporate leadership, academic course catalogues, and foundational textbooks, articles, and case studies. 
The researcher sought to collect a similar breadth of documents from each program. In total, nearly 70 documents were collected with 59 coded and included in this study. The following table describes the distribution of documents and the schools from which they were collected.

\section{Table 4}

\section{Distribution of Documents}

\begin{tabular}{|l|c|c|c|}
\hline Document & AUB & AUC & AUS \\
\hline Program/School Brochures & 1 & 2 & 2 \\
\hline Admissions Information & 2 & 2 & 1 \\
\hline Fact Book(s), Fact Sheet(s), Annual Reports & 1 & 3 & 1 \\
\hline Deans Message & 1 & 1 & 2 \\
\hline Program Web Pages & 1 & 6 & 7 \\
\hline Program/School Mission, Vision, Values & 1 & 1 & 1 \\
\hline Curriculum Overview & 1 & 1 & 2 \\
\hline Course Catalogues/Course Descriptions & 1 & 5 & 2 \\
\hline Syllabi & 1 & 2 & 1 \\
\hline Textbooks & 1 & 1 & 1 \\
\hline Case Studies & 1 & - & 1 \\
\hline Other Documents & 13 & 24 & 22 \\
\hline Totals: & & & 1 \\
\hline
\end{tabular}

Documents were collected and organized both physically and digitally. The physical copies served as the primary documents to be reviewed with the digital copies acted as backup in case the physical copies were lost or damaged. Coding was intended 
to be done with qualitative software such as NVivo or MAXQDA. This did not occur simply because the time and energy it would take to learn and utilize the software did not warrant its utility for this research. Instead, the digital materials were printed and collated with the other physical documents. Once there was an initial critical mass of documents, they were read and coded. This included coding with highlighters, the use of different colored Post-It notes, and note cards. These pieces of data were then transferred into an Excel document where colors could be retained while codes could also be noted and easily organized.

As the study proceeded, the same coding process occurred if any additional or updated documents became available. The collection, organization, and analysis of physical and digital materials did not happen in one, smooth, unidirectional path. Consistent with the study design element of circular hermeneutics, the process of utilizing documents for data collection involved multiple feedback loops both within Phase 1 and between the first and subsequent phases. This initial phase influenced the subsequent path and progress of the study into and throughout Phase 2 and Phase 3. Phase 1 spoke to Phase 2 and Phase 3, just as did Phase 2 and Phase 3 influenced the other two phases. While this is the nature of interpretivist qualitative research, it was also important to not get stuck too long in this first phase and move on from Phase 1 into Phase 2, and eventually from Phase 2 to Phase 3. The research continued into Phase 2 with an understanding of how these schools and programs viewed, or at least professed to view, leadership and leadership education.

Phase 2 - Campus Visits. During the summer and fall of 2019, the researcher took two trips to visit each of these schools and MBA programs. Each trip followed the 
same pattern: spending 4 nights/3 days in Cairo while visiting AUC, then traveling to Beirut to also have 4 nights/ 3 days to visit AUB, and then spending the same 4 nights $/ 3$ days near Dubai to be able to visit AUS. The purpose of these trips was threefold. First, to have conversations with program faculty and staff to gain their perspectives and insights. Second, to be able to observe the physical and cultural elements of each campus and program. Third, as already discussed, to collect documents and materials that were not available online. In being consistent with the naturalistic nature of this type of research, visiting is important and it was essential that this researcher spend time in the natural setting of the phenomena being studied.

Just as circular hermeneutics was an important rhythm throughout this study, so was the naturalistic nature of this study. It is a belief of this research, and is expressed in this study, "that social phenomena are situated within and cannot be isolated from their social context, interpretations of such phenomena must be grounded within their sociohistorical context” (Bhattacherjee, 2012, pp. 105-06). The teaching of leadership and its utility by alumni are certainly grounded in their regional and cultural contexts and thus must be studied within and with a view of the region. This is especially true as the researcher has spent much of the past 15 years in the region but is not a native to the region. Both research and researcher needed to be in the place where leadership is taught and utilized, because of the research needing to be contextualized and the 'outsider' nature of the researcher. The researcher did not spend as much time as they would have liked and much, much more time would have been preferred.

The first purpose of visiting each campus and program was to be able to meet with faculty members in order to learn how leadership is taught and how they experience 
students' learning of the topic. The researcher identified the most appropriate individuals by searching faculty profiles that were accessible on each program or school's website. Individuals were selected on the bases of who had experience or interest in leadership or management practice or teaching, as noted in their biographies, curriculum vitae, or identified as lecturers/facilitators of specific leadership-oriented courses. The range of these individuals included adjunct faculty, full-time, tenured faculty, special chairs/directors, and deans of the school. An Excel spreadsheet was created that noted each individual's name, contact information (email and phone), office location, teaching and research interest, and any other information that might be helpful for the researcher to know.

Approximately four weeks before the first visit, each of the prospective faculty were individually contacted via their school email address listed online. This initial email introduced the researcher, the research topic, why the faculty member was being asked for a meeting, and the dates the researcher would be at the faculty member's campus (Appendix F). Further, the researcher attached both an introduction from their dissertation committee chair, Dr. Afsaneh Nahavandi (Appendix G), as well as the abstract from the dissertation proposal (Appendix H). The intent of providing this information was to legitimize the reason for the contact and to encourage the individual to participate. If a response was received, it fell into 1 of 3 categories. The first category, affixed in the organizing Excel document with a 'green' tag, was for those who responded affirmatively in that they were willing and available to meet. Then, through a series of back and forth emails, a date and time was set to meet. Another category was those who were willing but not available to meet during this first trip. The researcher 
responded with a note of thanks and then responses were placed into the organizing document with an 'orange' label that indicated they would be contacted again before the second visit. The last category was for those faculty who responded but were not interested in or willing to meet. The researcher always responded to these individuals with appreciation for taking the time to respond and asking if there were others whom they recommended as potential interviewees. If no response at all was received after 7 days of the first email, a follow-up email was sent. If there was no response to the second email, the individual was put into the 'orange' list to be tried again before the second visit.

The organization of conversations with faculty prior to the second visit were very similar to that of the first. This list of faculty members contacted was a combination of those who had said they were willing to meet but not available during that first visit and individuals recommended from the first round of visits. About four weeks before the visit, the researcher sent similar emails to the first round that reintroduced the researcher, the research being done, a reiteration of why the faculty member was being asked for a meeting, and the dates the researcher would be at the faculty member's campus (Appendix I). The same two attachments were again included: an introduction from their dissertation committee chair Dr. Afsaneh Nahavandi (Appendix G) and the abstract from the dissertation proposal (Appendix H). Again, the responses fell into three similar categories as before. The 'green' category was those who responded affirmatively in that they were willing and available to meet the researcher. A meeting was then set up through a series of back and forth emails. The second 'orange' category was those who were willing but not available to meet during this second trip. If the researcher thought it 
was important to talk with that individual, they were asked to schedule a phone interview or to answer a few questions via email. The 'red' category where those who either did not respond to a second email or responded saying they were not willing or not available to meet.

The meetings with faculty typically took place on campus and usually in the faculty member's office. The exceptions were faculty members who were on sabbatical and thus wanted to meet off campus near their homes, as well as a few faculty members who were off-campus and abroad, and whom the researcher spoke with over the phone. Each conversation was intended to be conversational and less structured in nature. The researcher's intent was to be congruent with the temporal nature of the interpretivist, exploratory design of the study. The concern was to both understand the finding in relation to the research questions in order to make some sense of a topic that is little researched. Each conversation did include a time where the researcher introduced themselves and their work, asked about the faculty member's research and teaching background, and asked about their experience with students being taught leadership. Near the conclusion of each conversation, the researcher also asked if there were other faculty and alumni whom they recommended as additional, potential interviewees for this study. The researcher also brought with them and offered to each faculty a copy of the introduction letter from Dr. Nahavandi (Appendix G) and abstraction (Appendix H), as well as a business card. The researcher attempted to have a similar number of interviews from each school, with a corresponding range of interviewees from adjunct faculty to the dean of the school. In the end the researcher interviewed 14 faculty and incorporated 12 of them into the study: 5 from AUB, 3 from AUC, and 4 from AUS. The respondents 
whose data was not incorporated into this study was so because either the data provided was not pertinent to the study and or there was a concern about confidentiality.

The faculty the researcher spoke with where at several levels within the department, had similar research and teaching interests, and were of several nationalities. Faculty interviewed included adjunct faculty, professors of practice, tenured faculty, program directors, and deans. Their research and teaching interests included management theory, human resources, family business, international business, leadership development, organizational development, change management, SME, MENA regional development, governance and succession planning. Approximately half were nationals of the countries where they taught, with the other half being nationals from Canada, Great Britain, India, Monrovia, Russia, United States of America, and other unidentified nation states. Of the 14 the researcher spoke with 6 were female and 8 were male. The following table describes the number of individual faculty members from each school that provided data which was incorporated into this study.

Table 5

Distribution of Faculty Participation

\begin{tabular}{|c|c|c|c|}
\hline & AUB & AUC & AUS \\
\hline Adjunct Faculty & 1 & 1 & - \\
\hline Professor of Practice & 2 & - & 1 \\
\hline Tenured Faculty & 3 & - & 2 \\
\hline Program Director & - & 1 & - \\
\hline Dean/Former Dean & - & 1 & 1 \\
\hline Total: & 5 & 3 & 4 \\
\hline
\end{tabular}


The researcher did not ask to record a conversation and only did so if the faculty member volunteered permission to do so. The researcher decided not to ask to record the conversation in order to encourage the quick building of rapport and also to support the faculty member in speaking freely. The researcher acknowledges that there were at least two major categories of barriers facing individuals which inhibited them in speaking freely and clearly. The first barrier is the combination of cultural and linguistic differences. The great majority of faculty interviewed were from the Middle East and of those from the west only one was American. Further, many had English as a second language. These varying cultural differences created a barrier of understanding between the individual and the researcher. The second, and perhaps most important, is the political environment of both academia and the local, national context. The world of higher education is notoriously political, where tension and dispute are common. Further, the Middle East, including each of these three countries, is an area where free speech is dimmed as compared to the west. Regardless of why this is so, from a combination of it being less valued and being repressed by those with authority, it must be acknowledged. With the combination of internal academia politics and that of the regional/national context, it was important that the researcher do what they could to ensure what was said would not leave the room without stripping all identifiable indicators from it. Additionally, the researcher was well aware of their outsider status and attempted to mitigate it throughout the data collection process.

Because of this decision to not ask to record the conversations, the importance of notes, analytical memos, and member checking were elevated. Notes were taken at two points. Notes were taken during the interview with an attempt to capture important data 
points while also not distracting significantly from the conversation. Then, immediately after the end of the conversation, the researcher sat down, typed up, and added to the notes taken during the meeting. Then, alongside these notes, the researcher added analytical memos that included observations, thoughts, and reflections as well as language translations and questions for follow up. Finally, when there were seemingly significant questions or points that had been made, the researcher would member check by following up with the individual via email.

The secondary purpose for visiting each of these campuses and programs was observation. Akin to the analysis of documents in Phase 1, spending time in the cities that encompass these programs and students, in exploring these campuses, and in walking the halls of the business schools, the researcher was able to get a sense of these MBA programs. In spending time around each MBA program, the researcher came to know the feel of the space and was able to get a sense of the culture and sub-cultures of the universities and schools. While much less structured than other parts of data collection phases, there was much value in experiencing the physical space and essence of these programs; this is something that is nearly impossible to do from 6,000 miles away. It is important to note that in this second phase, there were some challenges and changes regarding the initial design of the study. One challenge was that the initial visit took place during summer and thus not many faculty members were available. The researcher made the most of the visit by meeting with those available and using it as foundation for the second visit. It was very helpful to contact faculty members a second time and state, "I'm sorry I missed you during my recent visit to ... while I was there I met with who recommended I connect with you about ." Having at 
least one conversation during the first visit set up many conversations the researcher was able to have during the second. A second common challenge that came up during the second visit was having a tight schedule and having faculty ask to change the days/times of meeting. Several times faculty asked to change the date or time of the meeting and the researcher had difficulty in being able to do so. This also somewhat affected the researcher's ability to compile and add-to their notes immediately following a conversation.

Through Phase 1 and Phase 2, the collection and review of documents, speaking with key faculty members, and observing the physical and cultural nature of the campuses, the researcher gained a solid foundation of how each MBA program professed to view and carried out leadership education. With this understanding the third, final, and most important phase could take place.

Phase 3 - Alumni Interviews. Given the research question, 'How are westerndeveloped theories of leadership adapted, translated, and absorbed into local contexts through MBA programs in the Republic of Egypt, the Lebanese Republic, and United Arab Emirates?' it was important to speak with the faculty, in the above Phase 2, but also, and most importantly, to speak with those most directly affected by the product of the programs: the alumni. Alumni, and not current students, of these programs were chosen for two primary reasons. First, it was assumed that alumni, having already graduated and thus having some or, ideally, more work experience, would be able to speak with more knowledge on the adaptation of leadership theories into their local contexts. Each of these programs required applicants to have some work experience but each of these requirements were minimal. The second motive in choosing alumni 
concerned access. If current students were to be interviewed the researcher would have had to gain permission from each school and program. This would have been time and effort intensive with little likelihood of being successful. For these two reasons, experience and access, it made most sense that for the purposes of this study MBA alumni would be those asked to provide data.

Individuals were identified through four primary means. First, through the Phase 1 document analysis, the researcher found that each MBA program highlighted notable alumni. Photos of famous alumni and quotes from recent alumni were used as marketing to encourage prospective students to apply. These individuals were noted by the researcher and contacted through public means. Secondly, at the end of each conversation with faculty, the researcher made sure to ask if there were any alumni the faculty member recommended as prospective interviewees for this study. Thirdly, simple searchers on LinkedIn resulted in lists of many individuals who noted in their public profiles that they were alumni from one of the three MBA programs. This sampling, being random in nature, was ideally a balance of the caliber of alumni provided by online marketing materials and standout students that faculty recommended. Lastly, just as faculty were asked for recommendations, alumni who agreed to be interviewed were also asked to recommend others they knew who would be willing to speak with the researcher. This last tactic of snowball sampling proved to be very beneficial to the eventual outcome of this study. The researcher utilized all four of these streams in collecting names and contact information and then organized them in an Excel sheet before reaching out to each individual. 
Phase 3 continued with the contact of alumni. Contact was made electronically, typically through email or LinkedIn, and the researcher asked the individual if they were willing to participate by being interviewed on the phone, through video chat, or by email. Similar to the initial contact with faculty in Phase 2, the first email or message to an alum introduced the researcher, the research topic, why they were being asked to participate and included three attachments: an introduction letter from the researcher's dissertation chair (Appendix G), the abstract from the dissertation proposal (Appendix H), and disclosure form. Like before, the intent of providing this information was to legitimize the reason for the contact and encourage the alum to participate. For alumni who responded positively, it was organized how they would like to participate (phone, video chat, or email) and when a good time for them would be. Similar to balancing the number and range of documents and faculty, it was the aim of the researcher to contact and interview approximately the same amount of alum from each program. This was an attempt to have a nearly balanced representation across the region.

Respondent alumni came from predominately from recent alumni classes, most of which work full time, represent a small range of nationalities, and were predominantly men. The year of graduation ranged from 2007 through 2019 with a few graduation years unknown. The majority of those interviewed were working in professional careers with two seeming to not be currently working. The majority of individuals appeared to identify as nationals of the countries where they had completed their MBA. Lastly, the alumni interviewed where predominantly male with three being female. A total of 14 alumni were interviewed with 1 of those not incorporated into this study. The following table describes the 13 participants interviewed and integrated into this study. 
Table 6

Distribution of Alumni Participation

\begin{tabular}{|c|c|c|c|c|c|}
\hline & & AUB & AUC & AUS & Total: \\
\hline Age Range & $21-30$ & 3 & 1 & 4 & 8 \\
\hline & $31-40$ & - & 2 & 1 & 3 \\
\hline & $40+$ & 1 & 1 & - & 2 \\
\hline & Total: & 4 & 4 & 5 & \\
\hline Gender & Female & 1 & 2 & - & 3 \\
\hline & Male & 3 & 2 & 5 & 10 \\
\hline & Total: & 4 & 4 & 5 & \\
\hline Resident Status & Studied Within Home Country & 3 & 4 & 3 & 10 \\
\hline as Student & Studied Outside Home Country & 1 & - & 2 & 3 \\
\hline & Total: & 4 & 4 & 5 & \\
\hline Industry & Banking \& Finance & 1 & - & - & 1 \\
\hline & Consumer Market \& Retail & - & 1 & - & 1 \\
\hline & Education & - & - & - & \\
\hline & Government \& Civil Services & 1 & - & 1 & 2 \\
\hline & Healthcare & - & - & - & \\
\hline & $\begin{array}{l}\text { Industrial Manufacturing \& } \\
\text { Construction }\end{array}$ & - & 1 & 1 & 2 \\
\hline
\end{tabular}




\begin{tabular}{|l|l|c|c|c|c|}
\hline \multirow{5}{*}{} & IT \& Communications & - & - & - & \\
\cline { 2 - 7 } & Management Consulting & 1 & - & - & 1 \\
\cline { 2 - 7 } & Petro Economy & - & 1 & 2 & 3 \\
\cline { 2 - 7 } & Real Estate & - & - & - & \\
\cline { 2 - 7 } & Transportation, Logistics, \& & 1 & 1 & - & 2 \\
\hline \multirow{5}{*}{$\begin{array}{l}\text { Import/Export } \\
\text { Where }\end{array}$} & Not Employed & - & - & 1 & 1 \\
\hline \multirow{2}{*}{ Employed } & Working Within Country of & 4 & 4 & 5 & \\
\hline & Graduation & 2 & 4 & 4 & 10 \\
\hline & Working Outside Country of & 2 & - & 1 & 3 \\
\hline & Graduation & & & & \\
\hline & & & & & \\
\hline
\end{tabular}

The two respondents whose data was not incorporated into this study had concerns about how the data would be used and confidentiality.

Opposed to the nearly structureless intent of the conversations with faculty, the interview format with alumni was very much structured. Phone and video chat conversations were semi-structured as they were more conversational in nature. Interviews that took place through email were much more structured and less conversational. The same questions were asked or covered in each type of conversation and kept on track with the use interview guide (Appendix J) in order to gather the same 
information from each participant. For interviews that were more conversational, there was no rigid structure as all questions were asked through the flow of the dialogue. Alternatively, for conversations that took place over email, the same questions were asked in the same order each time.

Data was gathered in three forms before being organized. During each phone or video chat conversation, the researcher took notes and noted data points that seemed to be important for the study. Individuals who participated in these two forms of interviews were asked if they could be audibly recorded, and if given consent the researcher would digitally record the audio of the conversation. Recordings taken over the phone were done through TapeACall and recordings of video chats were taken with Voice Memos on the researcher's iPhone. These recorded interviews were then transcribed by the researcher. Transcription was carried out solely by the researcher with the use of an Infinity USB Digital Foot Control paired with ExpressScribe Pro software. Those conversations conducted over email were naturally recorded in text format. Data gathered during Phase 3 was organized in an Excel sheet and was then analyzed and coded before themes were found in conjunction with the other two phases.

Between the design to the implementation, Phase 3 had two significant changes and challenges. The first, already noted, was the switch from intending to interview current students to that of focusing on alumni. This happened because of the two reasons mentioned above: access and potential value of data. Generally, alumni have more work experience and thus have more depth of understanding about the topic of leadership in their context. Also, access to alumni was much easier than it would have been with current students. The second substantial change from the initial study design was that 
there was intended to be a third visit to the region that did not take place. This third visit was to have taken place in late November or in January, before and after several regional and international holidays (national days, New Year's, etc.). What the researcher could not have known was that the level of instability in the region escalated to a degree that they did not feel comfortable traveling to the same region. This change necessitated a reworking of how data for Phase 3 was collected from in-person interviews to what was discussed above. It was the researcher's preference to have had the interviews with alumni take place face-to-face, be conversational in nature, and be in comfortable places for the interviewees.

Throughout the study, from the data collection process and to the completion of the study, confidentiality was a constant concern and given consistent attention. The reasons for this are, first and foremost, to ensure each individual's safety and, secondly, to facilitate an environment where they would be most likely to speak truthfully and openly. For this reason, the emphasis on confidentiality was communicated to each participant early and often. The researcher implemented a clear and consistent process for ensuring confidentiality. After meeting and interview notes and/or transcripts were organized, cleaned up, and coded, the pieces of data were then moved to the organizing Excel document in a format that stripped out personal identifiers. A key exists that translates each of the real-world names and other identifiers to those that protect the identity of each individual. The data could then be organized and analyzed since individuals and programs had anonymity. 


\section{Data Analysis}

Thematic analysis was determined to be the optimal approach to this research study. Thematic analysis involves a family of approaches that looks for patterned meaning across data sets (Thematic Analysis, The University of Auckland; Berard \& Ryan, 2010). As Opler put it:

"in every culture are found a limited number a limited number of dynamic affirmations called hemes, which control behavior or stimulate activity. The activities, prohibitions of activities, or references which result from the acceptance of a theme are its expressions...The expressions of a theme of course, aid us in discovering it" (1945, pp. 198-199)

This study, having a variety of sources, necessitated a type of analysis that could be used in the same manner across all three data sources.

The analysis process occurred in several stages that, akin to the data connection, happen in a progressive pattern but are also circular in nature. As the data was being collected in Phases 1 through 3, the researcher familiarized themselves with the data. In Phase 1, this was completed by simply reading the documents several times over. In Phase 2 and 3, the familiarization happened through reviewing notes, transcripts, and recordings. The next stage involved creating and applying codes to pieces of data. These labels were initially brief but abundant. As the analysis went on, some of these codes were folded into each other so as to not have an overwhelming number. At this stage of the analysis, data was coded and grouped within each of the three phases. Though many of the same codes were used in all three groups of data, it was important to keep these data sets isolated for the time being. In part, this was an attempt to keep the process 
simple. More importantly, it was employed to assist in future rounds of analysis, as it was expected that there would be differences in how leadership was professed to be valued, what and how it was taught, and the experiences of the students.

Once it was thought that all of the codes needed had been created and applied, they were then grouped together into preliminary themes. These initial themes were then checked against the datasets to know if they would make sense. Themes that fit were left as is and the themes that did not fit well were fine-tuned. Finally, the themes were formalized in name and defined. These themes created the basis for the following Discussion chapter. Using the thematic analysis approach of beginning with specific pieces of data, noticing both regularities and irregularities, and surmising the potential relationships between, is congruent with the inductive characteristic of interpretivist methodological framework research.

These sources of data were gathered, analyzed, and organized under the following sub-sections addressing each of the RQS. The first research question, RQS1, focuses on how each program situates leadership education within their program, what leadership models and theories are taught, and concludes with a discussion of what methods are used to teach leadership. With this understanding, RQS2 turns to how these theories and models are applied in practice with a particular focus on how historical and current context affect the expression of leadership. The combination of RQS1 and RQS2 addressed the overarching research question. This broader research question will be discussed in Chapter 5. 


\section{CHAPTER 4}

\section{FINDINGS}

The findings of this study came from three sources of data: program documents, faculty, and alumni. The data from these sources is used to answer one primary research question with two underlying research question sets (RQS). RSQ1 pertains to how leadership is situated, what is taught, and how it is taught. It was found that leadership is situated as being expressed as being very important with western-leadership theory being taught through traditional means of lecture, text books, case studies being conducted in groups and individually. RSQ2 looks at what programs, faculty, and alumni do with leadership education. There are nine specific themes that emerge within RSQ2. The first six are relevant to how leadership is applied in practice and includes: a local, regional, and international focus; relevance of a changing environment; interest in entrepreneurship and innovation; application within family businesses; management is preferred over leadership; and a dual attention given to professional and personal development.

\section{Research Question Set 1}

RQS1: How is leadership education situated within these MBA programs? What leadership theories and models are taught? What methods are used to teach leadership education?

The first set research of questions has three lines of inquiry. The first question focuses on how the theory of leadership is situated within each MBA program. That is, how do these programs position leadership and leadership education in terms of importance, or lack thereof, for their students and alumni. The second question is technical and straightforward in seeking to understand what leadership is taught. This 
attempts to learn what theories, models, concepts, systems, schemes, and the like, are delivered to students. Lastly, the question is asked as to how these leadership theories are taught. This regards the approaches, means, devices, and techniques that are employed by teaching faculty. RQS1 derives the majority of its data from program documents and conversations with faculty.

\section{Figure 7}

Research Question 1 Components

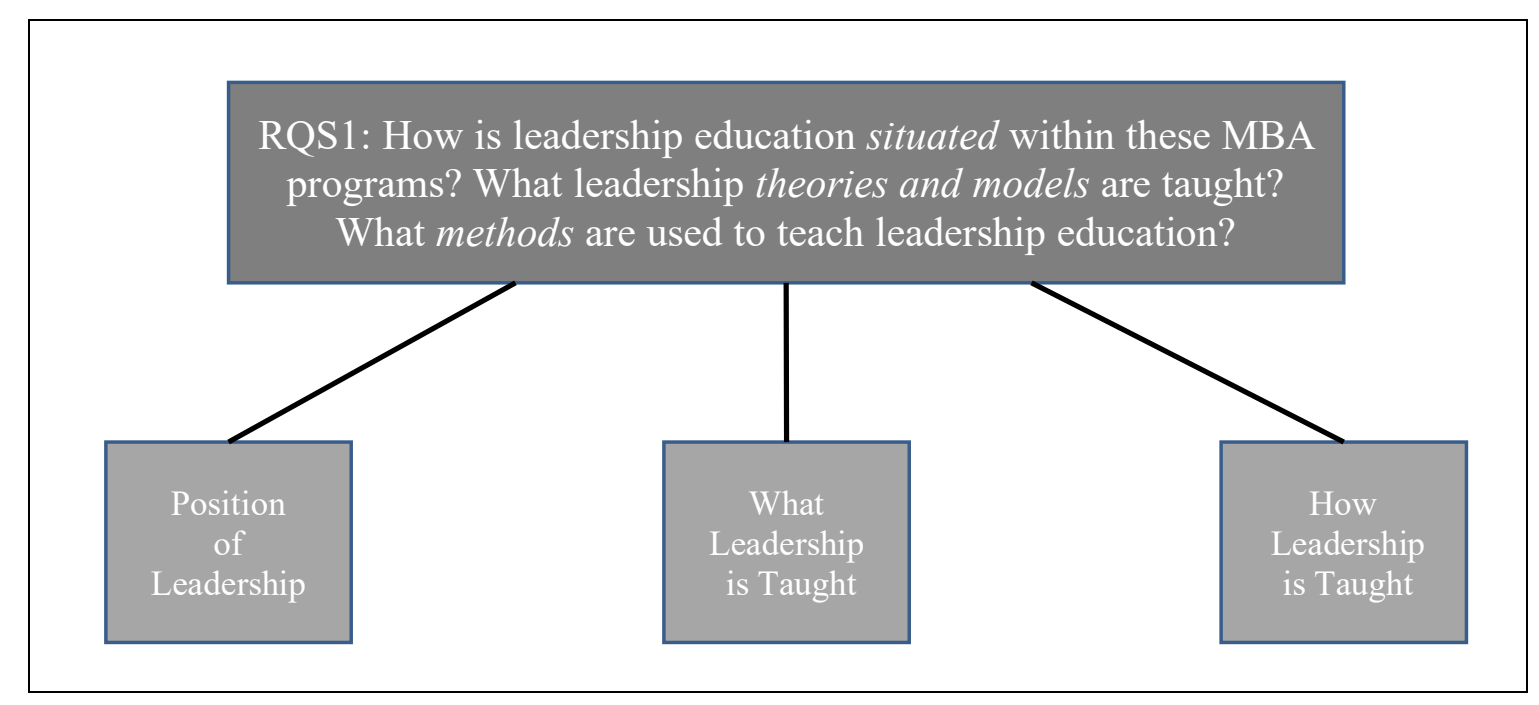

\section{Positioning of Leadership Education}

Within each of these programs there was a high degree of stated importance placed on leadership education. This importance was expressed both through publicly available documents, from conversations with faculty, and from the experience of former students. Documents speaking to the value placed on leadership and leadership education include the school's vision-mission-values, marketing materials, other online content, and through academic information. Further, faculty also conveyed the value of leadership education. Lastly, alumni had input about how they experience the school's value of 
leadership education. On the whole, these individual pieces of data speak to a high level of importance placed on leadership education.

One area where the value of leadership and leadership education is most clearly stated is in the programs' marketing materials. OSB at AUB specifically state their value of developing leaders through their MBA program by stating, "Our business education and knowledge sharing must be cognizant of this dynamic environment as we prepare our students to lead in today's ever-changing business environment" and "Suliman S. Olayan School of Business develops leaders to excel in the constantly and rapidly changing business world. Through an immersive business education experience, students build a strong knowledge base and gain individualized skills to meet the economic and social challenges of the future" (AUB, OSB Brochure). Further, under Program Highlights, the same brochure states that "Rigorous academic theory and research linked with real-world practice to build fundamental leadership and management skills" (AUB, OSB Brochure). AUC's MBA Brochure 2019-2020 trumpets the importance of leaders in stating their Mission is "The School of Business develops entrepreneurial and responsible global leaders and professionals" (AUC, MBA Brochure 2019-2020). AUS's MBA Brochure announces that "AUS is filled with world-class faculty and students, poised to become the innovators, thinkers, contributors and leaders of tomorrow."

Another rich source of data on the value of leadership in these MBA programs comes from online web page content. At AUB, in speaking to the evaluation criteria for applicants, the program states, "The MBA program is the breeding ground for the leaders and entrepreneurs of tomorrow. We aim to develop students to excel in the constantly and rapidly changing business world. The MBA Admissions team looks to attract and admit 
candidates with balanced competencies including excellent analytical skills and leadership potential" (AUB, OSB, MBA Admission). AUC has two pages, What We Offer and Who We Are, that each speak to their aim to advance their students into leaders: Become a Global Business Leader in that "Shaping you into a competent global business leader is more than a headline. We've tailored our MBA program to become a stepping stone to new professional heights and aptitudes for all those seeking empowerment and growth. By incorporating a comprehensive body of knowledge and the right skills, the program will help you develop a managerial perspective to address the challenges and seize the opportunities of today's everchanging local, regional and global business environment. (AUC, SoB, MBA, What We Offer)

and

Boasting an unrivaled reputation as the top private business school in Egypt and one of the best in Africa and the Arab world, the AUC School of Business is dedicated to transforming the young eager minds of today to the responsible change agents of tomorrow, all while developing relevance and leadership in an evolving ecosystem. (AUC, SoB, Who We Are). AUS's online content speaks even more heavily to the importance of developing leaders. 


\section{Table 7}

\section{AUS Online Leadership Content}

The master of business administration (MBA) program is designed to offer a highquality, comprehensive and gulf-oriented approach to the development of management and leadership skills. (AUS, SBA, Graduate Programs)

Through our MBA program, students are prepared for careers in management and leadership positions in both the private and public sectors. (AUS, SBA, Masters of Business Administration) Reputation for excellence and innovation. American education and local culture.... You will be able to take pride in having a deep knowledge in management and leadership and a broad perspective on business across the globe. (AUS, Discover the AUS MBA Difference)

The Master of Business Administration (MBA) program at American University of Sharjah (AUS) is like no other MBA in the region. Our mission is to prepare you for leadership positions in the private and public sector. Our program is designed to enable talented future leaders to make a vertical leap in their current career path, change job function or industry, or acquire an entrepreneurial toolkit to start or develop their own business. Our program adapts state-of-the-discipline business knowledge to the needs of the local market, allowing students to integrate new knowledge into business problem solving for a global context. (AUS, MBA Overview)

AUS MBA graduates are expected to achieve the following objectives: ... (3) excellent teamwork, interpersonal communication and leadership skills. (AUB, MBA Overview) 
When considering each school's vision, mission, values, or philosophy, we see the value of leadership and leadership development throughout. The opening line of the MBA program's philosophy at AUB's OSB is “OSB has been developing leaders and preparing them to excel in the constantly and rapidly changing business world" (OSB, MBA Program, Philosophy). At AUC, the School of Business directly states that their mission is to develop "entrepreneurial and responsible global leaders and professionals" (AUC, MBA Brochure 2019-2020). More specific to the MBA program, the Mission of the Department is to

develop business leaders who are dedicated to the betterment of society by providing a high quality business education to top caliber students from all segments of the Egyptian society as well as from other countries while focusing on continuous improvement and a commitment to excellence in learning, intellectual contributions, and service. (AUC, MBA Course Descriptions)

This value is stated again in their School Themes, i.e. school values, when speaking about responsible business: “AUC's School of Business aims to develop leaders for a sustainable future, taking into consideration the purpose and role of business in society, values, sustainable development, diversity, and stakeholder interests (AUC, School of Business, School Themes). At AUS, leadership is given weight in their Core Values that are "ELITE." Leadership is directly stated as a core value in that the "L" stands for leadership where the value is stated as, "We believe in making a difference through our aspiration to be leaders in the Gulf region. We constantly engage with businesses and government so that our graduates will become future leaders and our faculty lead the 
way with cutting-edge scholarship" (AUS, Core Values “Join the ELITE"). Further, the latter E in ELITE stands for Ethics, where the school states that they seek to "develop ethical and responsible leaders who are committed to the common good" (AUS, Core Values "Join the ELITE").

Another piece of the document collection spoke to how the programs valued leadership through their academic materials. At AUB, their MBA Curriculum states, in part, that their "courses will provide students with opportunities to learn, practice, and lead" (AUB, OSB, MBA Curriculum). The course catalogue states that "OSB has been developing leaders and preparing them to excel in the constantly and rapidly changing business world. Through an immersive experience in business education, we will empower students to build a strong knowledge base and gain individualized skills to meet the economic and social challenges of the future" (AUB, OSB Graduate Catalogue 20192020). Two of their Program Highlights that speak to leadership are "flexible, innovative curriculum which fosters collaboration, community, teamwork and an entrepreneurial spirit" and "rigorous academic theory is linked with real-world practice to build fundamental leadership and management skills" (AUB, OSB Graduate Catalogue 20192020). It is especially important to note that one of the core courses that all MBA students take at AUB is a course dedicated to leadership: Leadership and Organizational Behavior. This course seeks to serve as an introduction to behavioral aspects of the modern workplace, including such processes as leadership, communication, motivation, conflict resolution and team building, and the influence that the environment has on such behavioral patterns. The course will help students assimilate the different roles people play in 
an organization irrespective of their departmental positions or functional affiliations, and recognize the interactions inherent among people, structures and environments. Particular attention is accorded to leadership as a focal point of group processes and a critical ingredient in successful organizational endeavors and transformations. (AUB, OSB Graduate Catalogue 2019-2020)

The value of leadership education at AUC is again evident when looking at courses offered and course descriptions. At AUC the course that focuses on leadership, simple titled Leadership," is not a core course but is instead an elective. In the course descriptions for it, and two other courses, leadership education takes a prominent aspect of the course.

\section{Table 8}

\section{AUC MBA Course Descriptions Including Leadership Component}

Leadership - This course reviews the procedures, styles and methods of leadership in both theory and practice. Students will review the personal, relationship and organizational side of leadership as well as the leader as a social architect. At the completion of this course students will develop and acquire the necessary skills to become effective leaders through examples of real world leadership.

Managing Organizations in a Dynamic Environment: The course aims at acquainting the student with how a leader could manage an organization in a dynamic environment. The course focuses on the main functions of a manager such as planning, organizing, controlling, motivation, team building and with special emphasis on leadership.... 
Strategic Management of Innovation: ... This course will study the theory and practice of innovation as a process and an outcome based on a comprehensive model of innovation which consists of three determinants: innovation leadership, managerial levers and business processes.

(AUC, MBA Course Descriptions)

Similar to AUC, AUS does not require that MBA students take a course focused specifically on leadership, but does have an elective titled Leadership and Change Management. The description for this course states that it "Investigates the role of leadership in the context of global change. Gives particular attention to leadership issues as they pertain to organizational development, culture and the dynamics of change" (AUS, SBA, Graduate Course Descriptions). The syllabus for this course gives very specific course objectives and learning objectives:

Course Objectives: 1. Investigates the role of leadership. 2. To demonstrate change management as a function of leadership.

Learning Objectives: Describe why leadership his a process. Explain the interaction between values and leadership skills. Discuss how interaction between leaders, followers and situations develops into success. Evaluate the impact of power and influence on leadership behaviors. (AUS, Leadership and Change Management Syllabus)

Leadership is also mentioned briefly in the course description for Organizational Theory and Behavior

Applies management theory to factors that influence group performance while incorporating current management theory and research. Emphasizes the total organization and its subsystems with topics including structure 
and design, organizational culture, communication, individual and group dynamics, teamwork, power and influence, decision making, and the role of leadership. (AUS, SBA, Graduate Course Descriptions).

The importance of leadership education and development as expressed through this variety of documents was supported in how faculty view leadership. Highlights of these conversation are as follows.

\section{Table 9}

\section{Leadership Situated, Faculty}

Leadership is a growing topic in our program and it's being driven by the interest of our students. I think they're hearing more about it in media and are wondering how it fits with them, their education, and their careers. (Rashad, AUB Faculty) Teaching leadership is incredibly important to offer to our students. That's why one of their core courses is on leadership. In today's business world 'leadership' is the key word, the key philosophy. (Zara, AUB Faculty)

Egyptians see their country as having been a world leader for millennia. Everyone knows about the pharaonic empires where they ruled down and across Africa and over into the Fertile Crescent. Today Egypt continues to influence and to lead in the eastern Mediterranean, in north-east Africa, and in the Middle East with our allies. At AUC we teach the upper crust and if Egypt is going to continue to lead our students need to be taught to lead. (Samir, AUC Faculty) The School of Business at AUC knows that leadership is that vague concept that is essential for students to be at least introduced to. Not all are leaders and some have no interest but they need to know about it and have a taste of it. (Fatima, AUC Faculty) 
Not every student who goes through the MBA program takes the leadership course but many of the other courses have pieces of leadership in them. I'm thinking of two courses I teach ... where I require students to consider the leadership side of strategic management. (Zainab, AUS Faculty)

There is much talk here in the UAE about leaders and leadership but most of our students are younger and don't have any experience of being a leader, only followers. It's part of our job to familiarize them with the concept and allow them to use what they need. (Noor, AUS Faculty)

From the words printed in program documents to the voices of faculty, leadership education and development seems to be clearly held in high esteem in each of these programs. The texts express this in both range and frequency of where leadership and leadership development are talked about. Faculty placed a high degree of importance in leadership education by the energetic way in which they spoke about the topic and the access given to the researcher. With this understanding, we now to turn to specifically what is offered to students in terms of leadership education.

\section{What Leadership Is Taught}

Exactly what leadership education content is taught can be understood by looking at course descriptions, the texts assigned to students, and insights given from faculty.

A basic understanding of each leadership course and the essence of the content presented is gained through the course descriptions. 


\section{Table 10}

\section{Leadership Course Descriptions}

Leadership and Behavior in Organizations

This course sets the base for proper understanding and micro-level analysis of the role of individual and group behavior in organizations. It is designed as two independent modules. Module I concerns organizational behavior while Module II concerns leadership. The course will serve as an introduction to behavioral aspects of the modern workplace, including such processes as leadership, communication, motivation, conflict resolution and team building, and the influence that the environment has on such behavioral patterns. The course will help students assimilate the different roles people play in an organization irrespective of their departmental positions or functional affiliations, and recognize the interactions inherent among people, structures and environments. Particular attention is accorded to leadership as a focal point of group processes and a critical ingredient in successful organizational endeavors and transformations. Through this course students will analyze, evaluate and apply management and organizational behavior concepts, approaches and tools to both novel business problems and situations and to managerial decision-making situations. (AUB, OSB Graduate Catalogue 2019-2020)

Leadership

This course reviews the procedures, styles and methods of leadership in both theory and practice. Students will review the personal, relationship and organizational side of leadership as well as the leader as a social architect. At the completion of this course 
students will develop and acquire the necessary skills to become effective leaders through examples of real world leadership. (AUC, MBA Course Descriptions)

Leadership and Change Management

Investigates the role of leadership in the context of global change. Gives particular attention to leadership issues as they pertain to organizational development, culture and the dynamics of change. (AUS, SBA, Graduate Course Descriptions)

The specific content that is provided to students comes in three formats: text books, case studies, and topic-specific articles. The two primary textbooks used in these MBA programs are The Leadership Experience by Daft (2017) and Leadership: Enhancing the Lessons of Experience by Hughes, Ginnett, and Curphy (2015). The Leadership Experience is divided into five parts: Introduction to leadership, Research Perspectives on Leadership, The Personal Side of Leadership, The Leader as a Relationship Builder, and The Leader as Social Architect (Daft, 2017). Leadership is split into four parts: Leadership is a Process Not a Position, Focus on the Leader, Focus on the Followers, and Focus on the Situation (Hughes, Ginnett, \& Curphy, 2015).

Two other sources of leadership content come from case studies and topicspecific articles and papers. Both faculty and alumni recounted the wide use of case studies aimed at learning aspects of leadership. In fact, one faculty member reported that in their leadership course they put great importance on students interacting with the case studies as opposed to the textbooks. It was also noted by several faculty that they choose case studies that pertained to the MAME. Interestingly, the case studies that alumni remember were almost all examples from the west. Both alumni and faculty spoke highly of the utility of "real world" examples of leadership as experienced through case 
studies. Articles that are topic-specific were also reported by both faculty and alumni as a source of learning. Faculty stated that they use certain articles every time they teach a course, while others they add to the course content if a particular class is interested in a specific topic. In conjunction with textbooks, case studies and supplemental articles are a significant source of learning content for students at each of these programs.

\section{Table 11}

What is Taught, Faculty

Our leadership course is tied in with organizational behavior and while they are taught as different pieces there is overlap throughout. ...I don't know but I believe this course is typically the first-time students have been given formal leadership education and it's new to them. Because of this we must give the rudimentary foundations. There is much more I would like them to hear but there is just no time. (Rashad, AUB Faculty) We provide a formal American education at AUC, the same is true for what our students get for leadership education. How we teach is very much in the American way and what we teach is from the American perspective. (Samir, AUC Faculty) I think the leadership (education) we give to students in fairly standard. I know when I taught in (in a western country) we used the same texts, I think, that students use here. (Marwa, AUC Faculty)

Leadership is such a large topic that we have to do the basics. My students don't have time to read the entire textbook but they get the fundamentals. And for them that's enough. (Noor, AUS Faculty) 


\section{How Leadership is Taught}

Leadership is taught through a traditional combination of in-class and out-of-class assignments and learning opportunities. Further, there is an emphasis not only on obtaining knowledge but also personal development through individual work and in working with others.

The in-class learning experience includes lecture, class discussion, and content presented by students. Several faculty and alumni reported that lectures were kept to a minimum as much of the content was expected to be gathered from the readings. Despite this, lecture was an important facet of how leadership was taught. More emphasis seems to have been put on in-class discussion as a learning tool. Discussions focused on leadership-related topics that were presented in texts and case studies. Lastly, individuals and groups were expected to provide content and enable their own learning through presenting research and assignments about individual leaders or leadership topics. Outside of the classroom, three methods include assigned readings, group work, and the production of deliverables. Group work outside the classroom seems to be a particular focus at two of the programs that include group deliverables. Additionally, at least one program is experimenting with providing some weekly contact hours outside the physical classroom through web-based lectures and interactions. This seems to be an attempt to woo professionals who have difficulty getting to campus on a weekly basis.

Beyond the knowledge of leadership, several programs sought to actively develop an individual's leadership through the duration of a course. This work came through at least two broad methods: individually and with others. At one program students were required to keep a "leadership journal" where they were expected to note, track, and 
otherwise document their leadership journey during the course. The other way students learned about and developed their own leadership was through group work outside of class and the roles they took up during in-class discussion. Students were expected to learn about themselves through the direct interaction with others.

With this understanding of how schools and faculty situate leadership education, what is taught, and how it is taught, this research moves on to RQS2 that seeks to understand how these taught leadership theories are adapted into the local context.

\section{Research Question Set 2}

RQS2: How is leadership adapted and applied into local environments? How has history and culture affected this adaptation?

Through the analysis of the collected data from documents, faculty, and alumni, six distinct themes were distilled. Two sections distill from the data pertaining to this second research question. The first section is a set of six themes that are both spoken of in relation to leadership by both the MBA programs and the alumni from them. The six themes are:

1. Simultaneous local, regional, and international perspective and aim of impact

2. Effects of an ever-changing environment

3. Moving forward requires entrepreneurship and innovation

4. Significance of family businesses

5. The relation between management and leadership

6. Pursuit of personal and professional development through the program 
The second section consists of three themes focused directly on themes of leadership as reported by alumni that differ with how leadership is traditionally taught and understood in the West. These three themes are:

Leadership is enigmatic.

Leadership is for the few.

Leadership is in the future.

Collectively these nine themes constitute the findings of this study.

\section{Figure 8}

Research Question 2 Themes

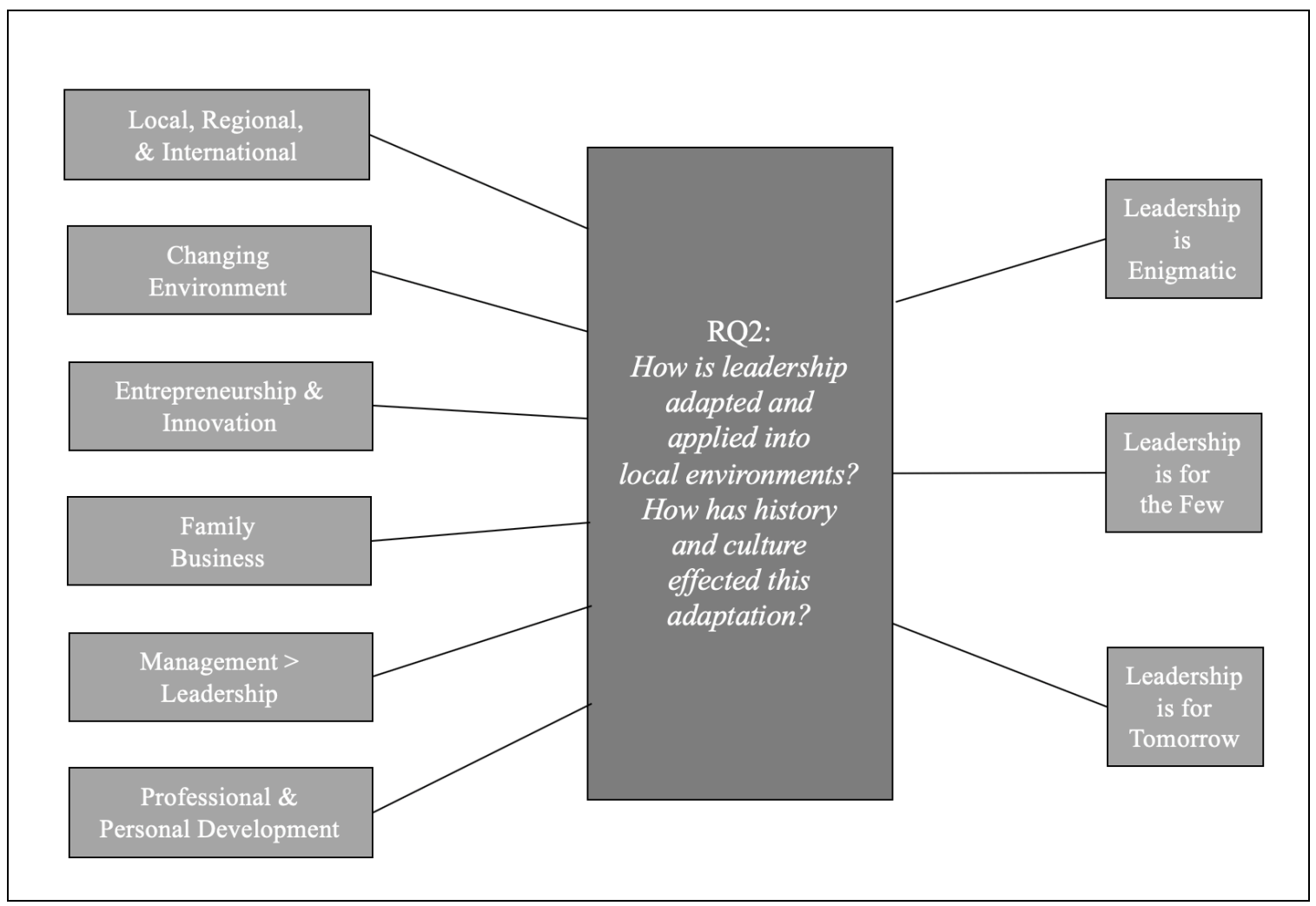

Local, Regional, and International Perspective and Aim of Impact

One of the most clearly and consistently communicated themes was one that is multi leveled. Documents and participant perspective alike spoke to a perspective that is 
simultaneously local, regional, and international. Further, there was a common aim for the future that was also interested in being local, regional, and interactional. What follows is a report of the understanding of the researcher; for a complete list of data collected from documents and participants can be found in Appendix K.

The AUC School of Business themes clearly states the school's interest in being aligned internationally, regionally, and locally: "Given its international orientation, distinct location, an expanse of expertise on regional issues, the School has identified three major themes where it will provide the international as well as the regional and local community with thought leadership and impact" (AUC, School of Business, School Themes). Further, when speaking directly about leadership the AUC School of Business positions the program in "Shaping you into a competent global business leader is more than a headline. ...By incorporating a comprehensive body of knowledge and the right skills, the program will help you develop a managerial perspective to address the challenges and seize the opportunities of today's ever-changing local, regional and global business environment” (AUC, School of Business, MBA What We Offer).

Respondents noted, often with a pride, that Egypt is known throughout the world for its history and current role in international happenings. One part of this is that Egypt both has access to and controls access to international trade routes. Because of its location Egypt in antiquity had access to the whole of the Mediterranean and has thus been connected to other civilizations, including western ones, to a high degree than other areas of the region. It is was reported that Egypt and its leadership is important in connecting the west with what is to the east and south. Further, this connection to the world continues today in Egypt being the caretakers of the Suez Canal. Respondents 
spoke of this vital waterway being a responsibility of Egypt and also a strength in being relevant internationally. It was also reported by alumni participants that the "American" designation of AUC was important to them. This, along with the university's 100 plus year history in Egypt, makes both the school and those associated with leaders in the world.

Respondents also spoke to a triad of regional focuses that Egypt attempts to balance. The most commonly noted regional association is Egypt's long-held and currently-deepening relationship with the Arab Middle East. Egypt is seen as a historic and contemporary influencer in Middle East in the Palestinian-Israeli conflict and the Sunni-Shia split currently expressed in the discord between an Iranian led partnership and Saudi led coalition. Egypt's impact to the east comes from the size of its population, economy, and military. A similar impact and subsequent Egypt leadership extends west Egypt has a significant interest and impact on the politics and economy in Libya, Tunisia and even into Algeria. The area of the most recent regional growth in influence extends south into the larger Africa region. In fact, Egypt's President Abdel Fattah el-Sisi is currently the chair of the African Union. Further, Egypt has specific interest in happenings in Sudan, South Sudan, Ethiopia, and Uganda as the water that flows through the Nile beginnings and passes through these countries. Because resources, including water, in the region have always been an issue Egypt is concerned with allowing the water to continue to run.

Respondents also spoke to the responsibility that AUC and its alumni have to leading Egypt today and going forward. Much of this discussion and focus on local issues all have to do with the fallout from the Arab Spring. While the Arab Spring was a 
regional phenomenon the fallout locally in Egypt has been significant. The changes from the Arab Spring and Egypt's two subsequent revolutions were often spoken about in social, political, and economic changes (more of about these changes are described below). It was not directly said, but the researcher garnered the sense from programs documents, faculty, and alumni that there was a common responsibility to positively effect, ie. lead, the new environment the country is in.

The same three geographic levels of focus and interest where found emanating from AUB and their alumni. The message from the Dean of the OSB states "If you look at the demographics, they're in favor of this region, of Asia, and Africa. By strengthening OSB's ties to local markets, the school can become an attractive destination for students looking to do business in the region" (AUB, OSB, Dean's Message). The tri level focus is also represented in how the school talks about itself: "OSB is highly regarded within the international community with rankings consistently place it as a MENA leader and provider of international vision and opportunity" (AUB, OSB About Us). Lastly, one of the values of the OSB is being anchored in its community but also extending internationally: "We are deeply rooted in the Lebanese community and the greater MENA region, and we interpret this fact as a definitive strength that is hard to replicate. It is the community that we are from, that we understand, and that we are committed to building from our developing position of international strength" (AUB, OSB Brochure).

The central topic that respondents spoke to concerning Lebanon's international focus, aim and impact surrounded its diaspora. Multiple respondents noted that there are many more Lebanese outside the boarders of Lebanon that within. Regions and countries noted as having significant numbers of Lebanese were in Africa (Nigeria, Ivory Coast, 
Sierra Leon), North America (Canada, Mexico, United States), and South America (Argentina, Brazil, and Colombia). Many in this diaspora own businesses and are encouraged to be actively involved in influencing the communities they live in. There seemed to be a direct relationship, or a perceived one between business leading to local influence. It seems that this trend is set to continue in that it was reported that many current students and recent alumni desire to go abroad either to the Gulf or to North America.

The distinction in Lebanon between what is regional and local is very much blurred. This is, in part, due to the country's relatively small geographic size and a population of just 8 million. Importantly, part of the regional-local distortion comes from that it is estimated that of the 8 million residents more than 2 million recently came to the country from Syria due to the civil and regional strife now entering its $10^{\text {th }}$ year. This massive influx of people has exacerbated internal tensions stemming from the 15-year civil war and endemic domestic struggles between the national government and military and the pseudo administration and militia of Hezbollah. The result of these regional and local features is a current economic and political crisis that has stalled much of the country.

There is also a triumvirate of purpose and intention as seen through documents and respondents associated with AUS. The MBA program describes this by stating "With the UAE's place as a business hub for the Middle East well-established, many regional and international businesses have set up offices here in addition to prominent local companies. These companies manufacture, import and export a wide range of products to countries throughout the region and all over the world" (AUS, Master of 
Business Administration). The same document asserts that "Graduates of our program are prepared to identify, analyze and understand the interrelationships among business organizations and international and domestic institutions in the UAE and throughout the world" (AUS, Master of Business Administration). When specifically speaking about leadership within the region that "We believe in making a difference through our aspiration to be leaders in the Gulf region. We constantly engage with businesses and government so that our graduates will become future leaders and our faculty lead the way with cutting-edge scholarship" (AUS, Core Values "Join the ELITE").

Pertaining to a view of internationally focused leadership respondents spoke about how the country has become an international transportation hub which has helped lead to a windfall of tourists as expressed in Expo 2020. A significant part of UAE's rapid development has come from the establishing of two major airlines in Abu Dhabi and Dubai, Etihad Airlines and Emirates Airlines respectively. Emirates Airlines is ranked $5^{\text {th }}$ top airline in the world for the most distance flown by passengers (Skytrax World Airline Awards 2019, 2020). Having Dubai and Abu Dhabi as these airlines central hubs have brought tens of millions of tourists to the country every year. The growth in the past 15 years of tourism is seen to have elevated the view of the country and the Gulf region. Finally, respondents pointed to their international focus by speaking about Expo 2020. Akin to hosting the Olympics, countries who host international expos are seemed to have "arrived" into the top tier of contemporary influencing countries.

Respondents also spoke of the need for leadership in the region. Because of a changing environment, which will be covered in the following section, the UAE has had to ally itself with one of the two competing blocks in the region. The UAE, with its long- 
held, historic ties to the broader Arabian Peninsula has joined Saudi Arabia and Egypt in attempting to thwart Iranian aggression in the Persian Gulf region. The UAE has lent military support economic support to the conflicts in Syrian and Yemen while also providing arms and personnel to the later struggle. The regional leadership of individuals from and the UAE as a whole in the Gulf and broader Middle East has both grown and is being sought to grow.

Finally, the UAE and its citizens are also quite interested in developing their own country. The government, led by the heads of the seven emirate families, has pushed initiatives such as Emiratization, Vision 2030, and Economic Vision 2050. Emiratization is the mandate that Emiratis must be included in the job sector and particularly so in the private sector. This is particularly important because as the country's economy and resident population has grown, those who are Emirati now constitute around $12 \%$ of the population. Emiratisation is broadly seen as an attempt to keep the UAE Emirati culture as dominant while adapting to growth and development. Supporting this broad aim is Vision 2021 that celebrates the countries golden jubilee in holding up the accomplishments, past and present, of the country. Looking further down the line is Vision 2030 and 2050 that seek to be design what the economy will look like in 10 and 30 years on.

Closely related to this attention to what is happening locally, regionally and, internationally is that it they are experienced to be changing.

\section{A Changing Environment}

Alumni, faculty, and program documents all report the importance of leadership in a changing environment. Words or phrases used in the documents include "dynamic," 
"ever-changing," "challenges of the future," and "evolving ecosystem." Alumni and faculty typically reported the environment as "unstable, "chaotic," "uncertain," and "volatile." This changing environment is reported to be both within and outside of the business world. There is an understanding that the situation within the business world is dependent on the context of what is going on in the rest of the country, region, and world. A complete list of data from documents and respondents can be found in Appendix L. The OSB at AUB directly adopts a perspective that the world, their region, and their country is ever changing. In the school's brochure it is stated that "

The business environment is becoming increasingly dynamic, driven by the shifting impact of globalization, demographic change, emerging technologies, and the growing importance of embracing sustainable practices, ethics and corporate social responsibility. Our business education and knowledge sharing must be cognizant of this dynamic environment as we prepare our students to lead in today's ever-changing business environment. (AUB, OSB Brochure)

Similarly, and specific to the MBA program, it is stated that OSB "develops leaders to excel in the constantly and rapidly changing business world" (AUB, OSB, MBA Brochure)

This focus on dynamic, shifting, growth, emerging, ever-changing, evolving, and uncertain times and the interest in leaders responding to it was echoed and emphasized by respondents. Evidence of this was provided by several faculty who, generally being older than the alumni, spoke to living through or closely observing from afar the Lebanese Civil War in the 1970s through the 1980s. They spoke of how beautiful whole, from coast to mountains, Lebanon was and how those 15 years traumatized their generation 
and the nation since. They also pointed to leaders who helped end the conflict and who spent a decade rebuilding the nation. Rafic Hariri, who led the nation as Prime Minister for more than a collective decade, was particularly noted as someone who was looked to for hope and development. The 1990s and early 2000s were a period of growth and building for the country that is, in no doubt, was in part due to his deep ties to the country in being a business tycoon. This same group also noted the continued changes happening due to regional and internal strife although this recent and present change was highlighted by the younger alumni.

The alumni, generally being younger, focused on change resulting from domestic conflicts between the establishment and Hezbollah, simmer discontent with neighboring Israel, and the strain that the tsunami of refugees have brought from the Syrian Civil War. Some respondents who spoke of Hezbollah dismissed the group as "terrorists without a cause" while others worried about the continue influence within politics and outside of with its strong militia that controls certain areas of the country and continues to fight in Syria. Perhaps the most important reason that younger respondents experience change has been through the nearly 2 million refugees that have flooded in from Syria's 10 year civil war. These refuges have put an overwhelming strain on an already taxed population in terms of housing, work, education, healthcare, and food supplies. Lastly, the ongoing restlessness of the relationship between Lebanon and Israel came up less often but it was noted how the past boarder wars and continued militarization of the boarder has created an uncertain situation and one that could erupt again soon.

Program documents from AUS also point to a changing world and business environment. The MBA program is "designed to provide our graduates with the skills 
they need to be competitive in today's dynamic, global marketplace," "business school graduates today must be exposed to the latest techniques and most current business practices if they are to be prepared to pursue careers in an ever-changing and complex world," and that the "business world is changing and expanding constantly as we seek to develop markets and respond to the needs of consumers and companies" (AUS, Master of Business Administration). Importantly, to the role of leadership, the elective course Leadership and Change Management "Investigates the role of leadership in the context of global change. It gives particular attention to leadership issues as they pertain to organizational development, culture, and the dynamics of change" (AUS, MBA, Course in Leadership Change Management).

Respondents who teach or who have studied at AUS also spoke to past, current, and on-going disruption. A phrase heard in interviews, as well as by Emiratis abroad, is that the Emirates is a "rapidly changing society." The evidence pointed to is broad but comes down to how much change has occurred in the country in less than 50 years. While the seven families of today's Emirates go back many centuries the codification of the country did not happen until late 1971. Oil had already been discovered but primarily in and around Abu Dhabi. The development of the country, and specifically Dubai, did not accelerate until the 1990 s and was not internationally known until the $21^{\text {st }}$ century. This growth from an economic, political, and generally unimportant backwater to the regional influencer it is today has indeed been swift.

While the stability of the UAE government has been an important factor in the country's growth, it is in a region where there is a significant amount of instability. The strife between Saudi, the UAE, and their allies with Iran and its supporters occasionally 
flares up in the water ways and petrofields in the Personal Gulf and on the Arabian Peninsula. The accompanying war in Yemen is in fact a proxy war between these same two alliances which threatens to spill into neighboring countries including Oman, Saudi Arabia, and the UAE. Other non-military threats that weigh heavy on the business leaders of the UAE include economic or financial melt downs as well as health crises. Middle East Respiratory Syndrome (MERS) did not infect nor cause many deaths in the UAE, but did cause significant economic uncertainty in the whole of the region. Similarly, the global recession of 2008 and 2009 deeply impacted the Emirates and threatens to do so again in the future.

Similar to documents reviewed at AUB and AUS those found at AUC speak to the changing nature of the environment. In an introduction to the whole School of Business it is stated that:

Dynamic political regimes, evolving economic systems and ever-changing social landscapes have become the new norm. In such a vibrant setting, keeping up with change is a challenging task on its own. Meanwhile, the corporate world keeps growing in complexity, competitiveness and uncertainty; it's survival of the fittest in today's business world. Any way you look at it, from an everyday life perspective or a business world outlook, today's world is changing and you need to step up if you plan on doing more than surviving. (AUC, School of Business, Introduction)

Again, in literature directed toward MBA students, the program posits that "Today's world is no longer bound by geographical dispositions making today's market an open 
integrated space. Yet, with this openness come both unprecedented opportunities and challenges" (AUC, MBA, Online Information).

Respondents, both faculty and alumni, of the AUC MBA program pointed to the recent and continued social change and resulting political and economic consequences. As previously noted, while the 2010-2011 Arab Spring did not begin in Egypt it did spread and profoundly affected the country's present and future. It is debated as to how much the Arab Spring was caused by existing or growing social struggles and how much the Arab Spring caused more of the same. Regardless, the upheaval in Egyptian society is difficult to overstate. Two of the difficult transitions have been in the government and economic realms. The Arab Spring saw a first revolution that led to the downfall of the late President Hosni Mubarak who one of the Middle East's longest tenured heads of state. President Mohamed Morsi was then elected but within a year was removed by another revolution that some call a coupe.

The interim leader of the government was General Abdel Fattah el-Sisi who is now the duly elected President of Egypt. His years in power have brought relative physical calm to the country but also strenuous economic reforms. President Sisi has attempted to move the Egyptian economy away from its traditional dependence on government subsidies and financial controls. The hope is that these short-term economic difficulties will eventually lead to a stronger, more mature, free-floating economy. Respondents noted the positive result of these political and economic challenge and changes are far from certain but there did seem a measure of hope that they would be in the long run. 
It is also vital note that this data, from all three sites, was collected before the awareness and spread of COVID-19. This researcher believes that this theme of change and resulting uncertainty is more intense now that the world and Middle East region deals with the health, economic, and social impact.

\section{Entrepreneurship and Innovation.}

Entrepreneurship and innovation are valued both for today but are also spoken of in a way that is interested in an enhanced future. These two related themes are widely valued with programs that have specific chairs, centers, core courses, and MBA specializations dedicated to entrepreneurship and innovation. A complete list of data from documents and respondents can be found in Appendix M.

Of the three sites visited for this research site with the strongest focus on innovation and entrepreneurship is at AUC's School of Business. The theme shows up in their mission statement: "The School's mission is to develop entrepreneurial and responsible global leaders and professionals" (AUC, MBA Brochure 2019-2020). It also is one of the school themes:

The school's executive education unit is developing more programs geared toward entrepreneurs, while numerous outreach efforts are conducted through the Center for Entrepreneurship, AUC Venture Lab and Entrepreneurship Society Student Club. In addition, the school aims to develop thought leadership in entrepreneurship by heading the African Academic Association on Entrepreneurship launched with five leading African business schools. (AUC, School of Business, School Themes) 
Finally the theme is addressed by the Dean as one of the focus areas of the school as a whole "which all aim to enrich knowledge in the School's focus areas of entrepreneurship, family business, responsible business and economic development" (AUC, School of Business, Message From the Dean).

Much of the conversation from respondents at AUC centered around two features, the AUC Venture Lab and the need for entrepreneurship and innovation to address current social and economic struggles. The AUC Venture Lab, hosted at the AUC School of Business, was the first public incubator lab in the Middle East. While there were earlier private, income generating incubators, the "V Lab" was the first to be funded by a university with the mission to accept teams of entrepreneurs both from the AUC community and from outside it. The V Lab has grown both in size and offerings to participants and is now seen as not only as important to Egypt but also the broader region with as many as 8000 jobs created from more than 170 startups. Many of the individuals and teams trained and supported by the V Lab are seeking to address social struggles within Egypt and the region. This interest in tackling social struggles seems to stem directly from the previously discussed lead up to and the fallout from the Arab Spring.

Similar to AUC, the theme of entrepreneurship and innovation came up both in the OSB's vision and values. The vision is to "Transform business thinking in the MENA region" (AUB, OSB Brochure). One of the school's values is to be daring and is self-described as "We allow ourselves to work differently, experiment where others might caution, and explore as a means to keep ourselves fresh and relevant. Daring is a mindset that allows us to be innovative, entrepreneurial, and creative in our way!" (AUB, OSB Brochure). The focus on the theme is included in the marketing material in proclaiming 
that "The MBA program is the breeding ground for the leaders and entrepreneurs of tomorrow. We aim to develop students to excel in the constantly and rapidly changing business world" (AUB, OSB MBA Admission).

Respondents, very much in concert with the MBA admission material, linked the need for entrepreneurship and innovation to address current challenges with the intention for a better future. One respondent pointed to the success of entrepreneurial Lebanese abroad and, specifically, in the United States. While this was held as a clear value there was also a feeling of disappointment that the innovation has not happened in Lebanon itself. With MBA graduates moving to the Gulf or to the west there seems to be a certain level of brain drain within the innovation sphere in Lebanon. With the current economic and political struggles, it is not likely that this stagnant sector will gain traction soon.

In their MBA overview, AUS describes their program as being "designed to enable talented future leaders to make a vertical leap in their current career path, change job function or industry, or acquire an entrepreneurial toolkit to start or develop their own business" (AUS, School of Business Administration, MBA, Overview). Further, students in the MBA program choose from four concentration areas: Finance, Human Resources Management, Management Consulting, and Innovation and Entrepreneurship (AUS, School of Business Administration, Discover the AUS MBA Difference).

The stated value of innovation and entrepreneurship from AUS alumni is comparable to other respondents but there was also a sense that it was not a primary concern and may not be attainable. Respondents spoke of the theme positively but in a sense that it is for others in other places. The influence of the business hub of neighboring Dubai plays heavy at AUS but for all the city is, it is not known as a center 
of innovation. Dubai, and the AUE as a whole, does not have the same sense of needing innovation to address current challenges as there is in Egypt or Lebanon. Because the intern al business ecosystem is so well developed and also greatly influenced by outside firms there seems to be little room for determined innovation from within. The idea is that 'why should I risk something, including earning a lot less, when I know I can get a good job with big company X?'

\section{Family Business.}

The fourth theme that is associated with leadership and leadership education is that of family businesses. Historically, family business, both on the small scale and regional scale, has been a central component to Arab society. This theme continues today, albeit in modern forms. The discussion of the nexus of family business and leadership often came back to succession planning and how in-group (family members) are treated as compared to those in the business who are not part of the family (outgroup). A listing of data from documents and respondents can be found in Appendix N.

The School of Business Administration at AUS has a well-developed, wellfunded, and growing focus on family business. The theme is one of the areas of research for the school:

"Faculty in the department conduct research on Family Business with specific foci on research questions related to the goal-setting process of family business firms, succession and successor attributes, corporate governance and governance attributes of family business firms, and family business questions related to regional development and public policy. (AUS, School of Business Administration, Areas of Research). 
One of the 3 endowed chairs within the school is the Sheikh Saoud Bin Khalid Bin Khalid Al Qassimi Chair in Family Business (AUS, School of Business Administration, Deans Message). And annually several courses are taught that focus soling on family business including one exchange with Universidad Panamericana in Mexico (AUS, School of Business Administration, Chair in Family Business Activity Report).

In the UAE, one features of this theme that respondents spoke of was how closely related government and business are together. Some communicated that this degree of relation is so high that the line between is, at times, nearly indistinguishable. It was also reported that the relationship between family and business values, priories, and roles can be incongruent or in outright conflict. This, the close relationship between family and business matters, is congruent with the history of the region as discussed in Chapter 2.

AUB's OSB has a research hub focused on family business and an MBA track in Entrepreneurship and Family Business (AUB, OSB About Us; AUB, OSB, MBA Curriculum). The theme of family business from respondents seems to center around their medium size of, the difficulty to grow, the difficulty in transitioning between generational leadership, and how in-group and out-groups are dealt with differently. The medium sized seems to be a product of decades of instability, with the relative small size of the country, and geographic restrictions of having ocean to the west, a militarized boarder with Israel to the south, and the destruction to the east in Syria. The difficulty to grow may stem from the same factors. Additionally, respondents reported that many family businesses in Lebanon are in their $3^{\text {rd }}$ or $4^{\text {th }}$ generation. With this comes the common struggles of who is to take up leadership positions as the senior generation leaves. These dynamics are within the context of clear in-group and out-group 
categories. Those who are part of the in-group are part of the family and are treated differently (in terms of pay, responsibilities, and discipline) than those in the out-group, those who are not part of the family. This distinction seems to be common and accepted within the local culture.

At AUC there are 5 research areas, 1 of which is family business (AUC, School of Business, Who We Are). Additionally, the MBA program is "based on entrepreneurship, family business, responsible business, and economic development (AUC, School of Business, MBA Brochure 2019-2020). Finally, AUC's School of Business makes a direct connection between entrepreneurship and family business: Developing expertise on family businesses that started up as entrepreneurial ventures and currently represent more than $80 \%$ of total companies in the region is another area of focus for the School. Within entrepreneurship-this entails the development of high-quality case studies, an introduction of courses on family business, as well as collaboration with regional institutes in joint research analyzing succession plans, governance, and the effect of regulations, culture, and environment on family business. (AUC, School of Business, School Themes) In Egypt respondents talked about the importance of large family owned business and the need to support the many "micro" family businesses. The large family businesses, typically in manufacturing and construction, are looked to physically develop the country and also as a provider of many jobs. On the other end of the spectrum are the thousands of micro family businesses (coffee/tea shops, hookah hangouts, fruit stands, meet shops, etc.) found on the streets of Cairo and every other city and village in Egypt. The expressed interest in these family businesses is how to support them as Egypt 
attempts to transition to a mature economy. Thus, the concern is both economic ne as well as social.

\section{Management $>$ Leadership.}

The fifth theme gleaned from reviewing program documents, speaking with faculty, and conversion with alumni is a preference for management over leadership. One form of this preference was shown by the documents in the number of courses offered and various forms of management as compared to those courses offered on leadership. Faculty expressed a strong preference for management and did so to a degree that at times seemed defensive. Alumni also articulated a partiality for management but seemed to be more moderate than faculty. The same group also expressed some hope that the notion of leadership may, along with innovation, be answers to the current local and regional volatility.

Below is a report and analysis of the theme with a more complete list of data from documents and respondents found in Appendix O.

At AUB the MBA Curriculum states that the program "in existence at AUB since the mid-1940s, is committed to the highest standards of quality in graduate management education. It is a general management program..." (AUB, OSB, MBA Curriculum). A highlight of the program is that "rigorous academic theory is linked with real-world practice to build...management skills" (AUB, OSB Graduate Catalogue 2019-2020). Finally, the program requires students take three core courses focused on management (Advanced Seminar in Strategic Management, Operations and Process Management, Marketing Management) and offers seven elective courses concentrated on management (New Venture Management, Family Business Management, Human Capital Management, 
Change Management, Trending Issues in Management, Special Topics in Management, Services Marketing Management) to 1 core course on leadership (Leadership and Behavior in Organizations) (AUB, OSB Graduate Catalogue 2019-2020).

The preference for leadership at AUB's OSB was strongly stated by one faculty in staying that "this is an MBA program and so management administration is the predilection... leadership has a place and it's not at the center of the education we offer to students" (Hamza, AUB Faculty). An alum respondent in Lebanon had a similar opinion in saying "I think we all like the idea of leadership and innovation but the day-to-day is management and so that's what we need to learn fully" (Omar, AUB Alum). These and other akin reports, may, again, be explained by the need to respond to the recent and current environment. With so much change and uncertainty that is simultaneously local and regional, and potentially international, the natural response is to control, regulate, and manage the situation.

AUC's preference for management as seen through documents is clearly seen in an overview of the program that states "the MBA is an internationally recognized degree that focuses on helping future managers discover and further develop their skills for a rewarding career in business management..." (AUC, School of Business, MBA Brochure 2019-2020). A description of the MBA program posted online is quite similar: If you're searching for the knowledge and skills that will help you to pursue a management career, an MBA from AUC is the right step. It will introduce you to the tools you need to conduct constructive analysis and will help you develop a managerial perspective to address the challenges and seize the opportunities of today's ever-changing local, regional and global business environment. Take your 
first step towards the management ladder today. (AUC, School of Business, MBA Online Information)

Finally, the ratio of management course that are core (Managerial Economics, Financial Management, Managing Organizations in a Dynamic Environment, Managing Human Capital, Marketing Management, Operations Management for Competitive Advantage, Strategic Management) or elective (Investments and Portfolio Management, International Financial Management, Strategic Brand Management, Managing and Coordinating Supply Chains, Managing Dynamic Projects, Selected Topics in Operations Management, Construction Management, Strategic Management Of Innovation) leadership courses is 14 to 1 (AUC, School of Business, MBA Brochure 2019-2020).

Respondents also related their preference for management over leadership in saying "All leaders are managers but not all managers are leaders. So when I came to this program I wanted the managerial skills. The leadership skills, I'll need those if I become a leader in my organization." and "I know some of my classmates wanted to learn more about leadership but I think that's not important when you're still learning business. I wanted to know more about how do I do this, how do I do that" (Abdullah, AUC Alum; Aliyah, AUC Alum). Similar to Lebanon, this may be attributed to the context that has been recently and threatens to be again tumultuous. Further, much of the recent history of the Egyptian context has been of command and control. Through several presidents, most of whom were close to the USSR, the Egyptian economy and society was run from the top in an authoritative manor. The researcher also heard from 
some that leadership, along with social innovation, are possible answers to the country and region's woes. This, when approached, was done so hesitantly.

The School of Business Administration has, among a few, one area of research dedicated to management research where "faculty members in the Department of Management purse and active research agenda with work appearing in many top journals in Management including..." (AUS, School of Business Administration, Areas of Research). Graduates of the MBA program are expected to achieve "proficiency in the core business knowledge required of an executive manager" (AUS, School of Business Administration, MBA, Overview). And similar to the other programs, the ratio of management courses (Managerial Economics, Management Decision Analysis, Financial Management, Management Information Systems, Operations and Supply Chain Management, Managerial Accounting, Marketing Management, Strategic Management) to leadership is 8 to 1 .

Respondents from AUS saw management as preceding leadership and thus given preference. One faculty member stated that "Most of our students are younger and so we start with management. I think leadership is very important but if you don't have management as a foundation then you can't understand leadership" (Danna, AUS Faculty). Other respondents spoke of management being the default in companies they work within and thus it must be attended to first. Respondents also spoke of leadership for being for the few and management for the many. This will be covered in a following section. One possibility for the preference of management by these respondents is that the UAE is a more stable environment. As discussed earlier, the country and region have their share of insecurities but not nearly to the degree as other parts of the region. 
Perhaps this more secure atmosphere along with a cultural preference for jurisdictive governing creates a setting where management works and is preferred, so why change it?

This preference for management over leadership may, in part, be due to issues of defining exactly what is "management" and what is "leadership." Indeed, the lack of clarity and agreement on what constitutes leadership is a finding of this study and will be discussed later in this chapter.

\section{Professional and Personal Development.}

A final theme expressed broadly by alumni and reinforced by faculty and program documents is the interest in professional and personal development. Program documents consistently speak to developing students in both ways. Faculty reported an attentiveness in encouraging students to grow both in their careers and career potential but also in their private, inner lives. Alumni variously reported that they in fact did mature through their time in the MBA programs. A more complete list of data from documents and respondents is found in Appendix P.

The mission statement of the Department of Management conveys the developmental aim in asserting that "Our mission is to develop business leaders who are dedicated to the betterment of society...while focusing on continuous improvement and a commitment to excellence in learning, intellectual contributions, and service (AUC, School of Business, MBA Course Descriptions). Online this is similarly stated in one part of what the MBA offers is for alumni to become a global business leader in that that the program has "tailored our MBA program to become a stepping stone to new professional heights and aptitudes for all those seeking empowerment and growth. By incorporating a comprehensive body of knowledge and the right skills, the program will 
help you develop a managerial perspective... (AUC, School of Business, MBA, What We Offer).

Alumni respondents reported that "the biggest thing I got from my MBA was confidence. Having the credential and skills is important by my confidence is from graduating from the program..." and "AUC's MBA really, like really, wants you to grow and change. I did in some ways but I'm still learning from the time there. (Aliyah, AUC Alum; Malik, AUC Alum). Again, perhaps this focus on personal and professional development is in response to the unsteadiness of the environment. There was a sense that individuals knew that that growth was part of the aim of the programs and also what they could do for the future of their community.

The Dean's Message from School of Business Administration at AUS expresses that "a student experience in SBA is one of self-discovery and personal development, in an enriching and multicultural environment" (AUS, School of Business Administration, Deans Message). The MBA overview is alike in state the program "is designed to enable talented future leaders to make a vertical leap in their current career path, change job function or industry, or acquire an entrepreneurial toolkit to start or develop their own business" AUS, School of Business Administration, MBA, Overview). Finally, the MBA brochure says that the program "offers early- and mid-career professionals the opportunity to further their education, gain practical application skills, develop important networks and become part of global elite of MBA-qualified individuals. An AUS MBA will set you well on the pathway to achieving your professional and career goals" (AUS, School of Business Administration, MBA Brochure). 
Faculty reported a keen interest, not only in the academic and subsequent professional development of their students, but also in the development of the individual. Indeed, this was reinforced in the surprise the researcher had in how much time and attention AUS faculty gave for this study. Alumni reported that they grew significantly in knowledge and professional understanding. Similarly, respondents noted areas where they grew personally including interpersonally and intrapersonally.

The OSB at AUB often tied personal and professional development to challenging times. The graduate cataloged states that

OSB has been developing leaders and preparing them to excel in the constantly and rapidly changing business world. Through an immersive experience in business education, we will empower students to build a strong knowledge base and gain individualized skills to meet the economic and social challenges of the future. (AUB, OSB Graduate Catalogue 2019-2020)

In the same vein admission resources say "The MBA program is the breeding ground for the leaders and entrepreneurs of tomorrow. We aim to develop students to excel in the constantly and rapidly changing business world" (AUB, OSB MBA Admission).

Alum and faculty contributors to the study had similar views of this theme. One faculty member said that "Our program wants students to grow in several dimensions. Of course, we want them to be more skilled in business but also as people" (Zain, AUB Faculty). An alum stated that "It was a short program, less than 2 years, but I changed a lot in that time. ... Yes, it was both professional and personal development. I got skills to be better in business, but I also got to know more about the differences in people and who I am" (Yusef, AUB Alum). Similar to what was seen in Egypt, the intent to grow 
and develop seems to come from a necessity to have some sort of retort to a devolving local and regional situation. This attempt at a better tomorrow is, at least in part, to be pursued through personal and professional development.

\section{Leadership Is.}

Beyond the above, there were three themes of how some alumni of these MBA programs' view leadership. These themes are contrary to most modern leadership theories developed and expressed in the west. These themes are: leadership is enigmatic, leadership is in the few, and leadership is for the future.

Leadership is Enigmatic. Leadership is experienced as vague, ambiguous, or as nebulous. In some way's leadership is seen as unclear because of language and/or cultural interpretations. For some it is the distinction between the use of the word in religious and political connotations that are difficult to apply to the business world. In yet others, leadership and its essence is blurred because of contradictions and over use.

There should be no surprise that there is much lost in translation. There is the issue of translating from English to Modern Standard Arabic (MSA), which is understood by most in the region, but also the difficulty of translation into local dialects. In the MAME there are five distinct regional dialects that are, variously, distinct from each other. One respondent from the UAE, who is very knowledgeable about leadership theory noted that there is no one word that can be used to capture what 'leadership' means. Another respondent said that

Translation is a problem for us because 'leadership' doesn't not have a direct translation in Arabic. There are two words you could use either 'zaeem' or 'qeeada' but neither really mean the same thing as 'leadership' in English. Zaeem 
is like the head, elder, head man or boss. Qeeada is like command, direct, or control. It's most like management focused so it's confusing. (Ali, AUB Alum) Another aspect of this difficulty of translation is that leadership is not universally defined the same way in the west. "What I don't get is why there are so many versions of leadership. We learned about a whole list of different types and talked about them but most of them I didn't get. I couldn't relate to them because I haven't seen them in Lebanon. Maybe there're parts I've seen but like I've never seen a pure servant leader" (Layla, AUB Alum). Regardless of the translation being into MSA, a dialect, or because of its multiple meanings, the process of converting 'leadership' into an understood term in Arabic renders it unclear.

Another reason that 'leadership is unclear is that it is overused. One respondent from Egypt stated that "I know what leadership is but many Egyptians don't know it. Like they use the term all the time but don't know what it is. It's a fad term. ... I think we don't know what it is because we what is a leader in the government is not the same type of leader in business" (Amara, AUC Alum). The researcher had the sense from some respondents that 'leadership' is a hot topic and because of this use, or over use, the meaning and understanding of the term has been diluted.

Leadership is or the Few. A second theme is that leadership is for only a handful of individuals and not for everyone. Respondents connected this trend to politics, business, and to family. A Lebanese respondent said that "In Lebanon we think of our leaders as the PM or other top governmental people. Sometimes we would say a leader is in business but he has to be really well known" (Omar, AUB Alum). Another respondent spoke directly to the way they saw this in business in saying that "Leaders are 
the $\mathrm{C}$ level. I know that even if you're a manager or director you should lead but no one really thinks of this. If you ask, who leads this or that company you think of the top, the CEO or other Cos" (Yasen, AUS Alum). A third respondent spoke to leadership emanating from business or religious titles: "I still think leadership is a role. It's one that you get from your title and what you do. ... If you're and imam you're a leader, if you're a CEO you're a leader" (Malik, AUC Alum).

This theme of leadership being for a few was also extended from business and politics into family. One respondent from Lebanon said that "Leaders are the head. It's the same in business or in family. Like, there is only one leader of a group" (Ali, AUB Alum). In the Gulf a respondent connected leadership and family in by saying that: Anyone in the UAE who is part of a royal family is a sheikh. That title means you're a leader, or at least that your family is a leader in the country. We all know the big families and the leaders within them. They're only a few families that really lead the country and in them there are a few big men who you hear about all the time. The whole family plays a role but we know the names like Mohammed bin Rashid Al Maktoum, Hamad bin Mohammed Al Sharqi, Khalifa bin Zayed Al Nahyan. (Hakeem, AUS Alum)

As previously discussed, the connection of society and family runs deep in the MAME. It should thus come as no surprise that the cultural values that tend to patriarchal extend across business, politics, and other areas of modern life.

Leadership is in the Future. The final theme experienced by alumni respondents is that leadership is not something for today but for the future. Several reported that it takes time to become a leader and while they may not consider themselves 
a leader at the moment, they could see being so in the future. One facet of this is that leaders are seen as older: “Do I think I'm a leader? Not really, I guess no. I'm young I think of leaders as older. There ones who have a lot of experience and are known for what they do. ... I think I can get there at some point but it will take time" (Malik, AUC Alum). Leadership in the future is also considered within family dynamics: "I'll be a leader for sure. I am in small ways now but that is only with my peers and brothers and sisters. I want to be a leader known in Beirut, maybe politics, because that's where my family is" (Yusef, AUB Alum). Leadership was also tied to having a compelling identity that others can look up to: "If you are to be a leader you need a story that people know. That story has to be big and powerful and developed over time. That's why there aren't young leaders. Like you can have a position in the government that is high up but you're not really a leader. Maybe those people will someday" (Jamal, AUS Alum).

\section{Conclusion}

In addressing RQS2 9 themes were found that were in two distinct groups. The first group related leadership to local, regional, and international perspective and aim of impact; the effects of an ever-changing environment; the importance of entrepreneurship and innovation to move forward; how leadership plays into family business; that management is preferred over leadership; and that there is interest in professional and personal development. The second set of 3 themes related to some of the difficulties the alumni respondents had with the notion of leadership. Leadership was described as being enigmatic, for the few, and for the future. 


\section{CHAPTER 5}

\section{DISCUSSION}

\section{Summary}

The purpose of this was to explore the translation, adaptation, and application of western-developed leadership theories being applied in the MAME context. It is known that researched and practiced leadership theories and models are taught in the region, but it was not previously known as to what was done with this education.

This qualitative study takes an interpretivist methodology with an exploratory design. The sites investigated included three American-styled universities across the MAME: the American University of Beirut, the American University in Cairo, and the American University of Sharjah. Data collection took place both remotely and in person, and included sources from program documents, conversations with faculty, and interviews with alumni. This data, along with observations and analytical memos, was organized and analyzed using thematic analysis. In this, codes were applied, collected, grouped, arranged, and rearranged until themes emerged inductively.

The findings of the study are grouped into two segments. The first set comes from RQS1 and focuses on how leadership education is situated, what leadership is taught, and how it is taught. It was discovered that the notion of leadership, and thus leadership education, is highly valued. The nature of leadership theories taught are the same, common models offered to students in the United States. These concepts are taught using western written textbooks alongside case studies with an aim to be experiential and personal for each student. 
The second set comes from RQS2 and focuses on how alumni of these programs applied or adapted this education into their local contexts, and how history or culture has affected this adaptation. Two groups of findings emerged from RQS2. The first set consists of six themes relating to leadership education:

- Local, regional, and international perspectives and aim of impact

- Changing environment

- Entrepreneurship and innovation

- Family business

- Management over leadership

- Professional and personal development

The second set of three themes related directly to alumni's experiences with the notion of leadership. Many see leadership as an enigmatic concept, something that is for only a few people, and, if it is for them, it is in the future.

(With the study purpose, design, methodology, and findings in mind, we now turn to a treatise that includes a discussion as to how the researcher makes sense of these findings, the limitations of this study, its contributions, and opportunities of future research.

\section{Discussion}

The discussion of this study encompasses three pieces. First, the finding themes will be discussed with what we know from the literature. The conversation then turns to viewing the findings from a bioecological and competing commitments model. Finally, the researcher will discuss what surprised them in the depth of importance of in-group the 
out-group dichotomy, the disinterest in cross-cultural adaptation, and lack of discussion about the role of faith and values associated with it.

\section{Findings vis-à-vis What We Already Know}

It is important in this discussion to first apply the findings of this study to what was demonstrated in the literature review of Chapter 2. This includes researched and practiced leadership theory, the cross-cultural models introduced by Hofstede and matured by the current GLOBE Study, and the understanding of leadership within the Islamic context.

Great Man, Great Traits. The researcher repeatedly heard the current MAME understanding and practice of leadership being of the great man and trait strain. From which leaders where spoken of and how they were spoken about, there was a clear traitbased perspective. In speaking about the UAE, there was much conversation about the heads of the government, specifically President of the UAE Emir Sheikh Khalifa bin Zayed Al Nahyan and Vice President \& Prime Minister of the UAE Emir Sheikh Mohammed bin Rashid Al Maktoum who are also the leaders of their emirate. The traits these individuals have include their family and having their family name, following the path that their fathers before them took in being raised from a young age to eventually lead, and being male.

Great man and trait theory are also currently active in Egypt. The current leader of the country, President Sisi, follows a long tradition of Egyptian heads of state who embodies three essential traits of Egyptian leadership. Going back millennia, the pharaohs of ancient Egypt were responsible for having what it took to lead the religious establishment, the economic property of controlled lands, and all aspects of the military. 
This trend continued into the $20^{\text {th }}$ century and to the present. Prior to being president Sisi, was a general in the Egyptian military. Since taking over as president he has pursued a liberalization of the Egyptian economy. Finally, he has also portrayed himself as supporting the two major religious groups in the country, Sunni Islam and Coptic Christians. President Sisi follows the traits of Egypt's past leaders in being part of the military, directing the economy, supporting existing religious groups, and, of course, he is a man.

Trait theory can also be seen broadly in the discussions about family business. The primary trait of those in leadership positions, or in line to be leading, within family business are just that, a family member. Similar to regional political families who raise leaders within, family businesses in the MAME raise leaders internally. The trait of being part of the family, and typically being male, are two of the primary characteristics needed to eventually lead family businesses in the MAME. Great man and trait leadership theory are alive and well in the MAME.

Transactional. In considering leadership below the upper echelons, the most common form of leadership is perhaps transactional. As previously noted, this leadership theory is sometimes called "managerial leadership." This study's finding that management is preferred over leadership is congruent with the transactional style of leaders interacting with followers. In this form of leadership reward and punishment are the focus of motivating followers, that followers are not self-motivated and must be tightly controlled, and that followers have no other choice than to obey the leader. Further, this form of leadership is even more apparent when considering the strong ingroup, out-group orientation of the MAME. Those who are in-group, typically within an 
extended family, may be treated softly compared to those in the out-group. It seems that the MAME is content with transactional leadership and has not yet adopted other affiliated leadership models such as charismatic and transformational leadership.

The GLOBE Study. Within the GLOBE Study's Middle East group several outstanding leadership scores bear addressing in relation to this study's findings. The region's scores for both how much leadership should be team oriented and participative fall at the lowest end of the range of scores across the world. This means, that compared to other areas of the planet, the Middle East group values team orientation and participative forms of leadership the least. This is compatible with the finding of management being preferred over leadership. Similarly, the group score for charismatic leadership is also at the lowest end of the global range. This indicates a preference for leadership is not charismatic. Many view the opposite of charismatic leadership is being autocratic or transactional leadership.

Two other GLOBE Study outstanding leadership scores that bring weight to this research is that leaders are expected to be autonomous and self-protective. The Middle East cluster falls in the bottom quarter of the autonomy range and nearly at the top of the global self-protective range. These scores and their relation to the world-wide range could be connected to the importance of family businesses and the depth of separation between in-group and out-group members. In a region where autonomy is not highly valued, the individual is thus diminished and the group is elevated. Thus, the selfproactive value of leadership may not be viewed as that of or for individual but instead for the group. 
Out of the Desert. While a finding of this study is that the fluctuating context of the MAME directly affects the view of leadership there are also elements that have not changed and that still influence the region today. As show in the literature, the environment of the region is dominated by the desert that dramatically restricts the type and availability of economic resources. Control over these resources is thus of great concern for political, economic, and business interests alike. This in turn deepens the divide between in-group and out-group and leads to ongoing conflict. Out of this past and present context, characteristics of leadership have developed, solidified, and are valued and practiced. Some attribute them to Muhammed while others talk about the modern expression as being the IWE. Whether it be water or oil, the lack of resources in a desert region have led to a form of leadership that the MAME that have not kept up with the development of modern leadership theories.

With this understanding of this study's findings in relation to the literature review of leadership, cross-cultural leadership, and Muslim leadership values the discussion now turns to the importance of the individual within context.

\section{An Individual within Context}

This researcher makes sense of the findings through an understanding of the relationship between the concepts of bioecology and competing commitments. Bioecology is the branch of biology that studies the relationship between a living organism and the ecology around them. Competing commitments is the notion that individuals have multiple obligations that are innately incompatible, that must be dealt with, and eventually resolved. Together, these two concepts provide one explanation of how the existing literature and the findings of this study make some sense. Within 
multiple relationships, within the self, between the self and microsystems, and between systems there are contending obligations that must be resolved.

Within Self. Each individual, each biological entity, that lies at the center of the bioecological model has competing commitments, conflicts, and contradictions that are being understood and dealt with or repressed and pushed off to a later time. This was expressed in the findings of this study in that respondents reported the value of leadership but also that it was not for all or not for them now. Interviewees frequently expressed the competing commitment to holistically valuing leadership but also not for everyone, in fact only for the few. Similarly, leadership is valued but it is not for now and is only possible in the future. This is incongruent with the majority of contemporary western leadership theory that sees leadership as an aspect of everyday life that is constant and always present. Thus, there are conflicts internally, both between the professed value of and the lived understanding of leadership, as well as leadership education saying leadership is for anyone and is now, and the experience of individuals in the MAME that see it as for the few and for the future.

Between Self and Microsystem. It is also easy to understand the opportunity for there to be tension between the responsibilities to the self and from the microsystem. For those pursing an MBA in the MAME, three microsystems surround many individuals, play a significant role in their immediate environment and relate to their experience of leadership: their families, the domain of business in which the individual works, and, in particular, when the two come together in family business. It is well understood, in practice and from the literature, that the MAME places particular importance both on one's extended family and in extension to a broader in-group. For centuries, family and 
business, even when not a family business, have gone hand in hand. Historically, trade and commerce have been how the Middle East created, sustained, and controlled wealth by families and groups of families. This continues today in each of the three countries considered here. This was mirrored in this study's findings in that leadership is often attributed to the very top, patriarchal head of the family business or to those who are part of the family but no one else.

Between Self, Microsystem, and Larger Systems. In the theory of bioecology the self does not have direct contact with the two outer systems (the exosystem and macrosystems), but there is still influence between the self and each level of system. As stated before, both Lebanon and Egypt have recently or are currently experiencing significant political, economic, and societal disorder and change. The UAE is experiencing something similar because of its physical location and economic, political positioning alongside countries such as Saudi Arabia and in opposition to others including Iran. Several of the findings of this study seem to be an attempt of these individuals struggling to grow, change, or adapt to local and regional instability.

Professional and Personal Development. Within these unstable contexts, one answer for the individual is to grow and develop both professionally and personally. It was shown in the findings that programs (through their documents and the perspective of faculty) and alumni look to the internal growth of the individual as a response to external instabilities. There is an understanding that the individual at the center of many systems, and since the individual can't change each system to fit them well, they themselves must be developed to better respond to and impact the systems on which they do have influence. 
Management Preferred. Given this same context, it is no surprise that management is the default approach. In local, regional, and international contexts that are experienced as increasingly volatile, it is natural to attempt to cope and survive the context through control and management. From programs and alumni alike, there were consistent expressions that management was the baseline, standard foundation not only of an MBA program but as a response to the exo and macro systems within which the school and individuals are situated. While management is constantly conveyed as the preference, there also seems to be an emerging hope, or in the least understanding, that it may not be enough.

Leadership Emerging? While management is preferred, there is an increasing experience that it is insufficient for the challenges facing the MAME. Leadership, as an addition to sound management, is being considered by these young professionals as another tool to respond to unstable contexts. If this is the case, it is in the earliest stages of development. This would be congruent with the tension between individuals, the notion of leadership, their experience of leadership, and the resulting lack of codified local understanding of leadership, as well as a dearth of leadership theories developed in and for the region. The notion of leadership may be emerging in these MBA programs and through individuals as a mechanism or approach to more directly and successfully interact with the meso and macro forces in the region.

Entrepreneurship and Innovation. Similarly, the consistent and increasing focus on entrepreneurship and innovation may be a direct response by micro systems (schools and programs) and individuals to the current transitional context. Each program had a focus on creating fresh product lines, new services, and improvements on how these are 
delivered to followers and customers alike. Like leadership coming to fill where management has been short, there is an understanding that what industry in the MAME has been is not addressing the needs of today or requirements of tomorrow.

Time. The experience of respondents and their view of leadership must be understood both through multiple systems but also considering these systems across time. Thus, this study, its participants, and its finding are all bound by the bioecological understanding of and the competing commitments of time. Time in the bioecological sense is concerned with both sociohistorical and personal conditions. The sociohistorical conditions include recent and present happenings as well as those that previously affected systems (micro through macro) that brought the individual and society to today.

Past sociohistorical events of the region or countries include regional wars, internal civil strife, the addition or subtraction of resources and material wealth, changes in government, and other regional or international interactions. For example, in Egypt these past sociohistorical events can go back thousands of years with those experienced by recent generations include the coming and going of outside influences from the British, to Soviet Union, to the United States; the revolutions of 1952 and 1971; the opening and expansion of the Suez Canal; and regional wars in 1956, 1967, and 1973.

Recent or present sociohistorical events include many that have already been mentioned, such as fallout from the Arab Spring, economic instability due to international tensions as well as emerging health crises, pollical regime change, and internal social discord. For example, recent sociohistorical events in Lebanon include minor internal direct effects form the Arab Spring, massive effects coming externally from the Arab Spring and subsequent Syrian civil war, the brain-drain of educated young adults heading 
to the west and the Gulf region, ongoing internal tensions between Sunni-Shia and Muslim-Christian, an unsettled boarder region to the south, and an internal political crisis that has led to lapses in economic reforms and payments to international organizations.

If this study had been conducted 20 years ago or 20 years from now, these sociohistorical factors may be very dissimilar resulting in different thematic findings. The value of, the relationship to, and understanding of leadership and leadership development would be expected to differ from time to literal time. Continued armed conflict, political strife, and economic uncertainty will continue to add to the sense of a chaotic, tumultuous environment and a lessening of the interest and ability to pursue the development of theories and practices of leadership. Alternatively, if a form of lasting stability comes over the region there may be great opportunities for individuals and institutions to invest in localized leadership theory and leadership development.

Not only are individuals in this study dealing with time in a sociohistorical frame but also in a personal scaffold of the particulars of their present place in life. Their ages ranged from early 20 s into mid 40 s, some individuals have a spouse while some do not, some do not have children and some do, many are living and working in their countries of origin, some have significant experience and hold management positions while some are attempting to make the transition into middle management levels, and so on. Each individual of this study is attempting to resolve their competing commitments vis-à-vis leadership that are internal, between themselves and their systems, and are doing so within a particular timeframe that is sociohistorical and personal. 


\section{Surprises}

The researcher was surprised by three items resulting from this study. The first is the degree of acceptance of divisions between in-group and out-group. Second, the nearly non-existent consideration in formal education for cross-cultural adaptation. And finally, the little to no contemplation on the effects of religion.

In-Group, Out-Group. It was expected that there would be some acceptance of privileges given to in-group members at the expense of those in the out-group. However, what was not expected was the degree to which this was true. Though expressed differently in each local context, each country had clear examples of the importance of in-group and out-group members. In the UAE, the importance of in-group, out-group context can be attributed to the number of Emiratis as compared to residents who are not nationals. Approximately $12 \%$ of those living in the UAE are national citizens with the other $88 \%$ being long-term, non-citizen nationals. This overwhelming majority of the population being, in essence, long-time visitors creates an intense 'otherness.' Respondents in Egypt talked about in-group, out-group being of the economic variety. Unlike the UAE, most residents of Egypt are citizens and there is great division economically across the spectrum of the large population. It was also noted by respondents that this in-group, out-group separation happens between Egyptians and westerners. Westerns are generally given privileges that many Egyptians will not give to their fellow citizens.

Little Culture. Another surprise was the general lack of cross-cultural attention given in MBA leadership education. Several faculty talked about having a "component" of cross-cultural consideration but it seemed as if it was always a small, added on 
module. Further, alumni respondents acknowledged the importance of national cultural differences but did not seem to know how to adequately work with it. There also was little interest or conversation regarding organizational culture. The researcher wonders if there is a connection here with the lack of clarity and understanding of leadership. Culture and leadership are alike in that they are very much intangible and ethereal. In a region of the world where the context is typically in flux, culture and leadership may not be as useful as those understandings that are tangible and immediately applicable, such as management and administration.

Absence of Faith. A final facet of this study that was expected but not found was the role of faith. Rarely did faith, Islam or otherwise, come up during the study. This was a surprise as anyone who has spent time in the MAME feels the constant influence of religion in, what seems like, all areas of life and society. It is also a generality that those with more education tend to be more liberally minded. This researcher wonders if the lack of conversation about faith stems in part from these respondents being well-educated and having privileged places in society. Another possibility could be that respondents did not report on the influence of faith because the researcher, being an outsider, may not have been perceived as someone to talk about with. 


\section{Conclusion}

The findings of this study can be understood through the concept of competing commitments within bioecology theory. Bioecology theory is how an organism and its levels of environment mutually influence each other over time. Competing commitments state that each person has obligations that cannot all be attended to, are thus in conflict, from which there must be some resolution. The long term and continuing state of instability in the MAME deeply affects individuals with their internal tensions, the pressures of large external systems on them, all of which are moderated by sociohistorical and personal events in time. These interactions have deeply affected how individuals understand, experience, and view leadership.

\section{Limitations}

The limitations of this study include seven boundaries that at the same time are both distinct and linked. First, the lack of previous studies provides little context and insight for this researcher. Second, the methods of the study are limited to data being gathered through documents, interviews, and observations. Third, the scope of this study is significantly limited in gathering data from graduates of three advanced-degree programs, all of which have an unabashed American business perspective. Fourth, the sample size and sample profile are limited to a few dozen individuals who have the opportunity and privilege to attend prestigious institutions of higher education. Fifth, in terms of time, both the time needed to complete the study was restricted due to natural necessities of completing a dissertation and by current events in the region. Sixth, the biases of the researcher deeply affect the study not only in differences in language and culture but given the etic position of the researcher as an outsider to the place and people 
being studied. Lastly, because of the above-mentioned limitations it is important to be clear that this study is not generalizable.

The scope of this study was necessarily limited. The criteria that defined the scope was limited to institutions of higher education in the MAME that have the highest regionally ranked graduate business programs. This criterion resulted in the three sites all being universities that are deeply rooted in and proud of their American-styled education. The sample breadth and depth of documents and interviewees are also limited. While the sample of documents were evenly distributed and fairly comprehensive it is acknowledged that these, being primarily publicly available, reflect a certain picture each program wants to project.

There are also limitations concerning the sampling of individuals interviewed. First, the sample size is small compared with the total number of alumni from these programs. Second, sample selection relied on the willingness of interviewees both to be interviewed but also to find others who may be interested. This snowball sampling style has inherent limitations and biases built in. Third, the sample profile of alumni tended to be highly educated, having significant wealth, and to have a status in their home communities. Finally, the data provided is self-reported, which is limited in-and-of itself.

Time and timing are another limitation. The time available to conduct this study was necessarily bounded by completing the preceding qualifications and the final oral defense and written deliverable prior to graduation.

Perhaps the most important limitation is the set of conglomerated limits of the researcher. There are practical obstacles the researcher brought with their presence such as not knowing each dialect of Arabic spoken. While the researcher does speak Arabic, 
they do not know all the local, particular expressions of the language. This is also true for the cultural values and practices of each context. The researcher has spent years living, visiting, working, and studying in the region but they are still not, and most likely will never be, proficient in understanding and working with the regional, country, or local cultures. This researcher, being an outsider, who is attempting to understand what only insiders can know and convey, produces the classic emic-etic difficulty. There are many limitations when a researcher comes from an etic, outsider perspective while attempting to understand the emic insight from those who are within the social group. Being an outsider, the researcher has a privileged place but also a limited view of the questions being asked, and findings uncovered.

The amalgamation of the limitations previously listed above makes this study not generalizable. The lack of previous study on this subject both necessitated this investigational study and limited it by not providing previously understood context. Most studies have a lineage of research to draw from and reflect back on. This is not the case here. Research in and on the Middle East is not nearly as expansive as it is in the west. Specifically, this is true when it comes to the understanding of leadership theories in the MAME and how leaders are developed. This lack of context dictated that this study be exploratory in design and execution and not explanatory or hypothesis testing. The researcher would have very much preferred to conduct a study that sought to explain or experiment but acknowledges that is for future study.

\section{Contributions and Future Research}

The gap this study was designed to attend to is the lack of research, literature, and general understanding on how western leadership theories are applied in the MAME. 
One contribution of this study is that it is now known what and how leadership is taught at prominent American styled MBA programs in the MAME. It was found that the leadership being taught is westerner developed and taught through using western textbooks, case studies, with an emphasis on personal leadership development. Knowing this, this study took the next step of questioning alumni as to what they did with this leadership education, and nine themes emerged. One set of themes concerned how these individuals view leadership: the concept is enigmatic, it is for the few, and for the future. The second set of themes focused on where leadership is applied: locally, regionally, internationally; in a changing environment; through entrepreneurship and innovation; in family business; secondary to management; and in professional and personal development.

Another contribution of this study is to begin to make some meaning of the findings. Particular attention was given to the distilled nine themes. In one respect there was a tension within individuals between the espoused value of leadership and their lived experience of leadership. Additionally, the effects between the individual micro, exo, and macro systems were considered in relation to the other findings. This environment, the combination of context and time, has greatly affected individuals in their understanding of and experience of leadership.

The contribution of these findings, along with the proposed interpretation, sets a foundation for future research and development of leadership theory and practice in the MAME. This breath of research could be expanded beyond the world of business education. Related to the works of Datar, Garvin, and Cullen (2010) in Rethinking the $M B A$, Moldoveanu and Martin (2008) in The Future of the MBA, and Amann et. al. 
(2011) in Business Schools Under Fire, specific research could be conducted in the Middle East on the theory that leadership, along with entrepreneurship and innovation, are emerging responses to the perceived failures of management and the standard way of doing things. The methods of study could also be expanded into a mixed methods approach in order to gather more data from more sources. It is also important to encourage researchers who are native to the region to be encouraged to take up this research as they will have understandings and insights that those in the out group do not. This study is unique in that it offers a foundation for an area of researcher not previously explored and, because of this, there is much, much more to be discovered. Ultimately, it is the hope of the researcher that with enough research and experiential knowledge, models of leadership for and developed in the MAME might emerge. 


\section{References}

Abu-Sin, A. (1981). Islamic Administration. Dubai, UAE: The Contemporary Press.

Adair, J. (2010). The leadership of Muhammad. London, UK: Kogan Page.

Adnan Khurshid, M., Al-Aali, A., Ali Soliman, A., \& Mohamad Amin, S. (2014).

Developing an Islamic corporate social responsibility model (ICSR). Competitiveness Review, 24(4), 258-274.

Akhavan, M. (2017). Development dynamics of port-cities interface in the Arab Middle Eastern world-The case of Dubai global hub port-city. Cities, 60, 343-352.

Al-Burey, M. (1985). Administrative development: An Islamic perspective. London, UK: KPI.

Al-Kandari, A., \& Gaither, T. K. (2011). Arabs, the west and public relations: A critical/cultural study of Arab cultural values. Public Relations Review, 37(3), 266-273.

Al-Kubati, G., Al-Dubai, A., Mackenzie, L., \& Pezaros, D. P. (2015, June). Stable infrastructure-based routing for Intelligent Transportation Systems. Communications (ICC), 2015 IEEE International Conference, IEEE, 3394-3399.

Al-Kusbaisy, A. (1985). A model in the administrative development in Arab gulf countries. The Arab Gulf, 17(2), 29-48.

Al-Mazrouei, N. S. (2016). The UAE and Saudi Arabia: Border Disputes and International Relations in the Gulf. London, UK: IB Tauris.

Al-Omari, J. (2008). Understanding the Arab culture. Oxford, UK: Oxford Press.

Al-Tirmidhi. (2007). Jami' at-tirmidhi. (vol. 1-6). (Abu Khaliyl, Transl.). Riyadh, Saudi Arabia: Darussalam. (Original work published in 886). 
Albrecht, H., \& Bishara, D. (2011). Back on horseback: The military and political transformation in Egypt. Middle East Law and Governance, 3(1-2), 13-23.

Ali, A. J. (1986). Human resource problems and development in the Arab World: A challenge to multinational corporations. Academy of International BusinessSoutheast Proceedings, 267-274.

Ali, A. J. (1989). A comparative study of managerial beliefs about work in the Arab states. Advances in international comparative management, 4, 95-112.

Ali, A. J. (1990). Management theory in a transitional society: The Arab's experience. International Studies of Management \& Organization, 20(3), 7-35.

Ali, A. J. (1995). Cultural discontinuity and Arab management thought. International Studies of Management \& Organization, 25(3), 7-30.

Ali, A. J. (2005). Islamic perspectives on management and organization. Northampton, MA: Edward Elgar.

Ali, A. J. (2009). Islamic perspectives on leadership: a model. International Journal of Islamic and Middle Eastern Finance and Management, 2(2), 160-180.

Ali, A. J. (2010). Islamic challenges to HR in modern organizations. Personnel Review, 39(6), 692-711.

Ali, A. J. (2014). Business ethics in Islam. Northampton, MA: Edward Elgar.

Ali, A. J. (2015). Islamic work ethic in a dynamic world. Religions: A Scholarly Journal, $1,11-21$.

Ali, A. J. \& Al-Owaihan, A. (2008). Islamic work ethic: a critical review. Cross Cultural Management: An International Journal, 15(1), 5-19. 
Ali, A. J. \& Camp, R. C. (1995). Teaching management in the Arab world: Confronting illusions. International Journal of Educational Management, 9(2), 10-17.

Ali, A. J., \& Al-Shakis, M. (1985). Managerial value systems for working in Saudi Arabia: An empirical investigation. Group \& Organization Studies, 10(2), 135 151.

Ali, A. J., \& Weir, D. (2005). Islamic Perspectives on Management and Organization. Journal of Management, Spirituality \& Religion, 2(3), 410-415.

Ali, M. M. (2011). Holy Quran. Ahmadiyya Anjuman Ishaat Islam Lahore USA.

Ali, S. R., Liu, W. M., \& Humedian, M. (2004) Islam 101: Understanding the religion and therapy implications. Professional Psychology: Research and Practice, 6, $635-642$.

Alvesson, M., \& Sveningsson, S. (2013). Essay: Authentic leadership critically reviewed. In Authentic Leadership. Edward Elgar Publishing. https://doi.org/10.4337/9781781006382

American University of Sharjah, Fast Facts. (2019). Retrieved from https://www.aus.edu/fast-facts-fall-2018

American University of Sharjah, History. (2019). Retrieved from

https://www.aus.edu/history

Ather, S. M., \& Sobhani, F. A. (2007). Managerial leadership: An Islamic perspective. IIUC Studies, 4, 7-24.

AUB, Facts and Figures. (2019). https://www.aub.edu.lb/aboutus/Pages/facts.aspx

AUB, History. (2019). https://www.aub.edu.lb/aboutus/Pages/history.aspx

AUB, MBA. (2019). https://www.aub.edu.lb/osb/MBA/Pages/default.aspx 
AUC, History. (2019). https://auc100.aucegypt.edu/history/

AUC, New Cairo Campus. (2019). https://www.aucegypt.edu/about/visitorinformation/new-cairo-campus

AUC, School of Business, About. (2019). http://schools.aucegypt.edu/Business/about/Pages/default.aspx

AUC, School of Business, Accreditation. (2019). http://schools.aucegypt.edu/Business/about/Pages/Accreditation.aspx

Avolio, B. J., \& Gardner, W. L. (2005). Authentic leadership development: Getting to the root of positive forms of leadership. The Leadership Quarterly, 16(3), 315-338. https://doi.org/10.1016/j.leaqua.2005.03.001

Avolio, B. J., \& Walumbwa, F. O. (2014). Authentic leadership theory, research and practice: Steps taken and steps that remain. In D. V. Day (Ed.), Oxford Library of Psychology. The Oxford Handbook of Leadership and Organizations (p. 331356). Oxford University Press. https://psycnet.apa.org/record/2014-16828-016

Avolio, B. J., Bass, B. M., \& Jung, D. I. (1999). Re-examining the components of transformational and transactional leadership using the Multifactor Leadership. Journal of Occupational and Organizational Psychology, 72(4), 441462. https://doi.org/10.1348/096317999166789

Ayman, R., Chemers, M. M., \& Fiedler, F. (1995). The contingency model of leadership effectiveness: Its levels of analysis. The Leadership Quarterly, 6(2), 147-167. https://doi.org/10.1016/1048-9843(95)90032-2

Bano, M., \& Kalmbach, H. E. (Eds.). (2011). Women, Leadership, and Mosques: Changes in Contemporary Islamic Authority. Lieden, Netherlands: Brill. 
Bass, B. M. (1997). Does the transactional-transformational leadership paradigm transcend organizational and national boundaries?. American Psychologist, 52(2), 130-139. https://doi.org/10.1037/0003-066X.52.2.130

Bass, B. M. (1999). Two decades of research and development in transformational leadership. European Journal of Work and Organizational Psychology, 8(1), 932. https://doi.org/10.1080/135943299398410

Bechtold, M. C. (2014). From desert to destiny: Knowledge, attitudes and practices of Saudi Arabian leadership. International Journal of Human Resources Development and Management, 14(1-3), 157-169.

Beekun, R., \& Badawi, J. (1999). The leadership process in Islam. ProteusShippensbrug, 16, 33-38.

Belhaj, F. (2018). Fixing the education crisis in the Middle East and North Africa. The World Bank. http://www.worldbank.org/en/news/opinion/2018/11/13/fixing-the$\underline{\text { education-crisis-in-the-middle-east-and-north-africa }}$

Bickerton, I. J., \& Klausner, C. L. (2017). A history of the Arab-Israeli conflict. Upper Saddle River, NJ: Pearson Prentice Hall.

Blake, R. R., Mouton, J. S., \& Bidwell, A. C. (1962). Managerial grid. Advanced Management - Office Executive, 1(9), 12-15.

Blom, M. (2016). Leadership studies_-A Scandinavian inspired way forward?. Scandinavian Journal of Management, 32(2), 106-111.

Bloom, J., \& Blair, S. (2002). Islam: A thousand years of faith and power. New Haven, CT: Yale University Press. 
Blunt, P., \& Jones, M. L. (1997). Exploring the limits of Western leadership theory in East Asia and Africa. Personnel Review, 26(1/2), 6-23.

Bochman, D. J., \& Kroth, M. (2010). Immunity to transformational learning and change. The Learning Organization. https://doi.org/10.1108/09696471011043090

Boje, D. (2000). The Isles Leadership: The Voyage of the Behaviorists. The Leadership Box. Marquette, MI : Northern Michigan State University.

Bond, M. H. (2002). Reclaiming the individual from Hofstede's ecological analysis--A 20-year odyssey: Comment on Oyserman et al. (2002). Psychological Bulletin, $128(1), 73-77$.

Boulais, N. A. (2002). Leadership in children's literature: Qualitative analysis from a study based on the Kouzes and Posner leadership framework. Journal of Leadership Studies, 8(4), 54-63. https://doi.org/10.1177/107179190200800405

Brath, F. (2009). Nomads of south Persia: The Basseri Tribe of the Khamseh Confederacy. Boston, MA: Spaight.

Braudel, F. (1995). The Mediterranean and the Mediterranean world in the age of Philip II (Vol. 2). University of California Press.

Brayman, A. (1992). Charisma and Leadership in Organizations. London, UK: Sage.

Bronfenbrenner, U. (1977). Toward an experimental ecology of human development. American psychologist, 32(7), 513-531.

Bronfenbrenner, U. (1979). The ecology of human development. Boston, MA: Harvard University Press.

Bronfenbrenner, U. (1992). Ecological systems theory. London, UK: Jessica Kingsley Publishers. 
Bronfenbrenner, U. (2005). Making human beings human: Bioecological perspectives on human development. Thousand Oaks, CA: Sage.

Bronfenbrenner, U., \& Ceci, S. J. (1994). Nature-nuture reconceptualized in developmental perspective: A bioecological model. Psychological review, 101(4), 568.

Bronfenbrenner, U., \& Morris, P. A. (1998). The ecology of developmental processes. Theorectical models of human development, 1(5), 993-1028.

Burns, J. M. (1978). Leadership. New York, NY: Harper.

Butler, A. J. (1902). The Arab conquest of Egypt and the last thirty years of the Roman dominion. Oxford, UK: Clarendon Press.

Cambridge Institute for Sustainability Leadership. (2017). Global definitions of leadership and theories of leadership development. University of Cambridge. Retrieved from https:/www.cisl.cam.ac.uk/resources/sustainabilityleadership/global-definitions-of-leadership

Cambridge Institute for Sustainability Leadership. (2017). Global definitions of leadership and theories of leadership development. Cambridge, UK: University of Cambridge. https://www.cisl.cam.ac.uk/resources/sustainabilityleadership/global-definitions-of-leadership

Cameron, K. S. (2008). Paradox in positive organizational change. The Journal of Applied Behavioral Science, 44(1), 7-24. https://doi.org/10.1177/0021886308314703

Campbell, R. A. (2008). Leadership succession in early Islam: Exploring the nature and role of historical precedents. The Leadership Quarterly, 19(4), 426-438. 
Carlyle, T. (1840). Sartor Resartus: The Life and Opinions of Herr Teufelsdröckh. Heroes and Hero-worship (Vol. 1). New York, NY: Collier.

Carroll, J. M., \& Swatman, P. A. (2000). Structured-case: a methodological framework for building theory in information systems research. European journal of information systems, 9(4), 235-242. https://link.springer.com/article/10.1057/palgrave.ejis.3000374

Cervone, H. F. (2007). Working through resistance to change by using the "competing commitments model". OCLC Systems \& Services: International digital library perspectives, 23(3). 250-523. Retrieved from https://doi.org/10.1108/10650750710776378

Chanzanagh, H. E., \& Akbarnejad, M. (2011). The meaning and dimensions of Islamic work ethic: Initial validation of a multidimensional IWE in Iranian society. Procedia-Social and Behavioral Sciences, 30, 916-924.

Chhokar, J. S., Brodbeck, F. C., \& House, R. J. (Eds.). (2013). Culture and leadership across the world: The GLOBE book of in-depth studies of 25 societies. London, UK: Routledge.

CIA World Factbook, Lebanon.

Cleveland, W. L. (2018). A history of the modern Middle East. Routledge.

Cleveland, W. L., \& Bunton, M. (2016). A history of the modern Middle East. Hachette, UK: Westview.

Cohens, I. \& Harrison, B. (n.d.). Trait theory of leadership. https://oer.missouriwestern.edu/rsm424/chapter/trait-theory-of-leadership/ 
Cole, J. R., \& Kandiyoti, D. (2002). Nationalism and the colonial legacy in the Middle East and Central Asia: Introduction. International Journal of Middle East Studies, 34(2), 189-203.

Colla, E. H. (2003). " Non, non! Si, si!": Commemorating the French Occupation of Egypt (1798-1801). Mln, 118(4), 1043-1069.

Collinson, D. (2012). Prozac leadership and the limits of positive thinking. Leadership, 8(2), 87-107. https://doi.org/10.1177/1742715011434738

Conger, J. A. (1989). The charismatic leader: Behind the mystique of exceptional leadership. Jossey-Bass.

Conger, J. A., \& Kanungo, R. N. (1998). Charismatic leadership in organizations. Thousand Oaks, CA: Sage Publications.

Cooper, A. S. (2012). The oil kings: How the US, Iran, and Saudi Arabia changed the balance of power in the Middle East. New York, NY: Simon \& Schuster.

Cooper, C. D., Scandura, T. A., \& Schriesheim, C. A. (2005). Looking forward but learning from our past: Potential challenges to developing authentic leadership theory and authentic leaders. The Leadership Quarterly, 16(3), 475-493. https://doi.org/10.1016/j.leaqua.2005.03.008

Cordesman, A. H. (2018). Bahrain, Oman, Qatar, and the UAE: Challenges of security. Routledge.

Costas, J., \& Fleming, P. (2009). Beyond dis-identification: A discursive approach to self-alienation in contemporary organizations. Human relations, 62(3), 353-378. https://doi.org/10.1177/0018726708101041 
Creswell, J. W., Shope, R., Plano Clark, V. L., \& Green, D. O. (2006). How interpretive qualitative research extends mixed methods research. Research in the Schools, 13(1), 1-11.

Crouwel, J. (1987). Wheeled vehicles and ridden animals in the ancient Near East. Lieden, Netherlands: Brill.

CU, History. (2019). https://cu.edu.eg/History

CU, Master of Business Administration. (2019). http://postgraduate.foc.cu.edu.eg/mba$\underline{\text { major-1 }}$

Cullina, H. T. (2016). Leadership development in Egypt: How indigenous managers construe Western leadership theories (Unpublished doctoral dissertation). HeriotWatt University, United Kingdom.

da Cruz, M. R. P., Nunes, A. J. S., \& Pinheiro, P. G. (2011). Fiedler's Contingency Theory: Practical Application of the Least Preferred Coworker (LPC) Scale. IUP Journal of Organizational Behavior, 10(4). http://eds.b.ebscohost.com/eds/pdfviewer/pdfviewer?vid=0\&sid=51ca60dc-6d8e4862-8860-20d6d6cdfebe\%40sessionmgr101

Daly, M. W. (1998). The cambridge history of Egypt (Vol. 1). Cambridge University Press.

Den Hartog, D. N., House, R. J., Hanges, P. J., Ruiz-Quintanilla, S. A., Dorfman, P. W., Abdalla, I. A., ... \& Akande, B. E. (1999). Culture specific and cross-culturally generalizable implicit leadership theories: Are attributes of charismatic/transformational leadership universally endorsed?. The leadership quarterly, 10(2), 219-256. https://doi.org/10.1016/S1048-9843(99)00018-1 
Denzin, N. K., \& Lincoln, Y. S. (2005). Handbook of qualitative research. Thousand Oaks, CA: Sage.

Derue, D. S., Nahrgang, J. D., Wellman, N. E. D., \& Humphrey, S. E. (2011). Trait and behavioral theories of leadership: An integration and meta-analytic test of their relative validity. Personnel Psychology, 64(1), 7-52.

Dhabi, A. (2016). United Arab Emirates. Countries and Territories of the World, 444.

Dickson, M., Den Hartog, D., \& Mitchelson, J. (2003). Research on leadership in a crosscultural context: Making progress and raising new questions. The Leadership Quarterly, 14(6): 729-768.

Dictionary.com, Arab. https://www.dictionary.com/browse/arab

Dienesch, R. M., \& Liden, R. C. (1986). Leader-member exchange model of leadership: A critique and further development. Academy of management review, 11(3), 618634. https://doi.org/10.5465/amr.1986.4306242

DiMaggio, P. (1997). Culture and Cognition. Annual Review of Sociology, 23(1), 263287.

Diwakar, V. (2015). The effect of armed conflict on education: evidence from Iraq. The Journal of Development Studies, 51(12), 1702-1718.

Djalili, M. R., \& Kellner, T. (2014). Iran's Syria policy in the wake of the 'Arab Springs'. Turkish review, 4(4), 396-405.

Dorfman, P. W., Howell, J. P., Hibino, S., Lee, J. K., Tate, U., \& Bautista, A. (1997). Leadership in Western and Asian countries: Commonalities and differences in effective leadership processes across cultures. The Leadership Quarterly, 8(3), 233-274. 
Dorfman, P., Javidan, M., Hanges, P., Dastmalchian, A., \& House, R. (2012). GLOBE: A twenty year journey into the intriguing world of culture and leadership. Journal of World Business, 47(4), 504-518.

Egypt. (2019). In CIA World Fact Book. https://www.cia.gov/library/publications/theworld-factbook/geos/ae.html

Ehteshami, A. (2007). Globalization and geopolitics in the Middle East: Old games, new rules. London, UK: Routledge.

Ekvall, G., \& Arvonen, J. (1991). Change-centered leadership: An extension of the twodimensional model. Scandinavian Journal of Management, 7(1), 17-26.

El Mallakh, R. (2014). The Economic Development of the United Arab Emirates (RLE Economy of Middle East). Routledge.

El-Fathaly, O., \& Chackerian, R. (1983). Administration: The forgotten issue in Arab development. In Ibrahim, I. (Ed.) Arab Resources. London, UK: Croom Helm, $193-212$

Eldawy, D. (2019). A Fragile Situation: Will the Syrian Refugee Swell Push Lebanon Over the Edge? Migration Policy Institute. https://www.migrationpolicy.org/article/syrian-refugee-swell-push-lebanon-overedge

Erdogan, B., \& Bauer, T. N. (2014). Leader-member exchange (LMX) theory: The relational approach to. The Oxford Handbook of Leadership and Organizations, 407-434.

Esposito, J. L. (2005). Islam: The straight path (Vol. 4). New York, NY: Oxford University Press. 
Essid, Y. (1995). A critique of the origins of Islamic economic thought (Vol. 11). Brill.

Evans, M. G. (1996). RJ House's “A path-goal theory of leader effectiveness". The Leadership Quarterly, 7(3), 305-309. https://doi.org/10.1016/S1048$\underline{9843(96) 90021-1}$

Evans, Martin G. (1970). The effects of supervisory behavior on the path-goal relationship. Organizational Behavior and Human Performance. 5(3): 277-298.

Expert Program Management. (n.d.) https://expertprogrammanagement.com/2019/05/blake-mouton-grid/

Exploratory research. Research-Methodlogy.net. https://researchmethodology.net/research-methodology/research-design/exploratory-research/

Fanak, United Arab Emirates, Geography. (2015). https://fanack.com/united-arabemirates/geography/

Faour, M. A. (2007). "Religion, demography, and politics in Lebanon." Middle Eastern Studies 43(6), 909-921.

Faqih, I. (1988). Glimpses of Islamic history. Delhi, India: Adam.

Fawcett, L. (Ed.). (2016). International relations of the Middle East. Oxford University Press.

Fellows, S. (2013). Role Theory. Encyclopedia of management theory (H. K. Kessler, Ed.). Thousand Oaks, CA: Sage Publications. http://dx.doi.org/10.4135/9781452276090.n233

Fernandez, C. F., \& Vecchio, R. P. (1997). Situational leadership theory revisited: A test of an across-jobs perspective. The Leadership Quarterly, 8(1), 67-84. https://doi.org/10.1016/S1048-9843(97)90031-X 
Fiedler, F. E. (1978). The contingency model and the dynamics of the leadership process. In Advances in experimental social psychology, 11. 59-112. Academic Press. https://doi.org/10.1016/S0065-2601(08)60005-2

Fiedler, F.E. (1967). A theory of leadership effectiveness. New York, NY: McGraw-Hill.

Field, R. H., \& Andrews, J. P. (1998). Testing the incremental validity of the VroomJago versus Vroom-Yetton models of participation in decision making. Journal of Behavioral Decision Making, 11(4), 251-261. https://doi.org/10.1002/(SICI)1099$\underline{0771(1998120) 11: 4<251:: A I D-B D M 300>3.0 . C O ; 2-2}$

Fisher, W. B. (2013). The Middle East (Routledge Revivals): A physical, social and regional geography. New York, NY: Routledge.

Ford, J., \& Harding, N. (2011). The impossibility of the 'true self' of authentic leadership. Leadership, 7(4), 463-479. https://doi.org/10.1177/1742715011416894

Freedman, P. (2008). Out of the East: Spices and the medieval imagination. New Haven, CT: Yale University Press.

Friedman, T. L. (2000). The Lexus and the olive tree: Understanding globalization. New York, NY: Pan Books.

Fromkin, D. (2001). A peace to end all peace: The fall of the Ottoman Empire and the creation of the modern Middle East. London, UK: Macmillan.

Gardner, R. A. (2011). Critique of the discourse of authentic leadership. International Journal of Business and Social Science, 2(15), 99-104. https://ir.lib.uwo.ca/womenspub/2/ 
Georgopoulos, B. S., \& Tannenbaum, A. S. (1957). A study of organizational effectiveness. American Sociological Review, 22(5), 534-540. https://www.jstor.org/stable/2089477?seq=1\#metadata_info_tab_contents

Gibson, D. (2004). The Nabataeans: Builders of Petra. Bloomington, IN: Xlibris.

Gill, R. (2002). Change management-Or change leadership?. Journal of Change Management, 3(4), 307-318. https://doi.org/10.1080/714023845

Glesne, C. (2016). Becoming qualitative researchers: An introduction. New York, NY: Pearson.

GLOBE Overview, 2020. https://globeproject.com/study_2004_2007

GLOBE, 2020. (2018). https://globeproject.com/globe 2020

GLOBE, An overview of the 2004 study: Understanding the relationship between national culture, societal effectiveness and desirable leadership attributes. (2018). https://globeproject.com/study_2004_2007

GLOBE, Middle East. (2018). https://globeproject.com/results/clusters/middleeast?menu=list

Godwin, S. M. (2006). Globalization, education and Emiratisation: A study of the United Arab Emirates. The Electronic Journal of Information Systems in Developing Countries, 27(1), 1-14.

Goff, D. G. (2003). What do we know about good community college leaders: A study in leadership trait theory and behavioral leadership theory. https://files.eric.ed.gov/fulltext/ED476456.pdf

Goleman, D. (2000). Leadership that gets results. Harvard Business Review, 78(2), 4-17. https://hbr.org/2000/03/leadership-that-gets-results 
Gordis, D., \& Sanders, F. (2016). Israel: A concise history of a nation reborn. New York, NY: Harper Collins.

Graeff, C. L. (1983). The situational leadership theory: A critical view. Academy of Management Review, 8(2), 285-291. https://doi.org/10.5465/amr.1983.4284738

Graeff, C. L. (1997). Evolution of situational leadership theory: A critical review. The Leadership Quarterly, 8(2), 153-170. https://doi.org/10.1016/S10489843(97)90014-X

Great Man Theory, Villanova University. (2019). https://www.villanovau.com/resources/ leadership/great-man-theory/

Greaves, S. (2012). A primer of Middle Eastern leadership culture. Journal of Strategic Security, 5(4), 12. https://www.jstor.org/stable/26463976?seq=1\# metadata_info_tab_contents

Greenleaf Center for Servant Leadership. (2020). About. https://www.greenleaf.org/what-is-servant-leadership/

Greenleaf, R. K. (2002). Servant leadership: A journey into the nature of legitimate power and greatness. Mahwah, NJ: Paulist Press.

Grenness, T. (2006). Will the 'Scandinavian leadership model survive the forces of globalisation? A SWOT analysis. Paper presented at EISAM workshop, Toulouse 29-30 August 2006. http://www.eiasm.org/UserFiles/Tor\%20Grenness.pdf

Grenness, T. (2011). Will the 'Scandinavian leadership model survive the forces of globalisation? A SWOT analysis. International Journal of Business and Globalisation, 7(3), 332-350.

https://www.researchgate.net/publication/264440566 
Will the 'Scandinavian_leadership_model'_survive the forces_of_globalisation A SWOT analysis

Guéraiche, W. (2016). The UAE: Geopolitics, Modernity and Tradition. London, UK: Bloomsbury Publishing.

Haddad, E. (2018). The Lebanese Diaspora: An Exploration of Assimilation and Success in the United States.

Hadith, Sahba. (n.d.). Book 34.

Hägerdal, N. (2019). Ethnic cleansing and the politics of restraint: Violence and coexistence in the Lebanese Civil War. Journal of Conflict Resolution, 63(1), 5984.

Halaychik, C. (2016). Lessons in library leadership: a primer for library managers and unit leaders. Oxford, UK: Chandos Publishing.

Haleem, M. A. (Trans.). (2005). The Qur'an. Oxford, UK: Oxford University Press.

Hammad, A., Kysia, R., Rabah, R., Hassoun, R., \& Connelly, M. (1999). Guide to Arab culture: Health care delivery to the Arab American community. Dearborn, $M I$ : Arab Community Center for Economic and Social Services (ACCESS).

Hammad, A., Kysia, R., Rabah, R., Hassoun, R., \& Connelly, M. (1999). Guide to Arab culture: Health care delivery to the Arab American community. Dearborn, MI: Arab Community Center for Economic and Social Services (ACCESS). https://www.accesscommunity.org /sites/default/files/documents/health_and_research_cente 21.pdf Hancock, J. (1998). Lebanon and the west: UK, EU and US. Mediterranean Politics, 3(1), 163-169. 
Hawi, S. (1982). Lectures on leadership and leader. Amman, Jordan: Al-Sarg Printing Company

Herb, M. (2014). The wages of oil: Parliaments and economic development in Kuwait and the UAE. Cornell, NY: Cornell University Press.

Hersey, P., \& Blanchard, K. H. (1982). Grid principles and situationalism: Both! A response to Blake and Mouton. Group \& Organization Studies, 7(2), 207-210.

Hinnebusch, R. (2018). The international politics of the Middle East.

Ho, R. (1984). Development of an Australian work ethic scale. Australian Psychology, $19,321-332$.

Hodges, R. (1982). Dark age economics: The origins of towns and trade AD 600-1000. London, UK: Duckworth.

Hofstede-Insights, Country Comparison. (2018). https://www.hofstedeinsights.com/country-comparison/

Hofstede-Insights, National Culture. (2018). https://www.hofstedeinsights.com/models/national-culture/

Hofstede, G. (2003). What is culture? A reply to Baskerville. Accounting, Organizations and Society, 28(7-8), 811-813. https://www.researchgate.net/publication/222509599 What_is_Culture_A_Reply to Baskerville

Hofstede, G., Hofstede, G. J., \& Minkov, M. (2010). Cultures and organizations: Software of the mind. New York, NY: McGraw-Hill Education.

Hogg, M. A., Martin, R., Epitropaki, O., Mankad, A., Svensson, A., \& Weeden, K. (2005). Effective leadership in salient groups: Revisiting leader-member 
exchange theory from the perspective of the social identity theory of leadership. Personality and Social Psychology Bulletin, 31(7), 991-1004.

Hopwood, D. (2015). The Arabian Peninsula: Society and Politics. Routledge.

House, R. J. (1971). A path goal theory of leader effectiveness. Administrative Science Quarterly, 321-339. https://www.jstor.org/stable/2391905?seq=1\#metadata info tab contents

House, R. J. (1996). Path-goal theory of leadership: Lessons, legacy, and a reformulated theory. The Leadership Quarterly, 7(3), 323-352. https://doi.org/10.1016/S1048$\underline{9843(96) 90024-7}$

House, R. J., Dorfman, P. W., Javidan, M., Hanges, P. J., \& de Luque, M. F. S. (2013). Strategic leadership across cultures: GLOBE study of CEO leadership behavior and effectiveness in 24 countries. Thousand Oaks, CA: Sage.

House, R. J., Hanges, P. J., Javidan, M., Dorfman, P. W., \& Gupta, V. (Eds.). (2004). Culture, leadership, and organizations: The GLOBE study of 62 societies. Thousand Oaks, CA: Sage.

House, Robert J. Mitchell, T.R. (1975). Path-goal theory of leadership. Journal of Contemporary Business. 3: 1-97. https://apps.dtic.mil/dtic/tr/fulltext/u2/a009513.pdf

Howell, J. M., \& Avolio, B. J. (1992). The ethics of charismatic leadership: submission or liberation?. Academy of Management Perspectives, 6(2), 43-54. https://doi.org/10.5465/ame.1992.4274395 
Howell, J. M., \& Frost, P. J. (1989). A laboratory study of charismatic leadership. Organizational behavior and human decision processes, 43(2), 243269.

Howell, J. M., \& Shamir, B. (2005). The role of followers in the charismatic leadership process: Relationships and their consequences. Academy of management review, 30(1), 96-112.

Hutchings, K., \& Weir, D. (2006). Understanding networking in China and the Arab World: Lessons for international managers. Journal of European Industrial Training, 30(4), 272-290.

Ikram, K. (2018). The Political Economy of Reforms in Egypt: Issues and Policymaking since 1952. Cairo, Egypt: American University of Cairo Press.

Iliffe, J. (2017). Africans: the history of a continent (Vol. 137). Cambridge University Press.

Indiana University of Pennsylvania. (2018). Ali Abbas. https://www.iup.edu/management/ faculty/ali,-abbas/

Issawi, C. (2013). An economic history of the Middle East and North Africa. New York, NY: Routledge.

Javidan, M., Dorfman, P. W., De Luque, M. S., \& House, R. J. (2006). In the eye of the beholder: Cross cultural lessons in leadership from project GLOBE. Academy of Management Perspectives, 20(1), 67-90.

Javidan, M., House, R. J., Dorfman, P. W., Hanges, P. J., \& De Luque, M. S. (2006). Conceptualizing and measuring cultures and their consequences: a comparative 
review of GLOBE's and Hofstede's approaches. Journal of international business studies, 37(6), 897-914.

Jebnoun, N., Kia, M., \& Kirk, M. (Eds.). (2013). Modern Middle East authoritarianism: Roots, ramifications, and crisis. New York, NY: Routledge.

Jones, M. L. (2007). Hofstede-culturally questionable?. University of Wollongong Research Online. https://ro.uow.edu.au/cgi/viewcontent.cgi?article=1389\&context=commpapers

Joseph, S. (2018). Farming the desert: agriculture in the oil frontier, the case of the United Arab Emirates, 1940s to 1990s. British Journal of Middle Eastern Studies, 45(5), 678-694.

Kabasakal, H., \& Bodur, M. (2002). Arabic cluster: a bridge between East and West. Journal of World Business, 37(1), 40-54.

Kabasakal, H., Dastmalchian, A., Karacay, G., \& Bayraktar, S. (2012). Leadership and culture in the MENA region: An analysis of the GLOBE project. Journal of World Business, 47(4), 519-529.

Kandiyoti, D. (2002). Post-colonialism compared: Potentials and limitations in the Middle East and Central Asia. International Journal of Middle East Studies, 34(2), 279-297.

Katouzian, H. (2010). The Persians: Ancient, Mediaeval and Modern Iran (pp. 1-452). New Haven, CT: Yale University Press.

Katz, D., Maccoby, N., \& Morse, N. C. (1950). Productivity, supervision, and morale in an office situation. Part I. https://psycnet.apa.org/record/1951-07726-000 
Katzman, K. (2010). United Arab Emirates (UAE): Issues for US Policy. DIANE Publishing.

Kegan, R., \& Lahey, L. L. (2001). The real reason people won't change. HBR's 10 Must Reads on Change, 77-94. https://hbr.org/2001/11/the-real-reason-people-wontchange

Kegan, R., \& Lahey, L. L. (2016). An everyone culture: Becoming a deliberately developmental organization. Harvard Business Review Press.

Kegan, R., Kegan, L. L. L. R., \& Lahey, L. L. (2009). Immunity to change: How to overcome it and unlock potential in yourself and your organization. Harvard Business Press.

Kellerman, B. (Ed.). (1986). Political leadership: A source book. University of Pittsburgh Press.

Ketchley, N. (2017). Egypt in a Time of Revolution. Cambridge, UK: Cambridge University Press.

Khadra, B. (1984). Leadership, ideology, and development in the Middle East. Journal of Asian and African Studies, 19(3), 228-239.

Khaldun, F. I. (2015). The Muqaddimah: An introduction to history (R. Rosenthal, Trans.). Princeton, NJ: Princeton University Press. (Original work published in 1377).

Khan, M. Z. (1982). Muhammad, seal of the prophets. London, UK: Majlis Khuddamul Ahmadiyya.

Khoiri, N. (2016). Madrasah culture based transformational leadership model. Nadwa, 10(2), 153-175. 
Kilinçoğlu, D. T. (2015). Economics and capitalism in the Ottoman empire. Routledge.

Kingsley, P. (2015). A new New Cairo: Egypt plans £30bn purpose-built capital in desert. https://www.theguardian.com/cities/2015/mar/16/new-cairo-egypt-plans$\underline{\text { capital-city-desert }}$

Kilınç, R., \& Warner, C. M. (2015). Micro-foundations of religion and public goods provision: Belief, belonging, and giving in Catholicism and Islam. Politics and Religion, 8(4), 718-744.

Korotayev, A., \& Zinkina, J. (2011). Egyptian revolution: a demographic structural analysis. Entelequia. Revista Interdisciplinar, 13(2011), 139-169.

Kouzes, J. M., \& Posner, B. Z. (2012). Leadership practices inventory: LPI. Weinheim, Germany: Wiley-VCH. http://www.finepointsleadership.com/wpcontent/uploads/2014/11/Sample-Group-Assessment-Report.2012.pdf

Kouzes, J. M., \& Posner, B. Z. (2017). The leadership challenge. San Francisco, CA: Jossey-Bass.

Kuran, T. (2003). The Islamic commercial crisis: institutional roots of economic underdevelopment in the Middle East. The Journal of Economic History, 63(2), 414-446.

Lacey, R. (2009). Inside the kingdom: Kings, clerics, modernists, terrorist, and the struggle for Saudi Arabia. New York, NY: Viking.

Ladkin, D., \& Taylor, S. S. (2010). Enacting the 'true self': Towards a theory of embodied authentic leadership. The Leadership Quarterly, 21(1), 64-74. https://doi.org/10.1016/ j.leaqua.2009.10.005 
Lancaster, W., \& Lancaster, F. (1988). Thoughts on the Bedouinisation of Arabia. Proceedings of the Seminar for Arabian Studies, 18, 51-62.

Lewin, R. (2008). U.S. universities rush to set up outposts abroad. New York Times. https://www.nytimes.com/2008/02/10/education/10global.html

Lewis, B. (1994). Islam and the West. Oxford, UK: Oxford University Press.

Lewis, B. (1997). The Middle East: A brief history of the last 2,000 years. New York, NY: Touchstone.

Lim, C. \& Lay, C. S. (2003). Confucianism and the protestant work ethic, Asia Europe Journal, 1, 321-322.

Little, D. (2008). American orientalism: The United States and the Middle East since 1945. Chapel Hill, NC: University of North Carolina Press.

Litz, D., \& Scott, S. (2017). Transformational leadership in the educational system of the United Arab Emirates. Educational Management Administration \& Leadership, 45(4), 566-587.

Liu, H. (2019). Just the servant: An intersectional critique of servant leadership. Journal of Business Ethics, 156(4), 1099-1112. https://link.springer.com/article/10.1007/s10551-017-3633-0

Louis, W. R., \& Louis, W. R. (1984). The British Empire in the Middle East, 1945-1951: Arab Nationalism, the United States, and Postwar Imperialism. Oxford University, UK: Oxford University Press.

Lumen, History of Leadership Theories. (n.d.). https://courses.lumenlearning.com/wmopen-organizationalbehavior/chapter/thehistory-of-leadership-theories/ 
Lunen Burg, F. C. (2010). Models of Decision Making. Focus on Colleges Universities, And Schools. 4(1).

Makdisi, S. (2006). Beirut, a city without history?. Memory and violence in the Middle East and North Africa, 201-214.

Management Study Guide (2012). Leader-member exchange (LMX) theory. http://managementstudyguide.com/lmx-theory.htm

Management Study Guide. (2012). Transactional leadership theory. https://managementstudyguide.com/transactional-leadership.htm

Mansfield, P. (2013). A history of the Middle East. New York, NY: Penguin.

Marcel, V. (2006). Oil titans: National oil companies in the Middle East. Washington DC: Brookings Institution Press.

Marcus, A., \& Gould, E. W. (2000). Crosscurrents: cultural dimensions and global web user-interface design. Interactions, 7(4), 32-46.

Mark, C. R. (2005, April). Egypt-United States Relations. Library of Congress Washington DC Congressional Research Service.

Marmenout, K. (2009). Women-focused leadership development in the Middle East: Generating local knowledge. INSEAD Working paper No. 2009/25/IGLC. https://ssrn.com/abstract $=1427729$

Martin, R., Guillaume, Y., Thomas, G., Lee, A., \& Epitropaki, O. (2016). Leadermember exchange (LMX) and performance: A meta-analytic review. Personnel Psychology, 69(1), 67-121. https://doi.org/10.1111/peps.12100

Maslanka, A. M. (2004). Evolution of leadership theories. Grand Valley State University. 
Maslanka, A. M. (2004). Evolution of leadership theories. Allendale, MI: Grand Valley State University.

Matar, L., \& Kadri, A. (Eds.). (2018). Syria: From national independence to proxy war. Springer.

Maznevski, M. L., Gomez, C. B., DiStefano, J. J., Noorderhaven, N. G., \& Wu, P. C. (2002). Cultural dimensions at the individual level of analysis: The cultural orientations framework. International Journal of Cross Cultural Management, 2(3), 275-295.

McKenzie, L. \& Love, K. (n.d.). Contingency theory of leadership. Organization and Administration in Recreation, Sport, and Leisure Management (L. Oakleaf, Ed.). https://oer.missouriwestern.edu/rsm424/chapter/contingency-theory-of-leadership/

McSweeney, B. (2000). The fallacy of national culture identification. 6th Interdisciplinary Perspectives on Accounting Conference, Manchester, UK.

McSweeney, B. (2002). Hofstede's model of national cultural differences and their consequences: A triumph of faith-a failure of analysis. Human Relations, 55(1), 89-118.

Meirovich, G., \& Gu, J. (2015). Empirical and theoretical validity of Hersey-Blanchard's contingency model. Journal of Applied Management and Entrepreneurship, 20(3), 56-73. https://www.researchgate.net/profile/Gavriel_Meirovich/publication/284178161 Empirical and theoretical_validity of Hersey$\underline{\text { Blanchard's contingency model_a critical }}$ 
_analysis/links/564eleb108aelef9296c5885/Empirical-and-theoretical-validityof-Hersey-Blanchards-contingency-model-a-critical-analysis.pdf

Mellahi, K., Demirbag, M., \& Riddle, L. (2011). Multinationals in the Middle East: Challenges and opportunities. Journal of World Business, 46(4), 406-410.

Mercer, J. (2006). Appraising higher education faculty in the Middle East: leadership lessons from a different world. Management in Education, 20(1), 17-26.

Merriam-Webster, Arab. https://www.merriam-webster.com/dictionary/Arab

Merrian, S. B. (2009). Qualitative research: A guide to design and implementation. Hoboken, NJ, Wiley.

Metcalfe, B. D. (2008). Women, management and globalization in the Middle East. Journal of Business Ethics, 83(1), 85-100.

Metcalfe, B., \& Mimouni, F. (Eds.). (2011). Leadership development in the Middle East. Cheltenham, UK: Edward Elgar Publishing.

Miller, J. M. \& Hayes, J. H. (2006). A History of ancient Israel and Judah. Louisville, KY: John Knox.

Mir, A. M. (2010). Leadership in Islam. Journal of Leadership Studies, 4(3), 69-72.

Mitchell, T. R., Biglan, A., Oncken, G. R., \& Fiedler, F. E. (1970). The contingency model: Criticism and suggestions. Academy of Management Journal, 13(3), 253267. https://doi.org/10.5465/254963

Mohtsham, S. M. (2007). Leadership in Islam. International Review of Business Research Papers, 3(2), 248-277.

Molloy, P. L. (1998). A review of the managerial grid model of leadership and its role as a model of leadership culture. Aquarius Consulting, 31 . 
Mouton, J. S., \& Blake, R. R. (1964). The managerial grid. Houston, TX: Gulf Publishing. https://pdfs.semanticscholar.org/644e/8743c65840a738ddbbe985897e3fc8815ac7. pdf

Mundhirī, A. H. Z. A. A. A. M., (2000). Mukhtașar Șahīh Muslim: The translation of the meanings of Summarized Sahih Muslim. Riyadh, Saudi Arabia: Darussalam.

Murphy, L. R. (1987). The American University in Cairo, 1919-1987. Cairo, Egypt: American University in Cairo Press.

Nahavandi, A. (2014). The art and science of leadership (7 $7^{\text {th }}$ Ed.). London, UK: Pearson. Nahavandi, A. and Krishnan, H. (2017), "Indo-European Leadership (IEL): A NonWestern Leadership Perspective", Global and Culturally Diverse Leaders and Leadership (Building Leadership Bridges), Emerald Publishing Limited, pp. 105123. https://doi.org/10.1108/S2058-880120170000003006

Naidoo, A. (2012). UAE MBAs among best in Arab world: For bes Middle East release a list of top programmes at institutions. GulfNews.com. Retrieved from https://gulfnews.com/uae/ education/uae-mbas-among-best-in-arab-world1.982683

Najm, N. A. (2015). Arab culture dimensions in the international and Arab models. American Journal of Business, Economics and Management, 3(6), 423431.

Nakata, C. (Ed.). (2009). Beyond Hofstede. London, UK: Palgrave Macmillan.

Nasr, S.H. (1984). Islamic work ethics. Hamdard Islamicus, 7(4), 25-35. 
Newman, L. (2015). Social research methods, Qualitative and quantitative approaches. New York, NY: Pearson.

Nikezic, S., Puric, S., \& Puric, J. (2012). Transactional and Transformational Leadership: Development Through Changes International Journal for Quality Research. 6(3). 285-296. http://www.ijqr.net/journal/v6-n3/11.pdf

Northhouse, P. G. (2016). Leadership ( $8^{\text {th }}$ Ed.). Thousand Oaks, CA: Sage Publications

Obeidat, B. Y., Shannak, R. O., Masa'deh, R. E. M. D. T., \& Al-Jarrah, I. (2012). Toward better understanding for Arabian culture: Implications based on Hofstede's cultural model. European Journal of Social Sciences, 28(4), 512-522.

Omran, H. (2018). UAE, Egypt's strategic ally for 47 years. Daily News Egypt. Retrieved from https://dailynewssegypt.com/2018/12/02/uae-egypts-strategically-for-47-years/

Opler, M. E. (1945). Themes as dynamic forces in culture. American Journal of Sociology, 51(3), 198-206. https://www.journals.uchicago.edu/doi/abs/10.1086/219787

Organ, D. W. (1996). Leadership: The great man theory revisited. https://doi.org/10.1016/S0007 -6813(96)90001-4

Paschall, R. \& Large, M. (n.d.). Transactional leadership. Organization and Administration in Recreation, Sport, and Leisure Management (L. Oakleaf, Ed.). https://oer.missouri western.edu/rsm424/chapter/transactional-leadership/

Patai, R. (2002). The Arab mind. New York, NY: Tucson, AZ: Recovery Resource Press. Patton, M. Q. (2015). Qualitative research \& evaluation methods: Integrating theory and practice. Thousand Oaks, CA: Sage publications. 
Pellegrini, E. K., Scandura, T. A., \& Jayaraman, V. (2010). Cross-cultural generalizability of paternalistic leadership: An expansion of leader-member exchange theory. Group \& Organization Management, 35(4), 391-420. https://doi.org/10.1177/1059601110378456

Pervin, L. A. (1994). A critical analysis of current trait theory. Psychological Inquiry, 5(2), 103-113.

Peters, L. H., Hartke, D. D., \& Pohlmann, J. T. (1985). Fiedler's Contingency Theory of Leadership: An application of the meta-analysis procedures of Schmidt and Hunter. Psychological bulletin, 97(2), 274-285. https://doi.org/10.1037/0033$\underline{2909.97 .2 .274}$

Powell, E. T. (2003). A different shade of colonialism: Egypt, Great Britain, and the mastery of the Sudan (Vol. 2). Univ of California Press.

Power, R. L. (2013). Leader-Member Exchange Theory in Higher and Distance Education. http://www.irrodl.org/index.php/irrodl/article/view/1582/2631

Randeree, K. (2008). Ethical leadership from Islamic perspectives: A model for social and organizational Justice. The International Journal of the Humanities, 6(4), 4953.

Raven, G. (2006). Methodological reflexivity: Towards evolving methodological frameworks through critical and reflexive deliberations. Environmental Education Research, 12(3-4), 559-569. https://www.tandfonline.com/doi/full/10.1080/13504620600799323 
Reams, J. (2016). Immunity to change revisited: Theoretical foundations for awareness based practices for leadership development. Integral Review, 12(1). Retrieved from http://scholarship.meridianuniversity.edu/id/eprint/68

Reber, G., Auer-Rizzi, W., \& Maly, M. (2004). The behaviour of managers in Austria and the Czech Republic: an intercultural comparison based on the Vroom/Yetton model of leadership and decision making. Journal for East European Management Studies, 411-429. https://www.jstor.org/stable/23280671

Reproduced from Situational Theories, Lumen Learning. https://journalhosting.ucalgary .ca/index.php/cjeap/article/view/42735

Rizk, R. (2008). Back to basics: an Islamic perspective on business and work ethics. Social Responsibility Journal, 4(1/2), 246-254.

Rockstuhl, T., Dulebohn, J. H., Ang, S., \& Shore, L. M. (2012). Leader-member exchange (LMX) and culture: A meta-analysis of correlates of LMX across 23 countries. Journal of Applied Psychology, 97(6), 1099-1130. https://doi.org/10.1037/a0029978

Rogan, E. (2015). A century after Sykes-Picot. The Cairo Review of Global Affairs, 19 (Fall 2015).

Rogan, E. (2017). The Arabs: A history. New York, NY: Basic Books.

Romani, V. (2009). The politics of higher education in the Middle East: Problems and prospects. Middle East Brief, 36(1), 1-8.

Rosa, E. M., \& Tudge, J. (2013). Urie Bronfenbrenner's theory of human development: Its evolution from ecology to bioecology. Journal of Family Theory \& Review, 5(4), 243-258. 
Ross, J. \& Kendall, T. (n.d.). Transformational leadership. In Organization and Administration in Recreation, Sport, and Leisure Management (Ed. Linda Oakleaf). https://oer.missouriwestern.edu/rsm424/chapter/transformationalleadership/

Russell, R. F., \& Stone, A. G. (2002). A review of servant leadership attributes: Developing a practical model. Leadership \& Organization Development Journal. https://www.emerald.com/insight/content/doi/10.1108/01437730210424/full/html

Safi, L. (1995). Leadership and subordination: An Islamic perspective. The American Journal of Islamic Social Sciences, 12(2), 204-223.

Salamey, I. (2013). The government and politics of Lebanon. Routledge.

Salem, Z. O., \& Agil, S. O. S. (2012). The effects of Islamic management ethics on organizational commitment of employees in Libyan public banks. Australian Journal of Basic and Applied Sciences, 6(7), 260-270.

Salzman, P. C. (2008). The Middle East's tribal DNA. Middle East Quarterly, 15(1), 2335.

Saouli, A. (2019). Sectarianism and Political Order in Iraq and Lebanon. Studies in Ethnicity and Nationalism, 19(1), 67-87.

Savin-Baden, M. \& Major C. H. (2013). Qualitative research: The essential guide to theory and practice. London, UK: Routledge.

Schriesheim, C. A., \& Bird, B. J. (1979). Contributions of the Ohio state studies to the field of leadership. Journal of Management, 5(2), 135-145. https://doi.org/10.1177/ 014920637900500204 
Schriesheim, C. A., \& Kerr, S. (1974). Psychometric properties of the Ohio State leadership scales. Psychological Bulletin, 81(11), 756-765. https://doi.org/10.1037/h0037277

Schriesheim, C. A., \& Neider, L. L. (1996). Path-goal leadership theory: The long and winding road. The Leadership Quarterly, 7(3), 317-321. https://doi.org/10.1016/S1048-9843(96)90023-5

Schriesheim, C. A., Castro, S. L., \& Cogliser, C. C. (1999). Leader-member exchange (LMX) research: A comprehensive review of theory, measurement, and dataanalytic practices. The Leadership Quarterly, 10(1), 63-113. https://doi.org/10.1016/S1048-9843(99)80009-5

Schwandt, T. A. (1994). Constructivist, interpretivist approaches to human inquiry. Handbook of qualitative research, 1, 118-137. https://www.researchgate.net/profile/Thomas Schwandt/publication/232477264_Constructivist_Interpretivist_Approaches to Human_Inquiry/links/557048d908aeab777228bfef/Constructivist-InterpretivistApproaches-to-Human-Inquiry.pdf

Shamir, B., House, R. J., \& Arthur, M. B. (1993). The motivational effects of charismatic leadership: A self-concept based theory. Organization science, 4(4), 577-594.

Shartle, C. L. (1979). Early years of the Ohio State University leadership studies. Journal of Management, 5(2), 127-134. https://doi.org/10.1177/014920637900500203

Shaw, I. (Ed.). (2003). The Oxford history of ancient Egypt. Oxford University Press. Shelton, L. (2018). The Bronfenbrenner primer: A guide to develecology. London, UK: Routledge. 
Shields, P. \& Rangarjan, N. (2013). A Playbook for Research Methods: Integrating Conceptual Frameworks and Project management. Stillwater, OK: New Forums Press.

Shwadran, B. (1985). The Middle East, oil and the great powers. Hoboken, NJ: John Wiley and Sons.

Singelis, T. M., Triandis, H. C., Bhawuk, D. P., \& Gelfand, M. J. (1995). Horizontal and vertical dimensions of individualism and collectivism: A theoretical and measurement refinement. Cross-Cultural Research, 29(3), 240-275. https://doi.org/10.1177/106939719502900302

Sivabalan, S. (2017). Egypt's Float Anniversary Has Lessons for Currency Baby-Sitters. Bloomberg. https://www.bloomberg.com/news/articles/2017-11-03/egypt-s-floatanniversary-has-lessons-for-currency-baby-sitters

Skytrax World Airline Awards 2019. (2020). The World's Best Airlines of 2019. https://www.worldairlineawards.com

Slabbert, A., \& Ukpere, W. I. (2011). A comparative analysis of the Chinese and South African work ethic. International Journal of Social Economics, 38(8), 734-741.

Slack, N., \& Cooke, S. (1984). Making management decision. Prentice-Hall International.

Smith, A., Helm, N., Stark, Z., \& Stone, I. (n.d.). Style theory of leadership. Organization and Administration in Recreation, Sport, and Leisure Management (L. Oakleaf, Ed.). https://oer.missouriwestern.edu/rsm424/chapter/style-theory-of-leadership/

Sontag, J. C. (1996). Toward a comprehensive theoretical framework for disability research: Bronfenbrenner revisited. The Journal of Special Education, 30(3), 319344. 
Spector, B. A. (2016). Carlyle, Freud, and the great man theory more fully considered. Leadership, 12(2), 250-260. https://doi.org/10.1177/1742715015571392

Spencer, H. (1873). The study of sociology (Vol. 5). New York, NY: Appleton.

Stewart, J. (2006). Transformational leadership: An evolving concept examined through the works of Burns, Bass, Avolio, and Leithwood. Canadian Journal of Educational Administration and Policy, 54.

Stogdill, R. M. (1950). Leadership, membership and organization. Psychological Bulletin, 47(1), 1-14. https://doi.org/10.1037/h0053857

Stone, A. G., \& Patterson, K. (2005). The history of leadership focus. Servant Leadership Research Roundtable Proceedings.

Stone, A. G., Russell, R. F., \& Patterson, K. (2004). Transformational versus servant leadership: A difference in leader focus. Leadership \& Organization Development Journal. 25(4), 349-361. https://www.emerald.com/insight/content/doi/10.1108/01437730410538671 /full/html?journalCode=lodj

Strube, M. J., \& Garcia, J. E. (1981). A meta-analytic investigation of Fiedler's contingency model of leadership effectiveness. Psychological Bulletin, 90(2), 307-321. https://doi.org/10.1037/0033-2909.90.2.307

Tahrir Square's place in Egypt's history. (2011). BBC. https://www.bbc.com/news/world-middle-east-12332601 
Taras, V., Steel, P., \& Kirkman, B. L. (2010). Negative practice--value correlations in the GLOBE data: Unexpected findings, questionnaire limitations and research directions. Journal of International Business Studies, 41(8), 1330-1338.

Terlutter, R., Diehl, S., \& Mueller, B. (2006). The GLOBE study_applicability of a new typology of cultural dimensions for cross-cultural marketing and advertising research. International Advertising and Communication, 419-438.

The World University Rankings, Cairo University. (2019). https://www.timeshighereducation. com/world-university-rankings/cairouniversity

Thompson, J. (2009). A History of Egypt: From Earliest Times to the Present. Cairo, Egypt: American University of Cairo Press.

Top Universities, Cairo University. (2019). https://www.topuniversities.com/universities/cairo-university

Triandis, H. C. (1993). The contingency model in cross-cultural perspective (M. M. Chemers \& R. Ayman Eds). Leadership theory and research: Perspectives and directions. https://psycnet.apa.org/record/1992-98503-007

Triandis, H. C. (1995). Individualism \& collectivism. Boulder, CO: Westview Press.

Trompenaars, F., \& Hampden-Turner, C. (2011). Riding the waves of culture:

Understanding diversity in global business. Nicholas Brealey International. New York, NY: McGraw-Hill.

Trompenaars, F., \& Hampden-Turner, C. (2011). Riding the waves of culture: Understanding diversity in global business. New York, NY: McGraw-Hill. 
Tudge, J. R., Mokrova, I., Hatfield, B. E., \& Karnik, R. B. (2009). Uses and misuses of Bronfenbrenner's bioecological theory of human development. Journal of family theory \& review, 1(4), 198-210.

Tudge, J. R., Payir, A., Merçon-Vargas, E., Cao, H., Liang, Y., Li, J., \& O'Brien, L. (2016). Still misused after all these years? A reevaluation of the uses of Bronfenbrenner's bioecological theory of human development. Journal of Family Theory \& Review, 8(4), 427-445.

Turner, L. (2015). Explaining the (non-) encampment of Syrian refugees: Security, class and the labour market in Lebanon and Jordan. Mediterranean Politics, 20(3), 386404.

Ulrichsen, K. C. (2016). The United Arab Emirates: Power, Politics and Policy-Making. Routledge.

United Arab Emirates. (2019). In CIA World Fact Book. https://www.cia.gov/library/ publications/the-world-factbook/geos/ae.html

USC, Research Guide. (2019). http://libguides.usc.edu/c.php?g=235034\&p=1559832

USC, Types of Research Design. (n.d.). https://libguides.usc.edu/writingguide/researchdesigns

Valenta, M., Knowlton, K. E., Jakobsen, J., Mouawiya, A. A., \& Strabac, Z. (2019). Temporary Labour-Migration System and Long-term Residence Strategies in the United Arab Emirates. International Migration.

Van Knippenberg, D., \& Sitkin, S. B. (2013). A critical assessment of charismatictransformational leadership research: Back to the drawing board?. The Academy 
of Management Annals, 7(1), 1-60.

https://doi.org/10.1080/19416520.2013.759433

Van Oorschot, I. (2014). Negotiating knowledges abroad: non-Western students and the global mobility of knowledge. Compare: A Journal of Comparative and International Education, 44(6), 895-915.

Vandayani, P., Kartini, D., \& Hilmiana, Y. A. (2015). The impact of national culture on effectiveness of situational leadership Hersey-Blanchard. Development, 1, S4. http://www.feb.unpad.ac.id/dokumen/files/The-Impact-Of-National-Culture-OnEffectiveness-Of-Situational-Leadership-Hersey-blanchard.pdf

Vecchio, R. P. (1987). Situational Leadership Theory: An examination of a prescriptive theory. Journal of Applied Psychology, 72(3), 444-451. https://psycnet.apa.org/buy/1987-35930-001

Volmer, J., Spurk, D., \& Niessen, C. (2012). Leader-member exchange (LMX), job autonomy, and creative work involvement. The Leadership Quarterly, 23(3), 456465. https://doi.org/10.1016/j.leaqua.2011.10.005

Vroom, V. H., \& Jago, A. G. (1978). On the validity of the Vroom-Yetton model. Journal of Applied Psychology, 63(2), 151-162. https://doi.org/10.1037/0021-9010.63.2.151

Vroom, V.H. (1964). Work and motivation. New York, NY: Wiley.

Wagner, T., Kegan, R., Lahey, L. L., Lemons, R. W., Garnier, J., Helsing, D., ... \& Rasmussen, H. T. (2012). Change leadership: A practical guide to transforming our schools. John Wiley \& Sons. 
Watenpaugh, K. D. (2014). Being modern in the Middle East: Revolution, nationalism, colonialism, and the Arab middle class. Princeton, NJ: Princeton University Press.

Weber, M. (1947). The theory of social and economic organization. New York, NY: Henderson \& Talcott Parsons.

Weber, M. (1992). The protestant ethic and the spirit of capitalism. (Parsons, T., Trans.). London, UK: Routledge. (Original work published in 1930).

Weiker, W. F. (1992). Ottomans, Turks, and the Jewish Polity: A History of the Jews of Turkey. Lanham, MD: University Press of America.

Winkler, I. (2010). Role theory of leadership. In Contemporary Leadership Theories (pp. 75-83). Physica-Verlag HD. https://link.springer.com/chapter/10.1007/978-37908-2158-1_10

Yahya, M., Kassir, J., \& El-Hariri, K. (2018). Unheard Voices: What Syrian Refugees Need to Return Home. Carnegie Endowment for International Peace.

Yawar Baig, M. (2012). Leadership lessons from the life of Rasoolullah. Self published: Mirza Yawar Baig.

Yeakey, G. W. (2002). Situational leadership. Military Review, 82(1), 72. https://www.questia.com/library/journal/1P3-107668250/situational-leadership

Yousef D. A. (2000). Organizational commitment as a mediator of the relationship between Islamic work ethic and attitudes toward organizational change. Human Relations, 53(4), 513-537. 
Yukl, G. (1998). Leadership in organizations. Englewood Cliffs, NJ: Prentice Hall. https://www.researchgate.net/publication/10773181_The Two_Faces_of_Transfo rmational_Leadership_Empowerment_and_Dependency

Zaccaro, S. J. (2007). Trait-based perspectives of leadership. American psychologist, 62(1), 6-16. https://psycnet.apa.org/buy/2006-23492-003

Zahlan, R. S. (2016). The Making of the Modern Gulf States: Kuwait, Bahrain, Qatar, the United Arab Emirates and Oman. Routledge.

Zahlan, R. S. (2016). The origins of the United Arab Emirates: A political and social history of the Trucial States. Routledge.

Zeghal, M. (2007). The 'recentering' of religious knowledge and discourse: The case of al-Azhar in twentieth-century Egypt. Schooling Islam: The Culture and politics of modern Muslim education, 107-130.

Zubaida, S. (1993). Islam, the people and the state: Political ideas and movements in the Middle East. IB Tauris. 


\section{Appendix A}

\section{Hofstede's Cultural Dimensions}

POWER DISTANCE INDEX (PDI): This dimension expresses the degree to which the less powerful members of a society accept and expect that power is distributed unequally. The fundamental issue here is how a society handles inequalities among people. People in societies exhibiting a large degree of Power Distance accept a hierarchical order in which everybody has a place and which needs no further justification. In societies with low Power Distance, people strive to equalize the distribution of power and demand justification for inequalities of power.

INDIVIDUALISM VERSUS COLLECTIVISM (IDV): The high side of this dimension, called Individualism, can be defined as a preference for a loosely-knit social framework in which individuals are expected to take care of only themselves and their immediate families. Its opposite, Collectivism, represents a preference for a tightly-knit framework in society in which individuals can expect their relatives or members of a particular ingroup to look after them in exchange for unquestioning loyalty. A society's position on this dimension is reflected in whether people's self-image is defined in terms of "I" or "we."

MASCULINITY VERSUS FEMININITY (MAS): The Masculinity side of this dimension represents a preference in society for achievement, heroism, assertiveness, and material rewards for success. Society at large is more competitive. Its opposite, Femininity, stands for a preference for cooperation, modesty, caring for the weak and quality of life. Society at large is more consensus-oriented. In the business context 
Masculinity versus Femininity is sometimes also related to as "tough versus tender" cultures.

UNCERTAINTY AVOIDANCE INDEX (UAI): The Uncertainty Avoidance dimension expresses the degree to which the members of a society feel uncomfortable with uncertainty and ambiguity. The fundamental issue here is how a society deals with the fact that the future can never be known: should we try to control the future or just let it happen? Countries exhibiting strong UAI maintain rigid codes of belief and behavior, and are intolerant of unorthodox behavior and ideas. Weak UAI societies maintain a more relaxed attitude in which practice counts more than principles.

\section{LONG TERM ORIENTATION VERSUS SHORT TERM NORMATIVE}

ORIENTATION (LTO): Every society has to maintain some links with its own past while dealing with the challenges of the present and the future. Societies prioritize these two existential goals differently. Societies who score low on this dimension, for example, prefer to maintain time-honored traditions and norms while viewing societal change with suspicion.

Those with a culture which scores high, on the other hand, take a more pragmatic approach: they encourage thrift and efforts in modern education as a way to prepare for the future. In the business context, this dimension is referred to as "(short-term) normative versus (long-term) pragmatic" (PRA). In the academic environment, the terminology Monumentalism versus Flexhumility is sometimes also used.

INDULGENCE VERSUS RESTRAINT (IND): Indulgence stands for a society that allows relatively free gratification of basic and natural human drives related to 
enjoying life and having fun. Restraint stands for a society that suppresses gratification of needs and regulates it by means of strict social norms.

(Hofstede Insights, National Culture, 2018) 


\section{Appendix B}

Hofstede's Cultural Dimensions for the Middle East

\begin{tabular}{|l|c|c|c|c|c|c|}
\hline & $\begin{array}{c}\text { Power } \\
\text { Distance }\end{array}$ & Individualism & Masculinity & $\begin{array}{c}\text { Uncertainty } \\
\text { Avoidance }\end{array}$ & $\begin{array}{c}\text { Long Term } \\
\text { Orientation }\end{array}$ & Indulgence \\
\hline Egypt & 70 & 25 & 45 & 80 & 7 & 4 \\
\hline Iraq & 95 & 30 & 70 & 85 & 25 & 17 \\
\hline Kuwait & 90 & 25 & 40 & 80 & - & - \\
\hline Lebanon & 75 & 40 & 65 & 50 & 14 & 25 \\
\hline Libya & 80 & 38 & 52 & 68 & 23 & 34 \\
\hline Saudi Arabia & 95 & 25 & 60 & 80 & 36 & 52 \\
\hline United Arab Emirates & 90 & 25 & 50 & 80 & - & - \\
\hline & & & & & & \\
\hline Range & 70 to 95 & 25 to 40 & 45 to 70 & 68 to 85 & 7 to 36 & 4 to 52 \\
\hline
\end{tabular}

(Hofstede-Insights, Country Comparison, 2018) 


\begin{abstract}
Appendix C
GLOBE Project - Global Cultural Competencies

Performance Orientation: The degree to which a collective encourages and rewards (and should encourage and reward) group members for performance improvement and excellence.
\end{abstract}

Assertiveness: The degree to which individuals are (and should be) assertive, confrontational, and aggressive in their relationship with others.

Future Orientation: The extent to which individuals engage (and should engage) in future-oriented behaviors such as planning, investing in the future, and delaying gratification.

Humane Orientation: The degree to which a collective encourages and rewards (and should encourage and reward) individuals for being fair, altruistic, generous, caring, and kind to others.

Institutional Collectivism: The degree to which organizational and societal institutional practices encourage and reward (and should encourage and reward) collective distribution of resources and collective action.

In-Group Collectivism: The degree to which individuals express (and should express) pride, loyalty, and cohesiveness in their organizations or families.

Gender Egalitarianism: The degree to which a collective minimizes (and should minimize) gender inequality.

Power Distance: The extent to which the community accepts and endorses authority, power differences, and status privileges. 
Uncertainty Avoidance: The extent to which a society, organization, or group relies (and should rely) on social norms, rules, and procedures to alleviate unpredictability of future events. The greater the desire to avoid uncertainty, the more people seek orderliness, consistency, structure, formal procedures, and laws to cover situations in their daily lives. (GLOBE, An Overview, 2018) 


\section{Appendix D}

\section{GLOBE Project-Culture Clusters}

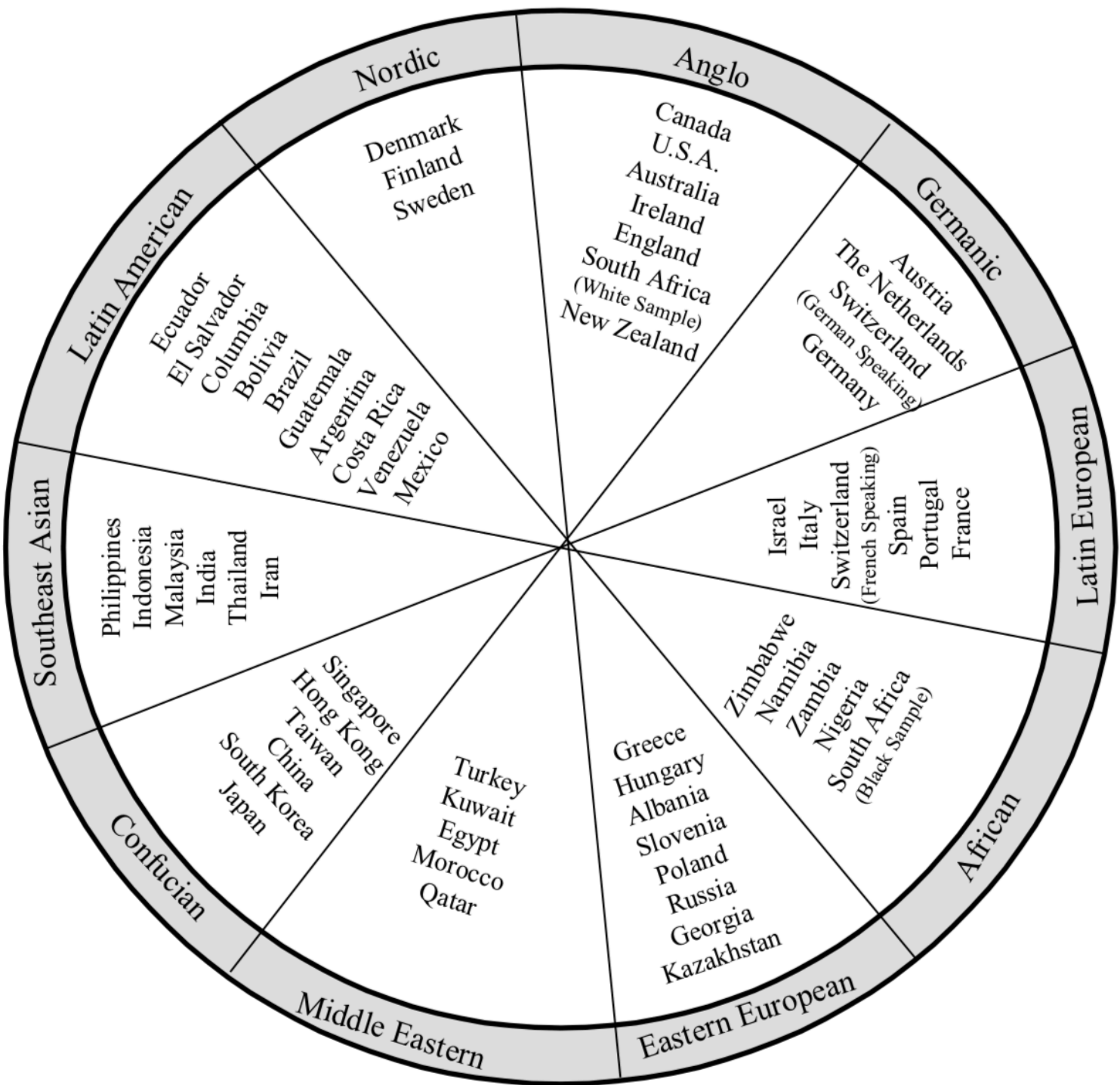

(Reproduced from House et al., 2004) 


\section{Appendix E}

\section{Coding Example}

\section{The MBA Program}

\section{Philosophy}

OSB has been developing leaders and preparing them to excel in the constantly and rapidly changing business world. Through an immersive experience in business education, we will empower students to build a strong knowledge base and gain individualized skills to meet the economic and social challenges of the future. Our MBA Program draws the most influential and innovative business thinkers and leaders to campus to address, teach and mentor students. You will find yourself surrounded by an adventurous learning community of passionate, highly motivated people who want to improve your experience and the world.

\section{Program Highlights}

- Flexible, innovative curriculum which fosters collaboration, community, teamwork $E I$ and anentrepreneurial spirit

- World-class faculty research and a focus on experiential and analytical learning

- Rigorous academic theory is linked with real-world practice to build fundamental eadership and management skills

- Ongoing assessment of learning outcomes geared toward continuous improvement

- A global community of alumni worldwide create a powerful network that lasts a Globa/ lifetime

Excellent teaching, executive connections and partnership opportunities are just some of the things you will experience at OSB. All our courses will provide students with opportunities to learn, practice and lead. Whether you are interested in consulting, strategy, innovation or other topics from health services to entrepreneurship, our MBA will provide you with the knowledge and recognition you are seeking from the business world.

\section{Admission to the Program}

Normally, there are two admission deadlines a ( Normally in March), for enrollment in the Fall term and in November, for enrollment the following Spring. For more details, please refer to the Admissions section of the AUB graduate catalogue under Application Procedures.

GMAT results are expected within a month after the regular deadline for Fall and Spring terms.

\section{Criteria for Admission}

The MBA program is looking to attract and admit candidates with balanced competencies including excellent analytical skills and teadership potential.

The following requirements will be needed to consider your application:

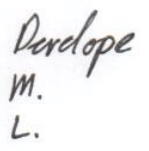

- Average GPA of at least 80 (3.2) from a university recognized by AUB

- An applicant is considered for admission on probation if $s /$ he has attained an average between 75 and 80 . 


\section{Appendix F}

\section{Email to Faculty, Initial}

To faculty:

Studying Leadership Theory in MBA Programs in the Modern Middle East

Greetings

I am an adjunct professor at the University of San Diego who is near completing my $\mathrm{PhD}$ in Leadership Studies. Toward this end I am entering the data collection stage of the process.

In brief, my topic is focused on understanding how western-developed leadership theories are taught, absorbed, and practiced by business school students in the modern Arab Middle East.

Your research and teaching interest in ___ may be very insightful to me and for the purpose of this study. Would it be possible for us to arrange a time for a 45-60 minute interview?

I will be in ___ and at ___ July ___ Any chance you are around and available any of these days? If not, could we arrange a phone call?

Attached is both my proposal abstract and a letter from my dissertation committee chair, Dr. Afsaneh Nahvandi.

Thank you for considering this. Your insights and experiences are important both for this study and for us to know how to better shape or create leadership models that serve the modern Middle East.

Cheers,

Derek Olson

$\mathrm{MA}, \mathrm{PhD}$ Candidate

derekolson@sandiego.edu

$1-202-525-6858$ 


\section{Appendix G}

\section{Introduction from Dr. Nahavandi}

May 31, 2019

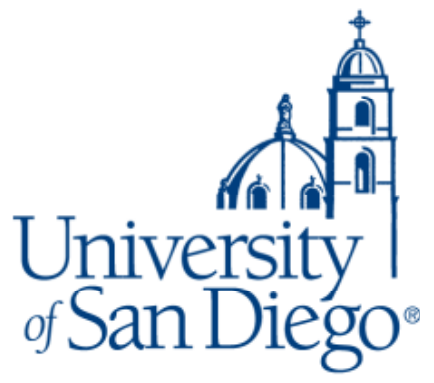

To Whom It May Concern:

It is with great pleasure that I introduce to you Mr. Derek Olson who is my doctoral student at the University of San Diego. Mr. Olson is coming to you to collect data for his doctoral dissertation about the applicability of Western-based leadership theories in the Arab MiddleEast. Mr. Olson conducts himself with a high degree of professionalism and upholds high ethical standards. He is an outstanding researcher with extensive knowledge of and respect for the region.

Mr. Olson's research is original and potentially ground-breaking. Increasingly, theories that are developed in one cultural context are being exported and applied to different contexts. However, there is little research that considers the appropriateness and applicability of the theories to different cultural contexts. His goal is to understand which concepts are applied and adopted, which are not and how and why they are applied. While his research can inform how theories are developed, the results can also be very useful for non-US universities that are teaching Western-based theories. They can be used to revise the curriculum to make it more applicable to Arab settings.

Mr. Olson has started his research with extensive document analysis. He is now traveling to several universities to interview faculty, students and alumni to conduct in-depth interviews.

I recommend Mr. Olson to you without any reservations. Please do not hesitate to contact me if you have any questions. Your assistance with this project would be most appreciated and he is eager to share his results with you after the completion of the project.

Sincerely,

Afsaneh Nahavandi, Ph.D.

Professor of Management, University of San Diego

Professor Emerita, Arizona State University

anahavandi@sandiego.edu 


\section{Appendix $\mathbf{H}$}

\section{Study Proposal Abstract}

Abstract

For more than a century Western scholars and practitioners have developed leadership theories and models that have been tested and applied in Western Europe and the United States. However, these theories have jumped cultural boundaries. They have been distributed for use across the globe, including in the modern Arab Middle East (MAME). This trend has been particularly strong in western-oriented institutes of higher education that offer Master of Business Administration (MBA) programs across the Middle East. While Western-developed leadership theory is being taught, we do not have much information about their cross-cultural applications in the Middle East. The purpose of this research project is to explore the translation and application of Western leadership theories in the MAME where increasingly Western, and particularly American-centric universities, are offering courses and degrees.

The design of this study is interpretivist in its methodological framework, exploratory in strategy, and practice-oriented. It is interpretivist because the focus is on understanding the phenomenon of the use of western-developed leadership theories in the Middle East. It is exploratory in design as it will be a basis and a first step to future research and development of Middle East-centric models of leadership. Because the goal is practice-oriented, MBA programs at American-styled schools were chosen since they tend to have students who have both experience in leadership and an interest in developing their own personal leadership.

The MBA programs selected are from the universities of American University in Cairo, American University of Beirut, and the American University of Sharjah. The methodology consists of two phases. The first phase will review of program documents related to leadership as well as on set of visits to each school to be able to gather data "on the ground" that cannot be collected from afar. Informed by the first phase, the second phase will consist of two more visits to each school to gather information through semi-structured interviews of faculty, current students and alumni.

The goal is to use the information from this research in future studies and model design toward more effective leadership in the modern Arab Middle East.

Keywords: Middle East, Arab, leadership, leadership theory, MBA, cross-culture 


\section{Appendix I}

\section{Email to Faculty, Second}

To __ faculty...

For those I've emailed with before...

Studying Leadership Theory in MBA Programs in the Modern Middle East

Dr.

I had an informative and quite successful first visit to in July and am now preparing to visit again in a couple weeks.

Do you have availability to meet for half an hour or so on September ,or ? $?$ As you know, the focus of the study is on the experience of students and alumni in terms of leadership theory they were exposed to during their MBA program. Integral in this are you the faculty and your experience with the students. I'm free each of those days and will make any time work that works for you.

As a refresher, my original email is below and attached are some documents that may be of help.

I hope the rest of your summer was restful and you're ready for another term to begin!

Cheers,

Derek Olson

MA, PhD Candidate

derekolson@sandiego.edu

1-202-525-6858 


\section{To faculty...}

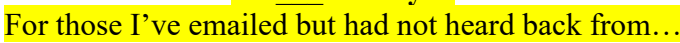

Studying Leadership Theory in MBA Programs in the Modern Middle East

Greetings Dr.

I am an adjunct professor at the University of San Diego who is near completing my $\mathrm{PhD}$ in Leadership Studies. Toward this end I am currently in the data collection stage of the process.

My topic, in brief, is focused on understanding how western-developed leadership theories are taught, absorbed, and practiced by alumni of MBA programs in the modern Arab Middle East.

Your research and teaching interest in may be very insightful to me and for the purpose of this study. Would it be possible for us to arrange a time for a 30 minute informal interview?

I made my first data collection trip to in July and am returning in a few weeks for a second round. I will be in __ and at AUC September __ through __. Any chance you are around and available any of these days? If not, could we arrange a phone call?

Attached is both my proposal abstract and a letter from my dissertation committee chair, Dr. Afsaneh Nahavandi.

Thank you for considering this. Your insights and experiences are important both for this study and for us to know how to better shape or create leadership models that serve the modern Middle East.

Cheers,

Derek Olson

MA, PhD Candidate

derekolson@sandiego.edu

1-202-525-6858 


\section{Appendix J}

\section{Interview Guide}

Dissertation

2019 Fall

Interview Guide

Style: conversational and informal while direct and clarifying

\section{Before MBA}

Where did you do your undergraduate study? What did you study?

Was style of education was it?

As an undergrad, did you learn about leadership or leadership theory?

Did you work before starting your MBA? If so, what industry and what did you do?

MBA

Why did you choose to do an MBA?

What brought you to this particular program?

Did you work during your MBA studies?

Did it seem like leadership was an important thing to learn in the MBA?

What do you think of the differences between leadership and management?

Was culture brought into the conversation about leadership? If so, how?

How did you experience the congruence between the leadership theory and culture?

Did your understanding and/or experience of leadership change between the beginning and end of the program?

\section{Post MBA}

What are you doing now? Was the MBA beneficial to it?

Does leadership theory make more sense/is it more relevant now?

What do you think is missing in the theories as it pertains to culture?

Anything else that seems important to know?

Concerning Emerging Themes (if not already covered...)

Developmental

Family Business

Entrepreneurship

Management vis-à-vis Leadership

Region in Crisis

Regional Focus 


\section{Appendix K}

Local, Regional, and International Perspective and Aim

\section{Table K1}

Local, Regional, and International Perspective and Aim, Documents

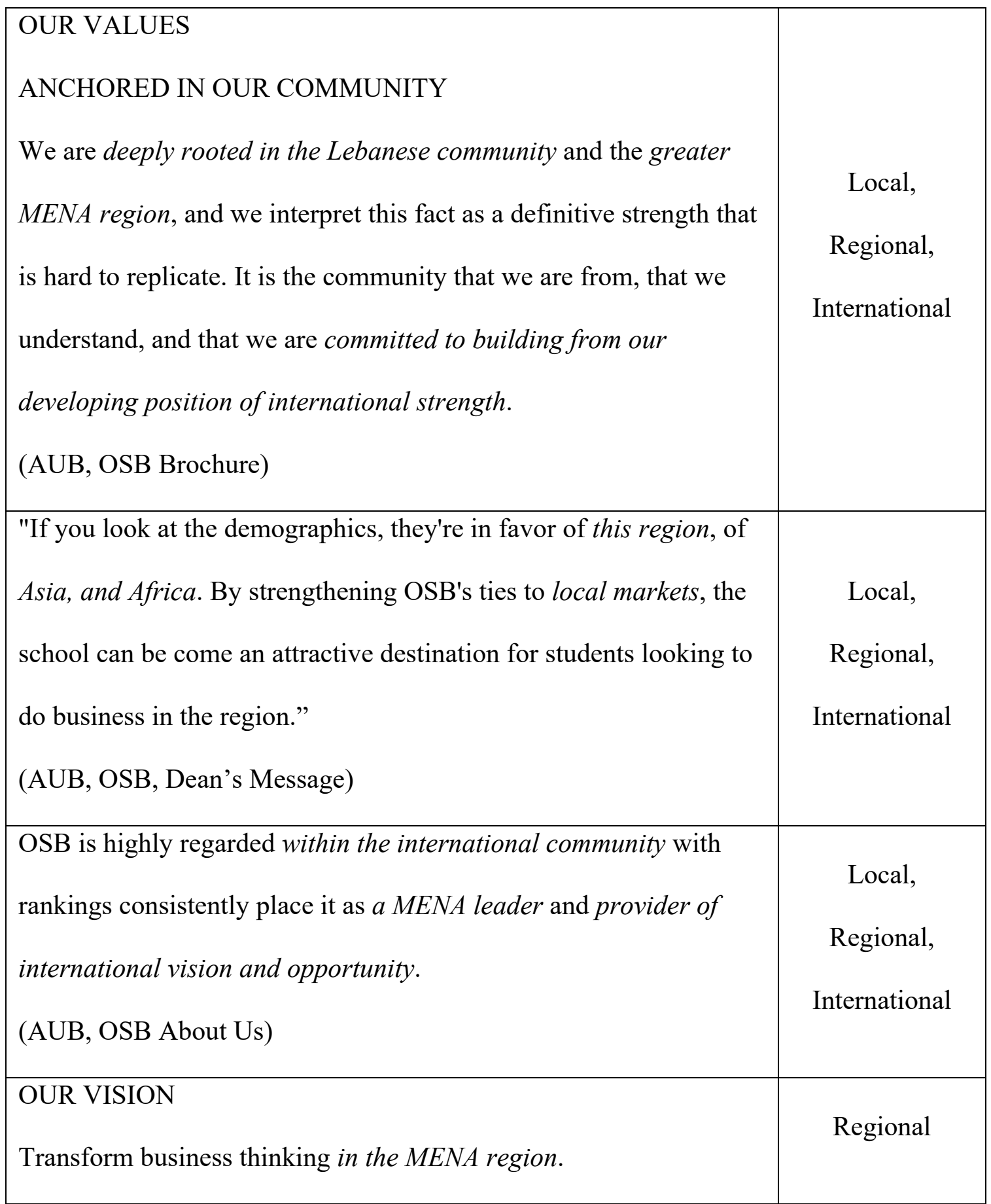




\section{OUR MISSION}

Enable world-class business research, learning, and knowledge transfer from our authoritative anchor point within the MENA region.

(AUB, OSB Brochure)

OSB boasts several research hubs and areas of excellence, manages global initiatives covering a wide array of subjects including data analytics, executive education, family business, entrepreneurship, corporate social responsibility, and features award winning faculty that hail from around the globe.

(AUB, OSB About Us)

Program Highlights

- A global community of alumni worldwide create a powerful network that lasts a lifetime

(AUB, OSB Graduate Catalogue 2019-2020)

Become a Global Business Leader

Shaping you into a competent global business leader is more than a headline. We've tailored our MBA program to become a stepping stone to new professional heights and aptitudes for all those seeking empowerment and growth. By incorporating a comprehensive body

International of knowledge and the right skills, the program will help you develop a managerial perspective to address the challenges and 


\begin{tabular}{|c|c|}
\hline $\begin{array}{l}\text { seize the opportunities of today's ever-changing local, regional and } \\
\text { global business environment. } \\
\text { (AUC, School of Business, MBA What We Offer) }\end{array}$ & \\
\hline $\begin{array}{l}\text { Given its international orientation, distinct location, an expanse of } \\
\text { expertise on regional issues, the School has identified three major } \\
\text { themes where it will provide the international as well as the } \\
\text { regional and local community with thought leadership and impact. } \\
\text { The themes are entrepreneurship and family business - a vital } \\
\text { engine for economic growth and job creation; responsible business } \\
\text { - an imperative vehicle for enabling social mobility and sustainable } \\
\text { growth; and finally economic development with a focus on } \\
\text { inclusiveness and accountability. These focus areas are of } \\
\text { increasing significance in a region on the threshold of economic } \\
\text { transformation and societal development. } \\
\text { (AUC, School of Business, School Themes) }\end{array}$ & $\begin{array}{l}\text { Local, } \\
\text { Regional, } \\
\text { International }\end{array}$ \\
\hline $\begin{array}{l}\text { AUC's School of Business is recognized as the top private business } \\
\text { school in Egypt and one of the best in the Arab world and Africa. } \\
\text { (AUC, MBA Brochure 2019-2020) }\end{array}$ & $\begin{array}{l}\text { Local, } \\
\text { Regional, } \\
\text { International }\end{array}$ \\
\hline $\begin{array}{l}\text { Enjoying seven decades' worth of history, the School of Business } \\
\text { has set the bar high for business education in Egypt, and the region } \\
\text { as a whole, since its inception. Our commitment to quality, pledge } \\
\text { for impact and ever-present sense of responsibility to develop future }\end{array}$ & $\begin{array}{l}\text { Local, } \\
\text { Regional }\end{array}$ \\
\hline
\end{tabular}




\begin{tabular}{|c|c|}
\hline $\begin{array}{l}\text { leaders and responsible change agents of tomorrow has inevitably } \\
\text { set the pace and paved the way in our every direction. } \\
\text { (AUC, School of Business, Message From the Dean) }\end{array}$ & \\
\hline $\begin{array}{l}\text { While the curriculum meets international standards, it also } \\
\text { addresses local and regional business issues. } \\
\text { (AUC, MBA Brochure 2019-2020) }\end{array}$ & $\begin{array}{c}\text { Local, } \\
\text { International }\end{array}$ \\
\hline $\begin{array}{l}\text { Our Vision } \\
\text { The School's vision is to be the leading knowledge hub with Arab } \\
\text { region relevance and global influence. } \\
\text { Our Mission } \\
\text { The School's mission is to develop entrepreneurial and responsible } \\
\text { global leaders and professionals. } \\
\text { (AUC, School of Business, Who We Are) }\end{array}$ & $\begin{array}{c}\text { Regional, } \\
\text { International }\end{array}$ \\
\hline $\begin{array}{l}\text { With the UAE's place as a business hub for the Middle East well- } \\
\text { established, many regional and international businesses have set up } \\
\text { offices here in addition to prominent local companies. These } \\
\text { companies manufacture, import and export a wide range of products } \\
\text { to countries throughout the region and all over the world. } \\
\text { (AUS, Master of Business Administration) }\end{array}$ & $\begin{array}{l}\text { Local, } \\
\text { Regional, } \\
\text { International }\end{array}$ \\
\hline $\begin{array}{l}\text { Graduates of our program are prepared to identify, analyze and } \\
\text { understand the interrelationships among business organizations and } \\
\text { international and domestic institutions in the UAE and throughout } \\
\text { the world. }\end{array}$ & $\begin{array}{c}\text { Local, } \\
\text { International }\end{array}$ \\
\hline
\end{tabular}




\begin{tabular}{|c|c|}
\hline (AUS, Master of Business Administration) & \\
\hline $\begin{array}{l}\text { 10. Reputation for excellence and innovation. American education } \\
\text { and local culture.... You will be able to take pride in having a deep } \\
\text { knowledge in management and leadership and a broad perspective } \\
\text { on business across the globe. } \\
\text { (AUS, Discover the AUS MBA Difference) }\end{array}$ & $\begin{array}{c}\text { Local, } \\
\text { International }\end{array}$ \\
\hline $\begin{array}{l}\text { Leadership } \\
\text { We believe in making a difference through our aspiration to be } \\
\text { leaders in the Gulf region. We constantly engage with businesses } \\
\text { and government so that our graduates will become future leaders } \\
\text { and our faculty lead the way with cutting-edge scholarship. } \\
\text { (AUS, Core Values "Join the ELITE") }\end{array}$ & Regional \\
\hline $\begin{array}{l}\text { The School of Business Administration (SBA) is well known in the } \\
\text { MENA region for the exceptional quality of its graduate and } \\
\text { undergraduate business programs. } \\
\text { (AUS, MBA Brochure) }\end{array}$ & Regional \\
\hline $\begin{array}{l}\text { Internationalization } \\
\text { Faculty in the department conduct research on the } \\
\text { internationalization of SMEs with specific foci on research } \\
\text { questions related the development and implementation of strategies } \\
\text { for internationalization, international entrepreneurship, services } \\
\text { internationalization, and foreign direct investment mechanisms in } \\
\text { developing countries. }\end{array}$ & International \\
\hline
\end{tabular}


(AUS, MBA, Areas of Research)

\section{Table K2}

Local, Regional, and International Perspective and Aim, Respondents

Many of my students are in their family's business that have offices in the Middle East and Europe. They must learn to work here in Lebanon and abroad. (Zain, AUB Faculty)

We very much want our students to have a glo-cal perspective. AUB is interested in Lebanon first but we live in an integrated world. (Kareem, AUB Faculty)

My students, the driven ones, all want to move to and work in the GCC. There aren't the opportunities here as there are in the UAE or Kuwait. (Zara, AUB Faculty) We serve Egypt but from an American perspective. That's why students come here. (Samir, AUC Faculty)

Egypt is a leading country in Africa and the Middle East North Africa. Our MBA students know this and want to lead. (Fatima, AUC Faculty)

We (faculty) in the MBA program are from abroad and the students appreciate that. Many, mostly the Emiratis, don't have a lot of experience with other cultures but they do if they are in business. (Raheem, AUS Faculty)

The program must focus both on the Emirates and the GCC because that's where our students have worked and led. (Danna, AUS Faculty)

Leaders here in the Emirates understand that the Emirates today are only this way because of the opening up to the world. (Zainab, AUS Faculty) 
We have to be interested in others because things are going on that we can't control. There is the war in Syria and the refugees and then there is Palestine. You know many people in the south are from Palestine? We have been a place where others come and stay and so in that we are leaders. We are looked to and so we must lead them. (Layla, AUB Alum)

Leaders must have internal and external views. That's one thing I learned the most from my MBA. I must both be looking at those I manage and lead but also must know what is going on around us. Here in Lebanon we have a bad past but there is bad right now in Syria and it directly affects us. (Yusef, AUB Alum)

You know Beirut used to be the Vienna of the Middle East and we will be again. Have you been downtown? It's beautiful and growing. If we can get a new government and be peaceful then we'll again be a place where Europeans will come to visit. (Omar, AUB Alum)

Is there a combination of local and global here? Yeah, I think so. It was different in my parent's time but OSB is really interested in both here and outside of it. (Ali, AUB Alum)

Here at AUC we are pretty much all Egyptian. And we are interested mostly in Egypt. But we do have a growing influence in Africa and we have to because of the Nile. And we also need to stay close with Saudi Arabia against Iran. (Malik, AUC Alum) The MBA program is almost all Egyptian but we get some others. They add a lot of helpful perspectives. When I was at AUC there was a guy from Italy and I liked his perspective. He was European but not typical European. He didn't look down on Egypt and wanted to stay and work after he graduated. (Amara, AUC Alum) 
I don't know if the program really wants students from far away. I think they want Egyptians and maybe some from the Gulf. ... I think Egypt wants to be more a part of the Middle East. We are not really Arabs and not Africans but we want to be involved in both areas. I know the company I work for has found success in expanding into Sudan and other parts of east Africa and we want to do more in Jordan. (Aliyah, AUC Alum)

Egypt and Cairo are at the X of Africa, Europe, and Asia. Everyone talks about how important Istanbul is but no, we are more important. We have a growing population that is better and better educated. (Abdullah, AUC Alum)

I came to AUS, I wanted my MBA from here because it's the best school and it's close to Dubai where I live. ... Yes, the school's is very much interested in Emiratization and the world. Look at Emirates airlines. People from all over the world fly here or through here and they come to know the UAE. They see what is built here and are amazed. (Khalil, AUS Alum)

The UAE wants to be the middle of the Middle East, they want to be the middle of the whole area. Kuwait and Qatar are also trying to do this but they are just following us. They might get other Arab's but I don't think others go. Have you? Everyone comes to the UAE to visit and work and so we are very international. Our leadership wants this very much. (Ahmed, AUS Alum)

I think we're becoming more Arab. We are Emiratis but we are more connected to others like Saudi Arabia. Where you here two days ago? It was Saudi's national day and did you see the Burj? It was lite up in the Saudi flag and there was the anthem and a message from MBS. (Hakeem, AUS Alum) 
One of the best things about studying here is that the other students and the UAE are both so diverse. ... I choose to stay and do school in my home country because we are so multi cultural. Look at all the people living in Dubai and Abu Dhabi from all over the world. My family is here and I'll stay here but we know how important it is to have others here.

(Jamal, AUS Alum) 


\section{Appendix L}

\section{A Changing Environment}

\section{Table L1}

\section{A Changing Environment, Documents}
The business environment is becoming increasingly dynamic, driven by the shifting impact of globalization, demographic change, emerging technologies, and the growing importance of embracing sustainable practices, ethics and corporate social responsibility. Our business education and knowledge sharing must be cognizant of this dynamic environment as we prepare our students to lead in today's ever-changing business environment.

(AUB, OSB Brochure)

Suliman S. Olayan School of Business develops leaders to excel in the constantly and rapidly changing business world. Through an immersive business education experience, students build a strong knowledge base and gain individualized skills to meet the economic and social challenges of the future.

(AUB, OSB, MBA Brochure)

OSB has been developing leaders and preparing them to excel in the constantly and rapidly changing business world. Through an immersive experience in business education, we will empower students to build a strong knowledge base and gain individualized skills to meet the economic and social challenges of the future. (AUB, OSB Graduate Catalogue 2019-2020)

Evaluation Criteria: The MBA program is the breeding ground for the leaders and entrepreneurs of tomorrow. We aim to develop students to excel in the constantly and 
rapidly changing business world. The MBA Admissions team looks to attract and admit candidates with balanced competencies including excellent analytical skills and leadership potential.

(AUB, OSB, MBA, Admission)

Dynamic political regimes, evolving economic systems and ever-changing social landscapes have become the new norm. In such a vibrant setting, keeping up with change is a challenging task on its own. Meanwhile, the corporate world keeps growing in complexity, competitiveness and uncertainty; it's survival of the fittest in today's business world. Any way you look at it, from an everyday life perspective or a business world outlook, today's world is changing and you need to step up if you plan on doing more than surviving.

(AUC, School of Business, Introduction)

Boasting an unrivaled reputation as the top private business school in Egypt and one of the best in Africa and the Arab world, the AUC School of Business is dedicated to transforming the young eager minds of today to the responsible change agents of tomorrow, all while developing relevance and leadership in an evolving ecosystem. (AUC, School of Business, Who We Are)

Become a Global Business Leader

Shaping you into a competent global business leader is more than a headline. We've tailored our MBA program to become a stepping stone to new professional heights and aptitudes for all those seeking empowerment and growth. By incorporating a comprehensive body of knowledge and the right skills, the program will help you 

develop a managerial perspective to address the challenges and seize the opportunities of today's ever-changing local, regional and global business environment.
(AUC, School of Business, MBA, What We Offer)
MBA: If you're searching for the knowledge and skills that will help you to pursue a management career, an MBA from AUC is the right step. It will introduce you to the tools you need to conduct constructive analysis and will help you develop a managerial perspective to address the challenges and seize the opportunities of today's ever- changing local, regional and global business environment. Take your first step towards the management ladder today.

(AUC, MBA, Online Information)

Today's world is no longer bound by geographical dispositions making today's market an open integrated space. Yet, with this openness come both unprecedented opportunities and challenges.

(AUC, MBA, Online Information)

Strategic Management of Innovation: Innovation is regarded as a critical source of competitive advantage in an increasingly changing environment. Innovation is production or adoption, assimilation, and exploitation of a value-added novelty in economic and social spheres; renewal and enlargement of products, services, and markets; development of new methods of production; and establishment of new management systems. ...

(AUC, MBA, Course Descriptions)

Our Master of Business Administration (MBA) program has been designed to provide our graduates with the skills they need to be competitive in today's dynamic, global 
marketplace. Business school graduates today must be exposed to the latest techniques and most current business practices if they are to be prepared to pursue careers in an ever-changing and complex world. The educational experiences our students have as they pursue their MBA at AUS prepare them for productive business careers and enable them to make valuable contributions to the organizations they join.

(AUS, Master of Business Administration)

The business world is changing and expanding constantly as we seek to develop markets and respond to the needs of consumers and companies.

(AUS, Master of Business Administration)

Leadership: Investigates the role of leadership in the context of global change. It gives particular attention to leadership issues as they pertain to organizational development, culture, and the dynamics of change.

(AUS, MBA, Course - Leadership Change Management)

\section{Table L2}

\section{A Changing Environment, Respondents}

Lebanon is always changing. Right now it's the government but in the past we've changed due to war. Our students know this and we try to prepare them for it. (Hamza, AUB Faculty)

Sometimes management and change don't always work well together. That's why teaching leadership to our students is important. Leadership and change are related, management and staying the same are related. (Kareem, AUB Faculty) 
We've made it through a lot of very difficult times. I remember the war and the Green Line. We made it through that and we'll make it out of the current government troubles. (Rashad, AUB Faculty)

We all know that we live in a world that is more integrated that ever. Because it's integrated more can go wrong more quickly. Our students know this and I try to help them to learn how to work best in it. (Samir, AUC Faculty)

The Arab Spring affected us greatly at all levels. Obviously the president changed several times but at a basic societal level we were changed. I'm afraid we are more clearly divided now but I don't know what this will mean. (Fatima, AUC Faculty) Business changes and so we prepare our students to work in that. It is the same back in Canada as it is here. Sure, the culture changes how the change looks but it's just all changing. (Marwa, AUC Faculty)

Our students are adept at working not only cross-culturally but also in different ways in different places. They understand that we must be flexible and....agile because the context is different and so we need different processes and techniques as things change. (Danna, AUS Faculty)

This school wasn't here a 30 years ago. This University City wasn't here 30 years ago. ... Education is a focus of the UAE government and it has payed off. The current generation of Emiratis are more educated than ever before and the country is attracting many from other parts of the region and India and Pakistan. The region and country are forever different because of it. (Zainab, AUS Faculty) Leadership is difficult in Lebanon because it is always changing. ... For my parents' generation it was the civil war where the country was destroyed. For my generation 
now it is the Syrian Civil War and the refugees here now. We have financial and government problems and we never know what will happen with Hezbollah and war with Israel. (Omar, AUB Alum)

Lebanon is chaotic, it is crazy. We have so many problems and we are so small. You would think that as a small country we could work well but we don't. That's why so many Lebanese leave and have left. ... When we have the opportunity to go somewhere most settled, more, how do you say it, stable, we do. We love our country and love being Lebanese but it's a difficult place to live. (Ali, AUB Alum) My family's business... has had a hard time growing. There were a few decades, starting in the 90s, but when the war in Syria came here it became hard. We have stores all the way up to Tripoli and down to Tyre and wanted to expand into Syria but can't because of the war. Alum, (Yusef, AUB Alum)

I think so many of my friends went to the Gulf because it's safer. Even after the recession the Gulf is growing and is stable. Lebanon, we don't know where it is going. ... I'm here because of family, otherwise I would try to work in Dubai or Abu Dhabi. (Layla, AUB Alum)

The Arab Spring was good and bad. Mubarak had been in power too long but he wasn't bad. Morsi was very bad, very corrupt. Those years gave us much grief. But was it worth it? Yes, I think so. Now the president is making reforms that are difficult in the short term but will be good for us in the long term. An example is the increasing cost of fuel. For many years gas was subsidized and now it is almost not at all. It's a shock to the economy but it will be good in the long term. ... Our leaders sometimes come from chaos and sometimes are the ones who make it. (Malik, AUC Alum) 
Egypt is on a good path, in a good way. We need stability after the Arab Spring. You know I was there, I was in Tahrir marching. Me and many friends, we were young. I had a friend killed and many beaten. I was gassed by tear gas. It was crazy times. We wanted democracy and a change but it was difficult. ... And now we have good leaders who are moving us forward. President Sisi is building a new capital and we are safer. The terrorists are being arrested and tourists are coming back. ... Where I work in business we are hopeful. (Amara, AUC Alum)

The revolutions, both of them, changed Egypt a lot. We, the young generation, were changed a lot.... I'm not sure it's over. I think we are more stable because of the president but there are still a lot of unhappy people. Many people supported Morsi and when we removed in the coup they were upset. I would have been too, but I did not support him. We are upper class and it's mostly the lower classes, the conservative religious, that supported him. But he just wanted power and not to move Egypt forward. You could see this in his "reforms." He tried to change everything and put Muslim Brotherhood people in all parts of the government. When we saw that and heard the stories we knew he couldn't stay. The Spring is over but we don't know the end of the story. (Abdullah, AUC Alum)

The economy is changing and that's why I like AUC's interest in entrepreneurship. They know that change is happening and that we must work with it. We don't want to be like a Syria, we want to be like a Dubai. ... I think we're changing because the world is changing. I think it's faster and faster and we in business have to keep up with it. I hear people talking about leading change but I don't know if that is possible. 
I heard that in school. I think I have to respond to change because the change is so big and what I can control for my business is so small. (Aliyah, AUC Alum)

You know that we've changed so much in just a few decades. These cities (Dubai and Abu Dhabi) didn't exist, the financial centers didn't exist, the construction didn't exist, the tourists didn't exist. And it's from our leaders, the leaders of the Emirates did this, they had the vision. Have you read Sheikh Mohammed bin Rashid Al Maktoum's My Vision? You should read it, buy it before you leave. You'll see how he sees leadership and what he wants for the Emirates. (Ahmed, AUS Alum)

Well, we are in a part of the world that is uncertain. We don't know what will happen with Iran or Iraq or Syria. Same for Yemen. There is all this war but then there is places like here that is growing and prosperous. And Saudi is opening up. So you have some countries going into destruction and some, like us, who want to be safe and grow and don't want to fight so much. (Yasen, AUS Alum)

I have seen so much change. When I started in finance in my 20s Dubai had a few new buildings and now you see it. I went to work in Europe and came back and couldn't believe it. My family would tell me the changes but I didn't understand it until I saw it. ... When I was a kid we didn't travel and I don't think anyone knew where Dubai was. But now everybody knows us and we go everywhere. Last weekend I went to Kenya because it was a fast flight and I wanted to see part of Africa. ... People coming here and us going to other places has made so much change. (Hakeem, AUS Alum) 


\section{Appendix M}

Entrepreneurship and Innovation

\section{Table M1}

Entrepreneurship and Innovation, Documents

\section{OUR VISION}

Transform business thinking in the MENA region.

(AUB, OSB Brochure)

\section{OUR VALUES}

\section{DARING}

We allow ourselves to work differently, experiment where others might caution, and explore as a means to keep ourselves fresh and relevant. Daring is a mindset that allows us to be innovative, entrepreneurial, and creative in our way!

(AUB, OSB Brochure)

Evaluation Criteria: The MBA program is the breeding ground for the leaders and entrepreneurs of tomorrow. We aim to develop students to excel in the constantly and rapidly changing business world. The MBA Admissions team looks to attract and admit candidates with balanced competencies including excellent analytical skills and leadership potential.

(AUB, OSB MBA Admission)

OSB boasts several research hubs and areas of excellence, manages global initiatives covering a wide array of subjects including data analytics, executive education, family business, entrepreneurship, corporate social responsibility, and features award winning faculty that hail from around the globe. 
(AUB, OSB About Us)

Program Highlights

- Flexible, innovative curriculum which fosters collaboration, community, teamwork and an entrepreneurial spirit

(AUB, OSB Graduate Catalogue 2019-2020)

MBA Elective Courses: New Venture Management, Social Entrepreneurship

MBA Tracks: Entrepreneurship and Family Business

(AUB, OSB Graduate Catalogue 2019-2020)

Our Mission: The School's mission is to develop entrepreneurial and responsible global leaders and professionals.

(AUC, MBA Brochure 2019-2020)

Entrepreneurship

Entrepreneurship is driven by a new generation that is better educated, technologysavvy, less risk-averse and more exposed to investors, mentors, and multinationals. Entrepreneurship is, therefore, a key driver of economic growth, social and economic development, and engaged citizenship in Egypt and the Arab region. AUC's School of Business is leading the effort to enhance entrepreneurship education through new concentrations and the expansion of course offerings on both the undergraduate and graduate levels. The school is also partnering with top universities worldwide, and its faculty members are some of the leading experts in the field. The school's executive education unit is developing more programs geared toward entrepreneurs, while numerous outreach efforts are conducted through the Center for Entrepreneurship, AUC Venture Lab and Entrepreneurship Society Student Club. In addition, the school 


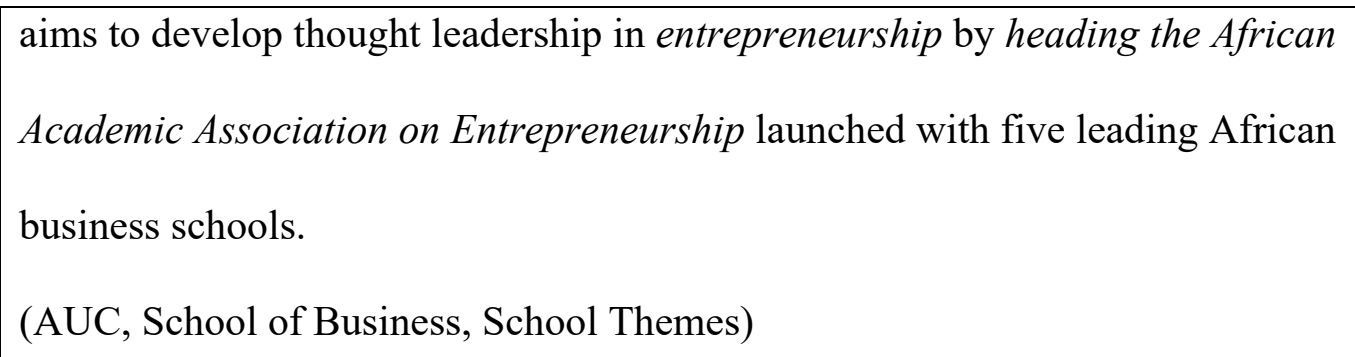


production or adoption, assimilation, and exploitation of a value-added novelty in economic and social spheres; renewal and enlargement of products, services, and markets; development of new methods of production; and establishment of new management systems. This course will study the theory and practice of innovation as a process and an outcome based on a comprehensive model of innovation which consists of three determinants: innovation leadership, managerial levers and business processes. The course will examine the impact of accelerating innovation on cost, product quality and marketability; organizational changes required to couple $R \& D$ with marketing and commercialization; and the managerial skills and professional expertise needed to develop a sustainable innovation practice within an organization.

(AUC, MBA Course Descriptions)

Alongside our academic and professional programs, the School boasts five research centers,

a renowned startup incubator in the $A U C$ Venture Lab and a business knowledge portal in Business Forward - which all aim to enrich knowledge in the School's focus areas of entrepreneurship, family business, responsible business and economic development. (AUC, School of Business, Message From the Dean) The Master of Business Administration (MBA) program at American University of Sharjah (AUS) is like no other MBA in the region. Our mission is to prepare you for leadership positions in the private and public sector. Our program is designed to enable talented future leaders to make a vertical leap in their current career path, change job function or industry, or acquire an entrepreneurial toolkit to start or develop their own business. Our program adapts state-of-the-discipline business 
knowledge to the needs of the local market, allowing students to integrate new knowledge into business problem solving for a global context.

(AUS, School of Business Administration, MBA, Overview)

Some students choose to become successful entrepreneurs.

(AUS, School of Business Administration, Deans Message)

Knowledge Management

Faculty in the department conduct research on Knowledge Management with specific foci research questions related to the transfer of knowledge management both within and between organizations, knowledge utilization, and innovation strategies and technical transfer in SMEs.

(AUS, School of Business Administration, Areas of Research)

4. General MBA or concentrate on key areas. You can choose a generalist MBA or select one of our four concentration areas: Finance, Human Resources Management, Management Consulting, and Innovation and Entrepreneurship. ...

10. Reputation for excellence and innovation....

(AUS, School of Business Administration, Discover the AUS MBA Difference)

AUS is filled with world-class faculty and students, poised to become the innovators, thinkers, contributors and leaders of tomorrow.

(AUS, School of Business Administration, MBA Brochure)

Innovation and Entrepreneurship: Introduces business innovation and explores the entrepreneurial process through which new ideas become the basis for viable enterprise.

(AUS, School of Business Administration, Graduate Course Descriptions) 


\section{Table M2}

Entrepreneurship and Innovation, Respondents
I think our program sees entrepreneurship as one of the ways forward. We are a management program but it's hard to manage entrepreneurship. Entrepreneurship is a leadership thing. (Hamza, AUB Faculty)

I teach a course in the entrepreneurship and family business track and am not sure why both are in the same track, it seems to me they should be separate. Either way, our school and program understand that these are not just trends in global business but are vital for Lebanon to move forward. ... We can't do what we've always done and expect to grow and move forward. (Rashad, AUB Faculty)

Innovation is the technical part and entrepreneurship is the social part. Innovation can be in physical ways but also in structural ways. Entrepreneurships is about moving people forward whether that is as individuals or as a group. (Zain, AUB Faculty) One of the school themes that I'm particular proud of is entrepreneurship. I don't teach any of the courses in this but I integrate the concept into each of the courses I do teach. ... It's the same as leadership, it should be in all parts in all organizations. (Marwa, AUC Faculty)

Do you know about the V Lab? I'm proud that our school has created this and it's been so successful. It's a place where our students can bring their dreams and, with help from our school, create those dreams. (Samir, AUC Faculty)

We talk a lot about innovation and entrepreneurship but I don't know how much sticks. Most of our students already have good jobs and are looking to be financially 
successful. ... I did have one kid last year who wanted to go back to Jordan and start some businesses. He was very motivated and said he has his family's backing. His family has multiple business in Jordan. (Noor, AUS Faculty)

Our school is well situated for being a hub of entrepreneurship and innovation. We have the divers population, infrastructure, and connections to the world. ... It is highly valued by the school and us faculty. (Zainab, AUS Faculty)

We have to innovate, we must. Innovation and business go together. I took the innovation track during my MBA program and am happy that OSB had it. ... Innovation is not just a hot topic in business, it's something that has always happened but we have not been good about it in Lebanon. With new technologies of communication anyone can be an entrepreneur, you don't just have to be in Silicon Valley. (Omar, AUB Alum)

I don't know much about innovation but I know that entrepreneurship is important. I took a class that focused on this entrepreneurship both in starting new businesses and doing it in existing businesses. I had always thought of it as something that happened when you started out new and wanted to be the next uni, like Careem. But now I know that a lot of entrepreneurship and innovation can happen in already successful companies. (Ali, AUB Alum)

Do you know about the Venture Lab? I haven't worked with them directly but I have friends who have launched businesses through the Venture Lab. They are all about entrepreneurship and startups. They're quite successful and are known in the region as a place to come and get training ... I think they train on a lot of things including 
leadership. I don't know specifics but I know the Venture Lab is an important part of AUC's business school for students and the area. (Abdullah, AUC Alum)

Egypt has so many problems that we need innovation. The problem is that most people who are innovating are at the top. They have the money and the time but the people who need it are all the normal people. We have 100 million people and many are so poor. The innovation needs to be for all the people at the bottom.... I think that's were leadership is. We have managed so much for so long and it's been ok but we need to do it different. ... The people I saw in school wanting to be entrepreneurs wanted it to be rich but they didn't really want to help others. (Malik, AUC Alum)

Innovation and entrepreneurship were talked a lot about in the program. There was one of the courses we had to take, I think, that was all about in this. ... I don't remember if there was a difference in this between management and leadership but I think it has to be both.... You know we're so influenced by America and we see the companies like Uber and their massive success and we want it. I think that's why the program focuses on it, it's because it's an American school. (Aliyah, AUC Alum) It's hard to be innovative in the UAE because there are so many companies already trying to do so many things. I remember a few of my classes it came up in but I don't think it was very interesting to most of us. Like, I know we always need to be progressing and changing but I don't think it always has to be called innovation or entrepreneurship. Sometimes these words are used too much when it's just something we should all be doing. (Jamal, AUS Alum)

I took the entrepreneurship concentration and really loved it. It was exciting to think about and plan for building something new. I remember we had a project in one of the 
classes where we had to put together a business plan for a new venture and the part I liked the most was looking for what people want but cant get right now. The company I proposed was one like a podcast for visitors to the UAE that gave you history on hundreds of spots and locations from Abu to Fujairah. ... It would make jobs for people across the UAE and let tourists know our country better. ... I have so many ideas of what I think we need. (Ahmed, AUS Alum) 


\section{Appendix N}

Family Business

\section{Table N1}

Family Business, Documents

OSB boasts several research hubs and areas of excellence, manages global initiatives covering a wide array of subjects including data analytics, executive education, family business, entrepreneurship, corporate social responsibility, and features award winning faculty that hail from around the globe.

(AUB, OSB About Us)

MBA Elective Courses: Family Business Management

(AUB, OSB Graduate Catalogue 2019-2020)

MBA Tracks: Entrepreneurship and Family Business

(AUB, OSB, MBA Curriculum)

Entrepreneurship: Developing expertise on family businesses that started up as entrepreneurial ventures and currently represent more than $80 \%$ of total companies in the region is another area of focus for the School. Within entrepreneurship - this entails the development of high-quality case studies, an introduction of courses on family business, as well as collaboration with regional institutes in joint research analyzing succession plans, governance, and the effect of regulations, culture, and environment on family business.

(AUC, School of Business, School Themes)

AUC's School of Business programs are based on entrepreneurship, family business, responsible business, and economic development. 
(AUC, School of Business, MBA Brochure 2019-2020)

Alongside its academic and professional programs, the School contains five research centers, a startup incubator and a business portal that collectively enrich knowledge in the School's focus areas of entrepreneurship, family business, responsible business and economic development.

(AUC, School of Business, Who We Are)

Alongside our academic and professional programs, the School boasts five research centers,

a renowned startup incubator in the AUC Venture Lab and a business knowledge portal in Business Forward - which all aim to enrich knowledge in the School's focus areas of entrepreneurship, family business, responsible business and economic development. (AUC, School of Business, Message From the Dean)

Family Business

Faculty in the department conduct research on Family Business with specific foci on research questions related to the goal-setting process of family business firms, succession and successor attributes, corporate governance and governance attributes of family business firms, and family business questions related to regional development and public policy.

(AUS, School of Business Administration, Areas of Research)

The school's research is further endorsed by three research chairs and a professorship: the Bank of Sharjah Chair in Banking and Finance, the Said T. Khoury Chair in Leadership Studies, the Sheikh Saoud Bin Khalid Bin Khalid Al Qassimi Chair in 
Family Business, and the Chalhoub Group Professorship in Luxury Brand Management.

(AUS, School of Business Administration, Deans Message)

Our team was involved in a set of teaching, research, and knowledge transfer activities to provide sustainable support to family businesses by creating value for business families and regional communities.

(AUS, School of Business Administration, Chair in Family Business Activity Report) Four courses of "Fundamentals of Family Business" were delivered during the academic year 2018-2019. More than 70 students have received education and training on how to govern and manage family business.

(AUS, School of Business Administration, Chair in Family Business Activity Report)

Student Exchange Experiences: Mexican students from Universidad Panamericana visited American University of Sharjah. We hosted them at our Family Business Course to discuss family business in Mexico and the UAE.

(AUS, School of Business Administration, Chair in Family Business Activity Report)

\section{Table N2}

Family Business, Respondents

We have many family businesses in Lebanon but many more in the region and in Europe. Some of these are large and span several countries and many are small, local ones. ... Our students who are part of family businesses are already in management and are being groomed to move up in the future. (Zain, AUB Faculty) 
Our school has several research foci, including family business and leadership. And we have a track in family business that I believe the chair and dean want to expand because of significant interest. (Kareem, AUB Faculty)

Family businesses in Egypt are either large and influential or mirco. You walk out this building and there are a dozen family business on this street alone but they are all small and will stay small. Then we have the large family businesses that work across the country and region. Managing and leading these (large) family organizations is complex because not everyone is treated equally. Some are ok with this and some are not. (Samir, AUC Faculty)

One of our research centers is family business. I'm not sure how important it is here in Egypt but it is certainly so for the MENA. ... Family business and the government are also closely tied, much more so that in the United States. (Fatima, AUC Faculty) Family business is big business in the UAE and that's why our school has such a heavy emphasis on it. Even students not from the UAE come here because they have family businesses somewhere in the Gulf. ... Leadership and succession is an important and complicated for these companies. (Noor, AUS Faculty)

There is a dedicated chair here at AUS for family business that was given as a gift from one of the seven royal families. They see family business and politics on a macro scale, similar to the Al Saud family. (Zainab, AUS Faculty) I am the VP of ... at my family's business. I grew up at my family's first store and felt as if I was groomed to always be a part of it. Family is very, very important to us Lebanese and so working together is very common.... My father is slowly taking steps 
backward and allowing me and my brother and sisters to take over. (Layla, AUB Alum)

I currently work for a family business but I'm not part of the family. I grew up as best friends with the patriarchs son and so that's how I started there. ... I see how strong the business is because of it's family. What I mean, yany, is not the small family but the big family. The bigger family has a network and the network has a network. The business has grown because of these networks. This can happen in a small country that has a strong identity, I'm not sure if it would work the same in bigger countries. (Ali, AUB Alum)

Businesses based on family's are important here but there can be problems. We have this word, I don't know how to translate it, but it has to do with how you treat people. Sometimes, not always, some will treat their family or their group differently that others. This can be in politics too. ... It's expected here, it's not a problem because everyone does it. It's natural to take care of those closer to you first and then others if you can. (Omar, AUB Alum)

Family business is very important for many of the people in my MBA group. They were typically older, maybe some were in the EMBA. I remember a lot of talk about succession and governance but I didn't have much experience in it in family businesses. Governance is one of my skill areas but it's very different in family business and I don't do much with that. I think that family compilates business and the larger the business and family the more complicated it is. I remember one guy telling a story about how he wanted two of his brothers to not be part of the company anymore because they didn't do anything. He was also pissed that all of his sisters were left out 
of important positions. They were part of the company but all the guys had the top positions. I remember him being very angry about this. (Aliyah, AUC Alum)

I think family business in the Middle East is an important the past but I don't know what it looks like in the future. You know, we were not as connected to the world as now. It's communication and it's transportation. ... Family businesses today are harder to start because there's more competition from places like the Gulf or Europe. I know there are a lot of small family business but I'm not talking about those. They will not grow. I'm talking about the already established business. It's harder now to start a business, family or not. Unless you start and grow fast you probably succeed. (Abdullah, AUC Alum)

The family businesses in the UAE are all connected together and connected to the government. They work things out so that there isn't really any competition. Like, for example, you see all these constructions? Go to downtown Dubai and what are the two big development companies you see? Damac and Emaar. Their names are everywhere, on all the buildings. They don't actually compete but work with the government and split up who will build what. Competition here is fake news. But who can be upset? We have grown and will keep growing. The government leadership has changed this here so much and even in bad times they made good decisions. (Yasen, AUS Alum)

When we talk about family businesses we talk about the big ones, the established ones. I don't think we'll see new ones start. Their life-cycle early on is very slow and our society is not slow anymore. It is very fast. And besides, there are only a small number of actually families in the UAE. The population has grown so fast because of 
those moving here not because there are more Emiratis. ... The other students in my MBA program who were interested in family business were part of big name families. They were here to get the business skills so they could have more legitimacy in the business. They needed the degree and the right words to use. (Khalil, AUS Alum) I think family business and different leaders are hard to talk about together. You have one leader of the business and so how why would you talk about others being leaders. You could lead a division but you aren't "the leader" that everyone talks about. Especially in family businesses the leader is the top, the head of the family. The best example is Sheikh Mohammed bin Rashid, the head of Dubai. He is the head of his family and the head of Dubai and second head in UAE. I don't think we should see business, family, and government very separate. (Jamal, AUS Alum) 


\section{Appendix O}

\section{Management}

\section{Table 01}

\section{Management, Documents}

The Master of Business Administration (MBA) program, in existence at AUB since the mid-1940s, is committed to the highest standards of quality in graduate management education. It is a general management program that encompasses different areas of business and offers a robust knowledge platform comprised of a set of functional, cross-functional, and skill-based, core and elective courses. Our courses will provide students with opportunities to learn, practice, and lead. Our graduates will acquire the vital knowledge and skill set needed to go on and build prosperous careers in various industries, including, management consulting, entrepreneurship, banking, marketing, media, and other. Our students can tailor their learning experience to suit their individual needs by choosing electives from various education streams, including relevant courses from various disciplines and faculties across campus.

(AUB, OSB, MBA Curriculum)

\section{Program Highlights}

- Rigorous academic theory is linked with real-world practice to build fundamental leadership and management skills

(AUB, OSB Graduate Catalogue 2019-2020)

MBA Core Courses: Advanced Seminar in Strategic Management, Operations and Process Management, Marketing Management

(AUB, OSB Graduate Catalogue 2019-2020) 
MBA Elective Courses: New Venture Management, Family Business Management, Human Capital Management, Change Management, Trending Issues in Management, Special Topics in Management, Services Marketing Management

(AUB, OSB Graduate Catalogue 2019-2020)

MBA Tracks: Health Care Management, Human Resource Management

(AUB, OSB, MBA Curriculum)

\section{CAREER OPPORTUNITIES}

Our graduates acquire vital knowledge and skills and go on to build prosperous careers in various industries, including management consulting, entrepreneurship, banking, marketing, media, and others.

(AUB, OSB, MBA Brochure)

MBA Program Overview: The MBA is an internationally recognized degree that focuses on helping future managers discover and further develop their skills for a rewarding career in business management...

(AUC, School of Business, MBA Brochure 2019-2020)

MBA: If you're searching for the knowledge and skills that will help you to pursue a management career, an MBA from AUC is the right step. It will introduce you to the tools you need to conduct constructive analysis and will help you develop a managerial perspective to address the challenges and seize the opportunities of today's ever-changing local, regional and global business environment. Take your first step towards the management ladder today.

(AUC, School of Business, MBA Online Information) 


\section{Our Curriculum}

Curated and refined over decades, our MBA program awards students with a versatile "toolbox" of analytical skills and technical competencies that are the main drivers of today's business professional's success. Meeting international standards all while addressing local and regional business peculiarities, our MBA is one of the most relevant and eclectic degrees offered in the region.

(AUC, School of Business, MBA, What We Offer)

MBA Foundation Courses: Managerial Economics, Financial Management, Managing Organizations in a Dynamic Environment, Managing Human Capital, Marketing Management, Operations Management for Competitive Advantage, Strategic Management

(AUC, School of Business, MBA Brochure 2019-2020)

MBA Electives: Investments and Portfolio Management, International Financial Management, Strategic Brand Management, Managing and Coordinating Supply Chains, Managing Dynamic Projects, Selected Topics in Operations Management, Construction Management, Strategic Management Of Innovation (AUC, School of Business, MBA Brochure 2019-2020) Management: Faculty members in the Department of Management purse and active research agenda with work appearing in many top journals in Management including...

(AUS, School of Business Administration, Areas of Research)

AUS MBA graduates are excepted to achieve the following objectives: (1) proficiency in the core business knowledge required of an executive manager; (2) understanding of 
the interrelations between business organizations and other societal situations; (3)

excellent teamwork, interpersonal communication and leadership skills; and (4) excellent decision-making skills rooted in critical thinking, analysis and problem solving.

(AUS, School of Business Administration, MBA, Overview)

Courses: Managerial Economics, Management Decision Analysis, Financial

Management, Management Information Systems, Operations and Supply Chain

Management, Managerial Accounting, Marketing Management, Strategic Management

(AUS, School of Business Administration, Graduate Course Descriptions)

Through our MBA program, students are prepared for careers in management and leadership positions in both the private and public sectors.

(AUS, School of Business Administration, Masters of Business Administration)

4. General MBA or concentrate on key areas. You can choose a generalist MBA or select one of our four concentration areas: Finance, Human Resources Management, Management Consulting, and Innovation and Entrepreneurship.

(AUS, School of Business Administration, Discover the AUS MBA Difference)

The master of business administration (MBA) program is designed to offer a highquality, comprehensive and gulf-oriented approach to the development of management and leadership skills.

(AUS, School of Business Administration, Graduate Programs) 


\section{Table $\mathrm{O2}$}

Management, Respondents

Do we have a preference of management over leadership? Yes, absolutely. This is an MBA program and so management administration is the predilection. ... Leadership has a place and it's not at the center of the education we offer to students. (Hamza, AUB Faculty)

We do offer a course in leadership that all students must take. I don't teach the course but have heard very good things about it. I approve that we require students to take it because it's like the other side of management. You can't have one without the other but management is easier to understand. (Rashad, AUB Faculty)

In Egypt management is the norm. I think it comes from both our culture of control and the influence of the Soviets. Before we were close with America we were close with the USSR.

They are very about managing and controlling things. (Marwa, AUC Faculty) Management and the Arab culture are congruent. Egyptians are not fully Arab but we are very similar. We like management because in a region with such limited resources and a growing population we need to be very careful about the resources. ... Leadership is important but not at the top of our priorities of the society. (Fatima, AUC Faculty)

We could do a better job with teaching leadership but the fundamentals of the program is management. I don't know how many other faculty have taught outside of business schools but it's what business schools do is teach management. (Samir, AUC Faculty) 
Most of our students are younger and so we start with management. I think leadership
is very important but if you don't have management as a foundation then you can't
understand leadership. (Danna, AUS Faculty)
I teach courses in...management and more and more students have interest in
leadership. I encourage them to take the leadership course but very much stick to the
content that is important in these courses. (Zainab, AUS Faculty)
We here at AUS and specifically at the school of business are attempting a delicate mix
of what is Emirati and what is American. We get a lot of students because it is the
American University of Sharjah. Our business program is supposed to be similar to
what is taught in America which is traditionally management. (Raheem, AUS Faculty)
I think of management and leadership in the way of hard and soft skills. Hard skills
you can know, you can learn them, they are real. Soft skills are harder to know. Like I
don't get them, or I don't know how to fully use them. It takes more energy and time
and I don't know if I'm doing it right. Hard skills are clear, or black and white.
(Yusef, AUB Alum) When you apply to MBA programs you read all the materials and talk with recruiters and they all talk about leadership and innovation. But then when you take your courses they are all about management. I think we all like the idea of leadership and innovation but the day-to-day is management and so that's what we need to learn fully. (Omar, AUB Alum)

Business is all about management. You must be able to manage people, finances, operations and the rest. Leadership is part of this but only a part. (Malik, AUC Alum) 


\begin{tabular}{l} 
All leaders are managers but not all managers are leaders. So when I came to this \\
program I wanted the managerial skills. The leadership skills, I'll need those if I \\
become a leader in my organization. (Abdullah, AUC Alum) \\
\hline I know some of my classmates wanted to learn more about leadership but I think that's \\
not important when you're still learning business. I wanted to know more about how \\
do I do this, how do I do that. (Aliyah, AUC Alum) \\
I think us Arabs understand management, we get it. Like we don't have to be taught \\
what it is. But leadership is a different thing that is similar but unclear to us. \\
(Hakeem, AUS Alum) \\
My parents' generation only uses the Arabic phrase for what Americans mean for \\
leadership to talk about government leaders. Management, or the people doing it, is \\
very common for my father to talk about. (Yasen, AUS Alum) \\
I'm not sure how real leadership is. I mean, we use it all the time but sometimes its for \\
specific people or their job but then some say everyone is a leader. It might real but \\
I'm still not sure how important it is. (Jamal, AUS Alum)
\end{tabular}




\section{Appendix P}

\section{Professional and Personal Development}

\section{Table P1}

Professional and Personal Development, Documents

The Master of Business Administration (MBA) program, in existence at AUB since the mid- 1940 s, is committed to the highest standards of quality in graduate management education. It is a general management program that encompasses different areas of business and offers a robust knowledge platform comprised of a set of functional, cross-functional, and skill-based, core and elective courses. Our courses will provide students with opportunities to learn, practice, and lead. Our graduates will acquire the vital knowledge and skill set needed to go on and build prosperous careers in various industries, including, management consulting, entrepreneurship, banking, marketing, media, and other. Our students can tailor their learning experience to suit their individual needs by choosing electives from various education streams, including relevant courses from various disciplines and faculties across campus.

(AUB, OSB, MBA Curriculum)

OSB has been developing leaders and preparing them to excel in the constantly and rapidly changing business world. Through an immersive experience in business education, we will empower students to build a strong knowledge base and gain individualized skills to meet the economic and social challenges of the future.

(AUB, OSB Graduate Catalogue 2019-2020)

Evaluation Criteria: The MBA program is the breeding ground for the leaders and entrepreneurs of tomorrow. We aim to develop students to excel in the constantly and 
rapidly changing business world. The MBA Admissions team looks to attract and admit candidates with balanced competencies including excellent analytical skills and leadership potential.

(AUB, OSB MBA Admission)

Suliman S. Olayan School of Business develops leaders to excel in the constantly and rapidly changing business world. Through an immersive business education experience, students build a strong knowledge base and gain individualized skills to meet the economic and social challenges of the future.

(AUB, OSB, MBA Brochure)

\section{FACULTY}

Our MBA Program draws the most influential and innovative business thinkers and leaders to campus to address, teach, and mentor students. The students will be surrounded by an adventurous learning community of passionate, highly motivated people who want to improve your experience and the world.

(AUB, OSB, MBA Brochure)

Become a Global Business Leader

Shaping you into a competent global business leader is more than a headline. We've tailored our MBA program to become a stepping stone to new professional heights and aptitudes for all those seeking empowerment and growth. By incorporating a comprehensive body of knowledge and the right skills, the program will help you develop a managerial perspective to address the challenges and seize the opportunities of today's ever-changing local, regional and global business environment. (AUC, School of Business, MBA, What We Offer) 
MBA: If you're searching for the knowledge and skills that will help you to pursue a management career, an MBA from AUC is the right step. It will introduce you to the tools you need to conduct constructive analysis and will help you develop a managerial perspective to address the challenges and seize the opportunities of today's everchanging local, regional and global business environment. Take your first step towards the management ladder today.

(AUC, School of Business, MBA Online Information)

Mission of the Department of Management: Our mission is to develop business leaders who are dedicated to the betterment of society by providing a high quality business education to top caliber students from all segments of the Egyptian society as well as from other countries while focusing on continuous improvement and a commitment to excellence in learning, intellectual contributions, and service (AUC, School of Business, MBA Course Descriptions)

In 2014, the entire school received accreditation from EQUIS. A high level of academic quality, professional relevance, innovation, and internationalization are required to achieve EQUIS accreditation. EQUIS accredits programs that focus upon the development of managerial and entrepreneurial skills.

(AUC, School of Business, MBA Brochure 2019-2020)

Dynamic political regimes, evolving economic systems and ever-changing social landscapes have become the new norm. In such a vibrant setting, keeping up with change is a challenging task on its own. Meanwhile, the corporate world keeps growing in complexity, competitiveness and uncertainty; it's survival of the fittest in today's business world. Any way you look at it, from an everyday life perspective or a 
business world outlook, today's world is changing and you need to step up if you plan on doing more than surviving.

(AUC, School of Business, Intro)

The Master of Business Administration (MBA) program at American University of Sharjah (AUS) is like no other MBA in the region. Our mission is to prepare you for leadership positions in the private and public sector. Our program is designed to enable talented future leaders to make a vertical leap in their current career path, change job function or industry, or acquire an entrepreneurial toolkit to start or develop their own business. Our program adapts state-of-the-discipline business knowledge to the needs of the local market, allowing students to integrate new knowledge into business problem solving for a global context.

(AUS, School of Business Administration, MBA, Overview)

The AUS Master of Business Administration (MBA) offers early-and mid-career professionals the opportunity to further their education, gain practical application skills, develop important networks and become part of global elite of MBA-qualified individuals. An AUS MBA will set you well on the pathway to achieving your professional and career goals.

(AUS, School of Business Administration, MBA Brochure)

A student experience in SBA is one of self-discovery and personal development, in an enriching and multicultural environment.

(AUS, School of Business Administration, Deans Message)

Our Master of Business Administration (MBA) program has been designed to provide our graduates with the skills they need to be competitive in today's dynamic, global 
marketplace. Business school graduates today must be exposed to the latest techniques and most current business practices if they are to be prepared to pursue careers in an ever-changing and complex world. The educational experiences our students have as they pursue their MBA at AUS prepare them for productive business careers and enable them to make valuable contributions to the organizations they join.

(AUS, School of Business Administration, Masters of Business Administration)

\section{Ethics}

We believe in honesty, ethics, and integrity. Following a code of honor is embedded in SBA studies from an early stage and translates into all aspects of our activities, whether studying, working or socializing. We develop ethical and responsible leaders who are committed to the common good.

(AUS, School of Business Administration, Core Values "Join the ELITE")

The master of business administration (MBA) program is designed to offer a highquality, comprehensive and gulf-oriented approach to the development of management and leadership skills.

(AUS, School of Business Administration, Graduate Programs)

\section{Table P2}

\section{Professional and Personal Development, Respondents}

A faculty's role is multi-faceted, but I think the most successful really care about their students. Not all students care about themselves and then you don't spend extra time on them. The ones that do want to learn then you do all you can to do that with them. (Zara, AUB Faculty) 
Our program wants students to grow in several dimensions. Of course, we want them to be more skilled in business but also as people. (Zain, AUB Faculty)

Who are students are when they leave any of our programs is something I take great pride in. They come in as one person and leave being someone different. Maybe not different but more than what they were 4 or 2 years before. In my position I push all of our faculty to take a real interest in developing our students, both undergraduate and graduate. (Samir, AUC Faculty)

The person is one person. If he grows in one way then he overall grows. I don't concern myself so much with all aspects of student's life but do what I can to help them grow professionally. (Fatima, AUC Faculty)

We are primarily academic and need to give our resources to that. There are other places students can grow in their personal lives but here they need to be academically, professionally, and ethically sound. (Marwa, AUC Faculty) I take a real interest in my students who show real ability to develop. This is especially in teaching...as it's all about developing in the intra and interpersonal skills. (Zainab, AUS Faculty)

The school takes really good care of faculty. We're all expected to live on campus so that we can create a community amongst. That should and I think does directly affect the students. We are taken care of and want to do the same for our students. (Noor, AUS Faculty)

I could tell from the first day that most of my professions wanted me to grow and that continued through my MBA. They were focused on me developing in the business way but it also made me personally grow. (Layla, AUB Alum) 
Yes, I developed. I think I understand business in a larger way than before. Before I knew my job and some of the people I work with. Now I have an idea of what's going on in marketing and finance and how it all fits together. (Ali, AUB Alum)

It was a short program, less than 2 years, but I changed a lot in that time. ... Yes, it was both professional and personal development. I got skills to be better in business, but I also got to know more about the differences in people and who I am. We did some work with the MBTI and that was really helpful. It helped me know why I usually do things a certain way or think a certain way. (Yusef, AUB Alum)

The skills I learned were both the ones that you should learn in an MBA program and also I learned a lot about myself. When I would be challenged in a way in a class I would later see how it affected me as a person. (Amara, AUC Alum)

The biggest thing I got from my MBA was confidence. Having the credential and skills is important but my confidence is from graduating from the program. I had a hard time in the first semester and almost didn't finish. One faculty member ... helped me and encouraged me and I finished. After making it through I'm so much more confident in what I can do. (Aliyah, AUC Alum)

AUC's MBA really, like really, wants you to grow and change. I did in some ways but I'm still learning from the time there. (Malik, AUC Alum)

One of the ways I grew through my MBA was from getting to know my colleagues. Some were, you know, uninterested in getting to know others but many were very excited to talk with you and become friends. We all had different stories and experiences and could learn from each other. (Khalil, AUS Alum) 


"If you're not developing your dying." That was something one of my professors
would say in the course she taught on... . It wasn't an entrepreneurial class but it could
have been said there and been the same. She meant that people need to develop.
(Jamal, AUS Alum)
I know that I grew but I was invested. You could see other students who were there
because they had to be, family or whatever, and they would sit there, do the
assignments, talk little, and I don't think they grew. (Yasen, AUS Alum)




\section{Appendix Q}

\section{Leadership Is}

\section{Table Q1}

Leadership is Enigmatic
Translation is a problem for us because 'leadership' doesn't not have a direct translation in Arabic. There are two words you could use either 'zaeem' or 'qeeada' but neither really mean the same thing as 'leadership' in English. Zaeem is like the head, elder, head man or boss. Qeeada is like command, direct, or control. It's most like management focused so it's confusing. (Ali, AUB Alum)

I'm still not sure what leadership is.... Yeah, I took the leadership course but I'm still like "what exactly is it?" It seems its kind of defined in different ways depending on how you see it. (Omar, AUB Alum)

What I don't get is why there are so many versions of leadership. We learned about a whole list of different types and talked about them but most of them I didn't get. I couldn't relate to them because I haven't seem them in Lebanon. Maybe there're parts I've seen but like I've never seen a pure servant leader. (Layla, AUB Alum) I don't know if the way we learned about leadership fits in Egypt. I mean we have leaders but we want our leaders to be very different then the types of leadership we learned in my MBA program. We want our leaders to be strong and leadership in the book sense seems very weak. (Aliyah, AUC Alum) I know what leadership is but many Egyptians don't know it. Like they use the term all the time but don't know what it is. It's a fad term. ... I think we don't know what it 


is because we what is a leader in the government is not the same type of leader in
business. (Amara, AUC Alum)
Leadership is important but we don't know what it is. We can point to leaders but
usually it's because of their position. Being a leader and what leadership is different
for us. (Jamal, AUS Alum)
Some educated people in the UAE don't like the idea of leadership because it's
ambiguous and there's so much talk of it. Even I get annoyed when everyone talks
about leadership and I'm like, 'do you even know what you're talking about?'
(Ahmed, AUS Alum)




\section{Table Q2}

Leadership is for the Few

Leaders are the head. It's the same in business or in family. Like, there is only one leader of a group. (Ali, AUB Alum)

In Lebanon we think of our leaders as the PM or other top governmental people.

Sometimes we would say a leader is in business but he has to be really well known.

(Omar, AUB Alum)

Leaders can be anyone but most people don't step up to be leaders. It's really true that the leaders we have are the ones who want to be leaders but most don't want to.

Leadership is hard and most people don't have what it takes to rise to the top. (Amara, AUC Alum)

I still think leadership is a role. It's one that you get from your title and what you do. ... If you're and imam you're a leader, if you're a CEO you're a leader. (Malik, AUC Alum)

In the class I took on leadership at AUS we had to investigate and create bios of someone we saw as a leader. They had to be from the MENA and have to be alive and everyone had to choose someone different. It was hard for some of us to think of leaders after others were already taken. Everyone wanted Rashid or MBS or like Sisi but then it like who else can we choose? It was hard to think of someone but then our professor helped us think of others. (Ahmed, AUS Alum)

Leaders are the $\mathrm{C}$ level. I know that even if you're a manager or director you should lead but no one really thinks of this. If you ask, who leads this or that company you think of the top, the CEO or other COs. (Yasen, AUS Alum) 


Anyone in the UAE who is part of a royal family is a sheikh. That title means you're a
leader, or at least that your family is a leader in the country. We all know the big
families and the leaders within them. They're only a few families that really lead the
country and in them there are a few big men who you hear about all the time. The
whole family plays a role but we know the names like Mohammed bin Rashid Al
Maktoum, Hamad bin Mohammed Al Sharqi, Khalifa bin Zayed Al Nahyan. (Hakeem,
AUS Alum)




\section{Table Q3}

Leadership is in the Future

I'll be a leader for sure. I am in small ways now but that is only with my peers and brothers and sisters. I want to be a leader known in Beirut, maybe politics, because that's where my family is. (Yusef, AUB Alum)

Do I think I'm a leader? Not really, I guess no. I'm young I think of leaders as older. There ones who have a lot of experience and are known for what they do.... I think I can get there at some point but it will take time. (Malik, AUC Alum)

I can't think of anyone I did my MBA with who I would say is a leader. Several will be because they have the family business or they were just go-getters. But you know, leaders in Egypt in are older. Even if you're an entrepreneur you're not seen as a leader. A leader has experience and insight that comes from years of living. Not just in business but in general. It takes a lot of time to be a leader. (Abdulah, AUC Alum) If you are to be a leader you need a story that people know. That story has to be big and powerful and developed over time. That's why there aren't young leaders. Like you can have a position in the government that is high up but you're not really a leader. Maybe those people will someday. (Jamal, AUS Alum) You think of how long it took Dubai to be a leader in the GCC. In some ways it was short but it also took several generations to go from finding the oil to building what you see now. Like Sheikh Mohammed bin Rashid is younger for being a leader but he has been bread for it. (Khalil, AUS Alum) 
IRB \#: IRB-2019-519

Title: Leadership Adapted: Towards an Understanding of How Western-Developed Leadership Theories are Translated and Practiced in the Modern Arab Middle East

Creation Date: 8-21-2019

End Date: 9-1-2020

Status: Approved

Principal Investigator: Derek Olson

Review Board: USD IRB

Sponsor:

\section{Study History}

Submission Type Initial Review Type Expedited Decision Approved

\section{Key Study Contacts}

\begin{tabular}{lll}
\hline Member Derek Olson & Role Principal Investigator & Contact derekolson@sandiego.edu \\
\hline Member Derek Olson & Role Primary Contact & Contact derekolson@sandiego.edu \\
\hline
\end{tabular}

